University of Louisville

ThinkIR: The University of Louisville's Institutional Repository

Electronic Theses and Dissertations

8-2005

\title{
Rated preference, complexity and familiarity for neo-traditional and modern development patterns using alternative visual medium.
}

James L. Mims 1953-

University of Louisville

Follow this and additional works at: https://ir.library.louisville.edu/etd

\section{Recommended Citation}

Mims, James L. 1953-, "Rated preference, complexity and familiarity for neo-traditional and modern development patterns using alternative visual medium." (2005). Electronic Theses and Dissertations. Paper 988.

https://doi.org/10.18297/etd/988

This Doctoral Dissertation is brought to you for free and open access by ThinkIR: The University of Louisville's Institutional Repository. It has been accepted for inclusion in Electronic Theses and Dissertations by an authorized administrator of ThinkIR: The University of Louisville's Institutional Repository. This title appears here courtesy of the author, who has retained all other copyrights. For more information, please contact thinkir@louisville.edu. 


\title{
RATED PREFERENCE, COMPLEXITY AND FAMILIARITY FOR NEO- TRADITIONAL AND MODERN DEVELOPMENT PATTERNS USING ALTERNATIVE VISUAL MEDIUM
}

\author{
By \\ James L. Mims \\ BLA, University of Florida, 1975 \\ MA, University of Florida, 1978
}

\begin{abstract}
A Dissertation
Submitted to the Faculty of the

Graduate School of the University of Louisville

in Partial Fulfillment of the Requirements

for the Degree of
\end{abstract}

Doctor of Philosophy

School of Urban and Public Affairs

University of Louisville

Louisville, Kentucky

August, 2005 
RATED PREFERENCE, COMPLEXITY AND FAMILIARITY FOR NEOTRADITIONAL AND MODERN DEVELOPMENT PATTERNS USING ALTERNATIVE VISUAL MEDIUM

\section{By}

James L. Mims

BLA, University of Florida, 1975

MA, University of Florida, 1978

August 1, 2005

by the following Dissertation Committee:

Dissertation Director 


\begin{abstract}
RATED PREFERENCE, COMPLEXITY AND FAMILIARITY FOR NEOTRADITIONAL AND MODERN DEVELOPMENT PATTERNS USING ALTERNATIVE VISUAL MEDIUM
\end{abstract}

James L. Mims

August 1, 2005

This dissertation examines the impact of complexity and familiarity on visual preference for two content domains defined as Neo-Traditional and Modern. This research has five main themes:

1. To determine if there is a method for community design professions to derive consensus about visual preference.

2. To determine if visual preference favors conventional suburban development patterns or traditional neighborhood development patterns.

3. To determine if scene complexity or coherency influences visual preference.

4. To determine if familiarity of scene content affects visual preference.

5. To determine if visual preference for a simulated scene correlates with its photographic counterpart.

To respond to these objectives the research steps included: 
1. Assembling a photographic library of street scenes throughout the Louisville, Kentucky and Cincinnati, Ohio metropolitan areas.

2. Categorizing the photographic library into three property value ranges described as low, medium and high.

3. Determining through ratings by a panel of experts which of the photographs best represented Neo-Traditional and Modern development patterns.

4. Preparing digital visualizations of two of the photographs selected by the panel of experts.

5. Submitting the photographs and images to a population sample of 304 people enlisted through the internet, and having those respondents rate the photographs and images on the basis of visual preference, scene familiarity and scene complexity.

The findings of this research are as follows:

1. People who participated in the survey favored modern development patterns over neo-traditional development patterns for all three price ranges.

2. Familiarity is a reliable construct of visual preference.

3. Complexity is not a reliable construct of visual preference.

4. Digital visualization can serve as a reasonable proxy to actual photographs. 


\section{TABLE OF CONTENTS}

PAGE

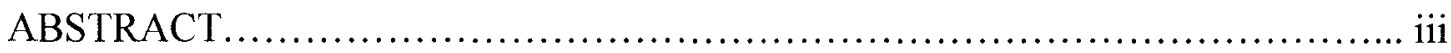

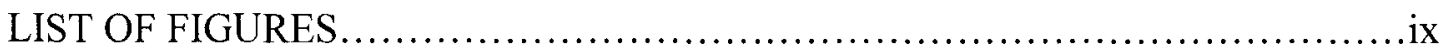

CHAPTER

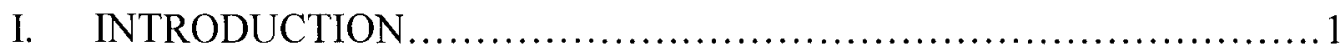

Research Background........................................... 1

Problem Overview............................................... 5

Research Questions.............................................. 9

Research Objectives............................................11

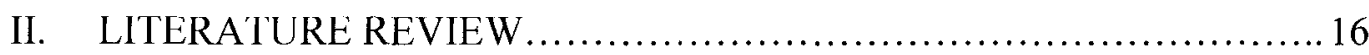

Design and Psychology........................................ 16

Dimensions of Traditional and Modern Development Patterns...........20

Comparative Characteristics of the Street........................23

Comparative Relationship of Building to Street................... 26

Comparative Relationships of Land Uses....................29

Summary Comparison.................................... 30

Dimension Hypotheses.............................................. 32

Characteristics of Visual Preference............................... 32

The Psychophysical Approach.................................. 33

Familiarity As A Construct of Preference.......................... 35 


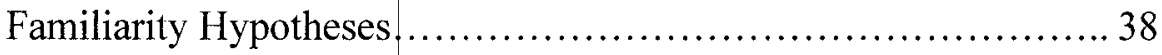

Theories on Coherence and Complexity.......................... 43

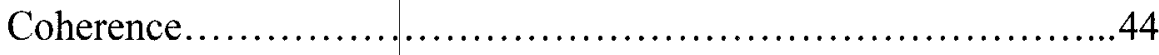

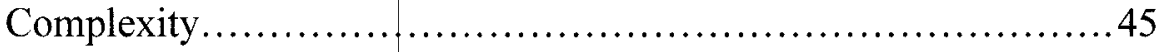

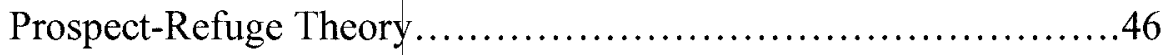

Optimal Perceptual Rate...................................... 48

Complexity-Coherence Hypotheses.............................51

Data Visualization............................................... 54

Visual Modeling Using the World Wide Web.......................... 59

Summary of Literature Findings and Re-Statement..................... 62 Of Hypotheses

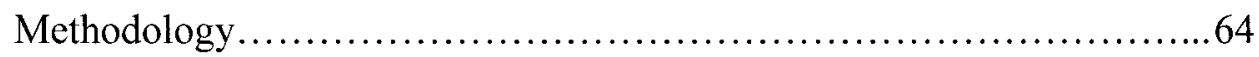

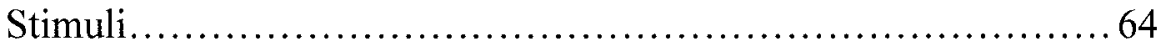

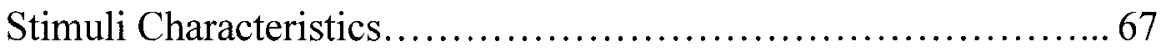

Panel Ratings.............................................. 72

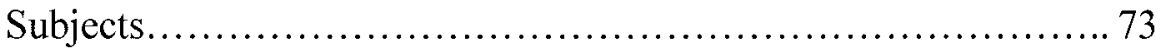

Procedures....................................................... 76

Analysis...................................................... 82

Dimensional Determination..................................... 82

Statistical Verification............................................ 85

Summary of Research Objectives and Contributors.................99 
III. METHODOLOGY ..................................................... 95

Research Objectives............................................... 95

Research Problem...................................................96

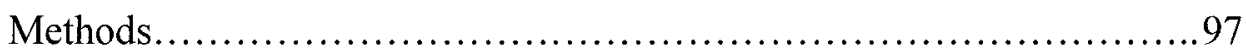

Stimuli......................................................... 97

Categorization of Stimuli...................................... 100

Panel Ratings.................................................. 103

Measurement of Traditional and Modern Dimensions............... 105

Digital Imaging............................................ 107

3D Graphics Technology .................................... 108

Statistical Verification......................................... 110

Questionnaire Design....................................... 111

Questionnaire Distribution.....................................114

IV. ANALYSIS AND CONCLUSIONS .....................................117

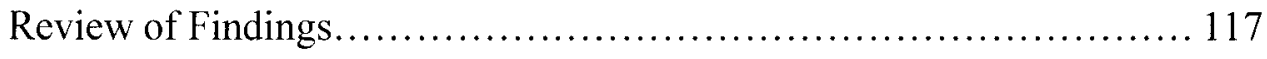

The Question of Visual Preference for Traditional vs. ................... 118 Modern Development Patterns

The Question of Visual Preference on the Basis of....................... 119 Scene Familiarity

The Question of Visual Preference on the Basis of. Scene Complexity

The Question of the Reliability of Digital Images.

When Compared to Photographs 


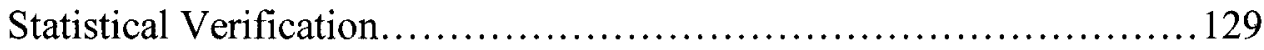

Conclusions and Implications...................................... 132

Biases and Limitations of the Research............................. 141

Summary of Contributions and Suggestions for...................... 142 Future Research

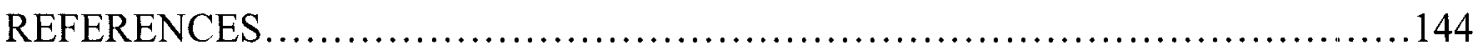

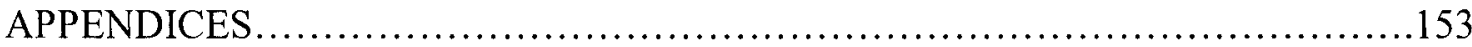

CURRICULUM VITAE .................................................. 190 


\section{LIST OF FIGURES}

Figure

1. Familiarity - Preference Matrix

2. Overall Appeal, Modern vs. Traditional...........................118

3. Relationship Between Visual Appeal and Familiarity................120

4. Relationship Between Visual Appeal and Familiarity.............. 120 (Somewhat Scale)

5. Relationship Between Visual Appeal and Familiarity (Not At All Scale)

6. Relationship Between Visual Appeal and Complexity.

7. Relationship Between Visual Appeal and Complexity .124 (Somewhat Scale)

8. Relationship Between Visual Appeal and Complexity (Not At All Scale)

9. Photograph (Image 6) vs. Digital (Image 17) ....................127

10. Photograph (Image 14) vs. Digital (Image 7) ................... 128

11. Relationship Between Visual Appeal and Complexity.............. 137 for Traditional Scenes

12. Relationship Between Visual Appeal and Complexity. 137 for Modern Scenes 


\section{CHAPTER ONE}

\section{INTRODUCTION}

\section{Research Background}

The years following World War II have been marked by a period of rapid de-concentration of American cities. This so-called Valhalla Syndrome has made a huge impact on American development patterns, and recent demographic data suggest that this trend is likely to continue into the foreseeable future (Von Hoffman 1999). Von Hoffman's research at The Joint Center for Housing Studies at Harvard University finds that, while the 39 largest metropolitan areas increased in population by 1.7 million during the period from 1980 to 1994 , suburban population in that same period grew by 17 million (Von Hoffman 1999). He further predicts continuation of this trend as a result of the strong influx of immigrants moving to the United States. Immigrant acquisition of existing homes in both the inner city and suburbs is enabling existing homeowners to buy new homes. Approximately 1.2 million new homes were built annually during the 1990's, most of which are located in suburban or exurban areas. Stable housing prices as well as strong trade-up buying by baby-boomers is also expected to provide impetus for continued growth of new home construction in 
suburban housing markets (Von Hoffman 1999).

Some contend that suburbanization of the United State has produced many of the maladies recognized by Americans, and share a belief the suburban environment is just plain ugly (Kunstler 1994; Katz 1994; Langdon 1994; Calthorpe 1993; Duany and Plater-Zyberk 1991). Hence, experts in urban affairs, planners, architects, and others wishing to create a better way to live are constantly proposing new strategies. One such strategy receiving considerable attention, particularly in Louisville, Kentucky is Neo-traditionalism, also known as New Urbanism, Traditional Neighborhood Development or Transit-Oriented Development. Proponents of Neo-traditionalism, while relying on many mutually supportive components, advocates the village as the basic development unit having the greatest chance of sustaining future needs for new housing in this country in a rewarding physical and social manner. Many interrelated principles propel this movement including:

1. Close association to a village center by limiting walking distance to a quarter mile or no greater than five minutes.

2. A mixture of uses in close association with each other.

3. De-emphasis of the automobile by narrower streets, removal of front-entry garages, greater use of alleyways and service corridors, and enhanced pedestrian and nonvehicular systems.

4. Centralized civic, commercial and employment opportunities located in a village center.

5. Strict governance of architecture, site planning and landscape design into a unified system of codes and appearance standards.

6. Reservation of high visibility sites for civic buildings, parks or structures having significant 
architectural character.

7. A grid street system enabling multiple vehicular routes in and around the village.

8. Integration of a wide range of housing types in close association with each other enabling a diversity of population to live within the same neighborhood.

9. Simple and direct building design relating closely to the adjoining street.

10. Adaptable architecture and site planning allowing the proliferation of outbuildings and other structures supportive to the principal use of the property.

11. Schools, parks, recreational, and entertainment opportunities located in close association with residential areas.

12. Use of greenways, wilderness areas and agricultural zones as a way to separate and distinguish the village unit.

13. Use of parochial architecture and landscape elements indigenous to the region.

14. Clear separation of public and private space by strategic placement of structures and landscape elements.

15. Use of a 1:6 ratio of structure height to separation along public streets.

16. Clarifications of street systems by avoiding roadway patterns that turn back on themselves.

17. Providing identifiable elements in the village fabric that encourage a sense of location and direction. (Langdon 1994; Katz 1994; Kunstler 1994; Calthorpe 1993; Duany and Plater-Zyberk 1991).

While support for these principles has enabled overwhelming success in high profile traditional developments like Seaside (Florida panhandle),

Celebration (Orlando, Florida) and Kentlands (Maryland), there continues to be skepticism about the long-term viability of this concept. Developed during the late 1980's and 1990's, Seaside, Celebration and Kentlands epitomize traditional 
development concepts. They bring together a mixture of land uses within close association to each other, to facilitate pedestrian and modes of transportation other than the use of the automobile. Each of these developments has a defined village center and a grid street pattern that de-emphasizes the automotive traffic. Each development adopts strict standards that reinforce architecture and landscape elements parochial to the area. The typical Traditional Neighborhood Development integrates a variety of housing types that are closely associated with the adjoining street.

In criticism of developments like Seaside, Celebration and Kentlands, some contend that integration of multiple land uses introduces unwanted traffic into residential neighborhoods, with the benefits of Transit Oriented Neighborhoods having been oversold (Crane 1996). Others question the ability to successfully design a compatible relationship between single- and multi-family homes (Mayo 1988). Naser and Julian (1995) suggest that further research is necessary to determine if neo-traditional developments achieve the sense of community that they claim.

Questions also arise about the loss of individual identity imposed by rigid codification of architecture, site design and landscaping inherent in New Urbanism concepts. A 1997 article in Landscape Architecture refers to Celebration as a "themed historic district" and a slave to its own "pattern book, covenants, and the homeowner's association"... "that reaches into the yards and even the houses of its residents." In this article Beardsley condemns this sort of 
"social engineering" as regulating the environment to such an extent that it "shapes the lives of the people" that resides there (Beardsley 1997). The heavyhanded approach by Disney Corporation to regulate appearance and behavior has resulted in what some critics consider a homogenized and even monotonous feel to the development (Beardsley 1997). Truman Burbank's query of the realness of his island home in the 1998 movie The Truman Show could well reflect the sentiment of the permanent cast who reside at Seaside.

\section{Problem Overview}

If suburbanization is to be an inevitable consequence of future housing development as Von Hoffman and Harvard researchers predict, how then can environmental designers' best respond to the challenges of devising neighborhoods that are economically viable, socially acceptable and visually pleasing? Neo-Traditionalists emphatically suggest their concepts are the only hope for avoiding the demise of suburbia as we now know it. Yet, traditional neighborhood design is the most recent in a long line of reform movements that have attempted to apply new design and planning principles to suburban development. We need only look at Ebenezer Howard's Garden City Movement; the Greenbelt Movement of Henry Wright and Clarence Stein; or the New Town Movement propelled by Rouse Corporation in their development of Columbia, Maryland. While these movements were not dismal failures, their much-heralded inaugurations did not sustain or redirect the pattern of development in this 
country.

The greenbelt town movement was a New Deal experiment to counteract the onslaught of slums in urban America. The vision of this experiment was to establish garden communities outside the cities using the best theories of professional planners in the combined disciplines of suburban housing and park design. As a government initiative, greenbelt towns were resisted by private real estate interests and characterized by that industry as "communist towns". While European planners consistently praised U. S. Garden Cities, the inability of these models to conform to the real estate system in this country was a contributing factor to their demise. (Glaab and Brown 1983).

John Nolen's design of Mariemont, Ohio was in the tradition of France's Beaux-Arts school of Architecture and rooted in the American City Beautiful Movement. Despite the strength of Nolen's plan for a factory town that emphasized civic buildings, plazas and landscaped parks, the factories never relocated to this suburban site and Mariemont today remains as a bedroom community to Cincinnati (Fulton 1996).

The American Garden City movement sought to maintain a village atmosphere that accommodated the country's increasing dependence on the automobile. The American Garden City movement promoted concepts of neighborhood units oriented around green space, civic buildings and plazas. The American City Garden movement emphasized suburban communities compatibly 
incorporated into farmland and natural areas. Despite all these well-intentioned principles to create a better model for suburban development, these early approaches fell by the wayside because of the huge demand for housing after World War II. That demand compromised these principles into the autodominated model of interior residential streets insulated by high-speed arterial routes and lined with strip malls (Fulton 1996).

The inabilities of designers and planners to guide the direction of neighborhoods, or for that matter, derive some reasonable consensus on how they believe the public realm should look, raises questions about how the civic design professions serve as a proxy for articulating the wishes of the public. Jacobs (1961) pointedly attacks "city planning" as a profession unable to understand, let alone use, common and ordinary principles for creating safe streets and vibrant neighborhoods. Lansing and Marans (1969) find considerable incompatibility between how architects-planners and the general public determine neighborhood quality. Hershberger (1969) finds architects view the world significantly differently than does the general public.

While negative connotations may symbolically surround the gregarious visual qualities of Las Vegas or the commonness of a commercial strip on the outskirts of town, Lang et al. (1974) suggest that the average citizen consider most American cities quite acceptable. Kaplan (1979) and Gans (1967) also find socalled experts perceive visual preference differently than mainstream society. Sancar (1985) concludes the development of a consistent theory in the 
area of landscape aesthetics is hampered by the absence of a well defined convergence of preference by either experts or the public, suggesting greater statistical verification is needed in the area of psychophysical theory. Mayo (1988) believes systematic failures in the capitalist economy preclude urban designers from providing design alternatives in an even and equitable manner. In short, those practicing as planners and urban designers continue to use skills without adequate information about public preference.

In her assessment of the controversy surrounding I. M. Pei's proposal for a glass pyramidal entry into the Lourve, Groat (1984) draws conclusions from three perspectives. First is an inability to readily assess public opinion in the area of design. Second is the importance of design issues when proposed in the public realm. And third, is the underlying question of whether a normative standard can be established for civic design and contextual issues.

It is the belief of this author that the design professions have fallen short of even understanding, let alone representing, the wishes of citizen clients. Typical tools of the profession (e.g., artist renderings presented in the context of public hearings) have been an impediment. While these methods may satisfy the moral or regulatory requirements to keep the public informed of proposed changes to their surrounding environment, they do little in facilitating consensus about anything. Dominant and contentious issues are addressed, while unexpressed ideas may never be considered. Techniques themselves also have limited design professions in their efforts to convey accurately and graphically complex concepts to the 
public. Artist renderings portray more art than fact. These techniques often have been criticized as glossy portrayals of otherwise boring and ugly proposals. Yet, artist renderings are inflexible, requiring considerable time and expense to modify in response to input received from the public. Subconsciously, planners and designers find it necessary to focus more on the amount of time necessary to revise their plans and renderings than on advocating the interest of the public to genuinely influence design decisions

In summary, the problem to be addressed by this dissertation is to improve the way community design professions determine consensus about visual preference. To that end, this dissertation proposes to investigate the topical question of whether visual preference favors traditional versus modern development patterns. Other related questions include the effect scene complexity and familiarity has on visual preference. And finally, this dissertation seeks to determine how technology, particularly graphic and imaging technologies, can be used in deriving a consensus about visual preference.

\section{$\underline{\text { Research Questions }}$}

Wolf (1981) tells us that city planning is founded in the public realm. That realm is one defined mostly from the exterior, in which the vantage point becomes the street, sidewalk, park, or plaza. Planning, being a profession largely born out of urbanization recognizes that space and distance often can attenuate the external effects caused by a more intense use of the land. The absence of 
separation between urban structures, in turn, accentuates the external effects of environment found in a surrounding neighborhood. For example, the house painted bright pink is likely to be perceived more dramatically in a suburban neighborhood than in an isolated wilderness area that is infrequently observed by the occasional traveler. Cultural and demographic variables also interplay with our perception of environment (Hall 1969). A house painted with intense colors may be perfectly acceptable in a Mexican-American neighborhood given the common use of these colors in Latin American neighborhoods (Lazalde 1998). The same may be true for demographic variations found in neighborhoods within the same community.

While the public realm may be considered a single forum for a community's planning efforts, in fact it is comprised of countless attributes. If we define that realm as one that can be perceived or otherwise experienced from the most common element of the urban complex, being the street, then it becomes apparent that realm is shaped by a number of changing dimensions.

The intent of this research is to define those dimensions in terms of public preference. How do people respond to communities developed according to New Urbanism principles when those communities are contrasted to the modern automobile subdivision? What is the value placed on the coherency of monist vistas when compared to complex visual environments? How does scene familiarity influence preference? Clearly, many questions are possible but those 
potential questions must be clarified through refinement, trial and definition.

\section{Research Objectives}

This research has five main themes. The first and foremost goal is to determine if consensus about visual preference is possible. Second, the research focuses on the question of visual preference for either modern or traditional neighborhood development patterns. The third theme of this research is to determine how contextual dimensions found in complexity and coherency influence visual preference. The fourth theme is to ascertain the effects of scene familiarity on visual preference. Finally, it is the intent of this research to provide insight as to the effectiveness of digital images to correlate with photographic images. The objectives of this research are intended to address the following:

1. If a consensus is possible, to determine if there is a method for community design professions to derive consensus about visual preference.

2. To determine if visual preference favors conventional suburban development patterns or traditional neighborhood development patterns.

3. To determine if scene complexity or coherency affects visual preference.

4. To determine if familiarity of scene content affects visual preference.

5. To determine if visual preference for a simulated scene correlates with its photographic counterpart.

A summary of the steps taken as part of this investigation are as follows:

1. Using photographs of traditional and modern neighborhoods in and around the Louisville Metropolitan Area, images were selected on the basis of photographic consistency with specific 
consideration for comparable vantage points, time of year, time of day, and photographic quality. Using property valuation records, the selected images were grouped to represent three distinct neighborhood value ranges.

2. Sixty photographs were prepared for panel ratings. Using a Tamarack 2400FS Film Scanner, slides and $35 \mathrm{~mm}$ negatives were scanned to produce consistent images derived from varied photographic medium and film brands. Adobe Photoshop 4.0 was used to adjust image size, color balance, brightness, and contrast to achieve greater photographic consistency.

3. Adobe Photoshop 4.0 was used to establish the printing format for panel ratings. Three 13" X 19" sheets were prepared, each having twenty photographic images. The three photo-sheets were arranged so that each sheet depicted images for one of the three neighborhood value ranges. Printing was performed using an Epson 1520 Stylus printer on Epson Photo Quality Glossy Paper. Ordering biases were removed by the raters' capacity to overview all images at a single glance.

4. Five local planners and / or designers with strong familiarity with dimensional definitions of traditional and modern neighborhood design performed ratings of the three photo-sheets. Ratings were made using a bipolar scale in which the extreme end of the scale most represented the alternative development dimension. In this case, a neutral rating indicated images showing no particular characteristics of either development dimension.

5. Using an analysis of means, ratings performed by the five local experts assisted in selecting nine photographs best representing traditional development patterns and nine photographs best representing modern development patterns. Of the nine photographs selected for each development dimension, three each were derived from the three neighborhood value ranges established for this experiment.

6. The 18 photographic images were included in a broader survey to determine visual preference of a population sample. This visual preference survey also measured defined opinions of complexity and familiarity for each of the 18 photographic images. 
7. In addition to the 18 photographic images, two digital images were prepared using AutoCAD 2000 as a platform to Alias Wavefront, Maya 4.5 modeling and visualization software. Digital images were vector based using coordinates from mapping made available by the Louisville and Jefferson County Information Consortium (LOJIC) and actual field mapping of the image areas. The digital images were included in the survey; one for each of the two development dimensions. Digital vantage points closely approximated the two photographic vantage points and attempted to represent these photographic images to the greatest extent possible.

8. Web-enabled research using the data base of a Louisvillebased market research firm was performed. E-mail invitations were sent subjects in the data base inviting them to participate in the survey. The first 400 respondents to accept the invitation were reviewed to derive an aggregate profile similar to the adult population of Metro Louisville. Recognizing that all 400 invitees would not complete the survey, actual responses reached 304.

9. Selected invitees completed a brief form included in the body of the initial e-mail in order to gather basic contact information such as name, address and phone number.

10. The 400 participants were mailed the visual preference survey along with a URL and password allowing them access to a web site and the assigned electronic survey form.

11. Respondents were asked to complete the survey on-line using a five-point "Click and Go" entry box designed to measure their opinions of visual preference, scene complexity and familiarity. Respondents were paid a prenegotiated fee to complete the survey. E-mail reminders were sent to non-responders to prompt their completion of the survey.

12. The mailed visual preference survey sent to the subjects included a cover letter providing a general explanation of the survey and instructions for its completion.

13. Each of the twenty images (18 photographic and two digital) included in the visual preference survey were 8 " $\mathrm{X}$ 10 " in size and bound by a stapled edge. Images were labeled to match the numbering order established by the electronic response form. These images were printed on an 
Epson 1520 Stylus printer using Epson Photo Quality Glossy paper.

14. The on-line response form used a five-point Likert scale, in which a response of one represented a very low opinion of preference, complexity or familiarity for an image and a response of five represented a very high opinion of preference, complexity or familiarity. A rating of three represented a neutral opinion. In all, sixty separate responses were required to complete the survey (three for each of the twenty images). One of the benefits of the webenabled research was its capacity to insure participants thoroughly completed the form prior to its being electronically submitted. Likewise, the electronic format precluded participants from changing their responses subsequent to their initial entry.

15. Pre-determined fields derived from the survey directly downloaded data for statistical verification into a Microsoft Excel spreadsheet.

Statistical verification was performed for five hypotheses as follows:

H1: Visual preference favors visual attributes characteristic of traditional development patterns.

$\begin{array}{ll}\text { Null hypothesis } & \mathrm{P}=0.5 \\ \text { Alternative } & \mathrm{P}>0.5 \\ \text { Significance Level } & \alpha=0.05 \\ \text { Critical Region } & \text { Critical Binomial Distribution, } \\ \mathrm{p} \geq 166 / 300 & \end{array}$

H2: Visual preference favors visual attributes characteristic of modern development patterns.

$\begin{array}{ll}\text { Null hypothesis } & \mathrm{P}=0.5 \\ \text { Alternative } & \mathrm{P}>0.5 \\ \text { Significance Level } & \alpha=0.05 \\ \text { Critical Region } & \text { Critical Binomial Distribution, } \\ \mathrm{p} \geq 166 / 300 & \end{array}$


H3: Visual preference of a scene is directly related to the amount of familiarity a subject has with the content domain of that scene.

Null hypothesis $\quad \rho=0$

Alternative $\quad \rho>0$

Significance Level $\quad \alpha=0.05$

Critical Values $\quad t$ distribution

H4: Visual preference of a scene is directly related to its complexity until an optimal level is achieved, whereupon it becomes inversely related to each additional increment of complexity.

Null hypothesis $\quad \rho \neq 0$

Alternatives $\quad \rho>0$

$\rho<0$

Significance Level $\quad \alpha=0.05$

Critical Values $\quad t$ distribution

H5: Preference for computer generated images positively correlate with actual photographic images.

Null hypothesis $\quad \rho=0$

Alternative $\quad \rho>0$

Significance Level $\quad \alpha=0.05$

Critical Values t distribution

16. Based on the foregoing statistical verification and testing, conclusions were made accepting or rejecting the stated null hypotheses. 


\section{CHAPTER TWO}

\section{LITERATURE REVIEW}

\section{Design and Psychology}

Better definition of this research subject has been accomplished by the usual twists and turns of a literature search in order to narrow the focus and successfully define what can be added to the body of knowledge. These twists and turns, while covering multiple disciplines, have returned continually to focus on skills traditionally found in both urban design and psychology. Although at first glance one may question this mix of skills, classic readings in urban design continually emphasize its dependence on how users function in the physical environment. Lynch (1960) refers to urban design as a "temporal art... always in relation to its surroundings, the sequences of events leading up to it, the memory of past experiences." Jacobs (1961) sees cities as an "immense laboratory" for testing theories on the "successes and failures in real life". Gropius (1970) sees the relationship between our feelings and our psychological senses as real as any material or structural problem in design. Appleyard (1981) emphasizes the connection between "environmental concerns" and "overall residential satisfaction" as found in the "house itself, privacy, neighbors' upkeep, appearance, social status, suitability for children, as well as paved streets." The 
street as seen by Allan Jacobs (1996) is a medium for "unlocking memories" to create "interest" and catch the eye. In so defining "great streets," Jacobs (1996) acknowledges their need to be "physically comfortable and safe" as well as visually engaging and memorable.

Psychologists Stephen and Rachel Kaplan (1982) regard environmental problems as people problems, and if designers can understand how people think and react in their environment, they can better respond to their needs in a constructive manner. The environmental psychologist asks how "a person makes his way through the environment, how one makes sense, how one copes, how one gets along" (Kaplan and Kaplan 1978). Appleton (1975) views psychology as an essential scientific investigation of the perceptual processes. In short, preference influenced by urban design is a psychological construct heavily influenced by our sense of well being and security (Nasar 1987; Nasar and Julian 1995).

If indeed the purpose of this research is to better understand parameters of visual preference, then the limitless attributes of that environment represent the range of possible dimensions that provide criteria for preference (Herzog et al 1976; Kaplan et al 1972). Visual preference surveys have been effective tools used by researchers to isolate attributes and ascertain how subjects respond to the environment. Naser (1988) used visual preference to develop evaluative maps based on interviews with residents and visitors in Knoxville and Chattanooga, Tennessee. Biddulph (1995) described how visual signs are used by "speculative house developers" to enhance sales. The desire for consistent signs within our visual world was further defined in Duncan's (1987) semiotic approach to urban 
cognition. Within this approach, urban landscapes are considered a series of signs that have to be read and understood by those who use them. Urban image can be at least partially defined on the basis of the visual cues provided (Gulick 1969; Lynch 1960).

Evaluative maps developed in Lynch's (1960) research allow him to portray urban image as being influenced by dimensions found in paths, edges, nodes, districts, and landmarks. Similar research by Gulick (1969) reinforces these same dimensions, but also acknowledges different perceptions we have as a result of varying socio-cultural associations. Nasar's (1988) evaluative maps allow him to determine preferential dimensions found in distinctiveness, visibility and significance, further affirming previous conclusions by Appleyard (1969) and Evans et al (1981).

Non-metric factor analysis and multidimensional scaling are used in psychological research to define dimensions of environmental perception. Such methods were used by Hertzog et al (1976) in the definition of psychological domains for scaling preference, familiarity and complexity of buildings in Grand Rapids, Michigan. In their research, 70 scenes were classified into five dimensions based on a pattern of preference so that three scales could be applied. Peterson (1965) used similar techniques in his evaluation of quantitative methods for assessing subjective urban systems. Woodcock (1985) used factor and cluster analyses to group visual stimuli of biomes into perceptual dimensions for the purposes of assessing preference in natural landscapes. Much of the research performed in determining visual preference continues to rely on multidimensional 
scaling or factor and cluster analyses as techniques for categorizing visual stimuli (Nasar 1987; Kaplan and Herbert 1987; Fenton 1985; Hertzog 1984; Frey 1981; Shafer, Hamilton and Schmidt 1969).

While use of multidimensional scaling techniques and factor analysis are ways to isolate dimensions of preference, Zehner (1970) selected the degree of planning in determination of preference. Naser (1987) used predetermined dimensions to measure perceived visual quality in his research on visual quality of commercial signs using dimensions found in the degree of "complexity" and "coherence". His selection of these two dimensions was based on previous research by Ward and Russell (1981) identifying those dimensions as subjective schemata used by the public in evaluating their surroundings. Research by Naser et al (1983) on emotional quality of scenes and observation points pre-selected dimensions applicable to evaluating Appleton's (1975) prospect and refuge theories. In other perceptual research, Naser (1987a.) defined dimensions of perception using multidimensional scaling techniques. In short, perceptual research uses various techniques to derive dimensions, ranging from totally random to narrowly-defined.

Fenton and Reser (1987) elaborated on the theoretical and methodological problems in assessing environmental preference and the "atheoretical and apsychological" approaches used by geographers and landscape architects doing research in this area. They further defined three principal approaches found in the literature to identify variables instrumental in influencing the perception of landscape quality. Objective quantification, as defined by them, used an 
instrumentalist view of the landscape, where objects in nature cause an aesthetic experience in people, regardless of an individual's background. Their normative approach accepted human judgment as a viable option in defining environmental dimensions. Finally, the phenomenological approach allows physical attributes to be considered in terms of a particular event. If indeed a particular physical event or setting is beautiful, the phenomenological approach presuppose descriptors of that event which explain the inherent qualities of that determination. It is from these constructs that dimensions can be formed for further study. Lynch (1960), Gulick (1969), and Moore and Golledge (1976), as physical planners and geographers, used cognitive dimensions as a starting point for further research in assessing perceptual visual quality.

\section{Dimensions of Traditional and Modern Development Patterns}

Eighty percent of the building construction in the United States has occurred since 1950, and much of that building is considered by some as "brutal, ugly, unhealthy, and spiritually degrading" (Kunster 1993). If Von Hoffman (1999) is correct in his prediction of continued suburbanization of America, its visual character could have considerable impact on our suburban landscape for years to come. Many scholars and designers see this as a pivotal point in the development continuum where either patterns represented by the modern suburban development will continue, or new patterns will emerge reviving interest in Traditionalism (Langdon 1994; Katz 1994; Kunster 1993; Cathorpe 1993; Duany and Plater-Zyberk 1991). 
The attributes of these two dimensions often are not clear and at times seemingly overlap. At tension; however, are basic differences between modernity and traditional city planning concepts of the early 1900's. Whether called Traditionalism, Neo-Traditionalism, Traditional Neighborhood Development or New Urbanism, the interest in an alternative model for conventional suburban development is an affront to Modernism. In broad terms, this affront is directed at specialization, segregation of task, privatization, and centralization (Calthorpe 1993).

From these characterizations of Modernism and Post-Modernism come claims of loss of community and human scale (Calthorpe 1993). Katz (1994) believes the massive modern suburbanization of the 1940's and 1950's has led to a fragmentation of society by undermining the bonds of community prevalent during earlier eras in the development in the United States. The transformation from Modernism to Traditionalism borrows from theories purporting to reestablish the public domain through greater diversity of uses and human scale (Calthorpe 1993). In short, New Urbanism wishes to restore the development of projects on a neighborhood scale, "having a mix of uses and housing types; a compact, interconnected street and block pattern, a clearly defined center for each neighborhood; and a pedestrian-oriented design" (Steuteville 1999).

A precedent for this design philosophy is found in the turn of the century City Beautiful Movement. Out of the disorder that accompanied rapid industrialization of Europe and the United States, this movement evolved from Beaux Arts traditions and a commitment to a sense of order with an emphasis on 
"formalistic, gridded streetscape oriented around local transit stops." (Fulton 1996) The sense of formal order employs parks and a focus on public buildings and civic space as a way to reinforce a sense of beauty and human scale. A critical component of the movement is its emphasis on the urban street as a venue for a variety of activities (Katz 1994).

In contrast, founding principles of the Modern Movement amplify function and an appeal for concise and economical solutions to production. Louis Sullivan's proclamation of "form should follow function" initiated intellectual articulation of the Modernist Movement in this country and captured the imagination of Frank Lloyd Wright, whose spatial and structural sense freed American architecture and urban design from requirements for style and ornamentation (Gropius 1970). Kunster (1993) contends that the immense damage caused by modernity, as seen in the rise of a new industrial complex, decimated any sense of social order found in the arrangement of the public realm. He further contends this recent ordering of space has evolved in a manner totally lacking in respect for reasonable limits to scale and growth.

Giant corporate structures allowed an evolution of public buildings and spaces devoid of human appeal and dominated by an over-dependence on and allocation of space to the automobile (Kunster 1993). This Modernist approach manifested by Gardiner led to planning practices that emphasized segregation of uses; separation of buildings from the street; greater emphasis on private space; and a disregard for the public domain (Calthorpe 1993). 
The epitome of this emphasis on function, precision and production perhaps may be most apparent in the American suburbs and the large-scale subdivision of real estate occurring after World War II. The momentum of this pattern cannot be any clearer than in the massive subdivision of property by Abraham and William Levitt. Initiated in 1951, their second Levittown development in Bucks County, Pennsylvania called for construction of 17,000 homes. With nearly 150 homes completed each day, Levittown perfected mass production of single family homes utilizing a repetitive rectilinear pattern. Houses with a single floor plan and standard exterior elevation aligned regimentally on 60 -foot wide lots characterized these early auto suburbs. The technique of mass production of single family homes on inexpensive fringe sites served as the model for the modern automobile subdivision that today remains as the dominant pattern of residential land development in the United States (Gans 1967).

\section{Comparative Characteristics of the Street}

Identifying the physical characteristics that differentiate the modern suburbs from traditional patterns may superficially seem insignificant. Frey (1981) found neighborhood preference patterns in Ann Arbor, Michigan included attributes of both modern and traditional development dimensions. Traditionalists characterize the modern automobile subdivision as "individual houses on big blobs of land among curvy streets" (Kunster 1993). While curvilinear streets are generally eschewed by Traditionalists, they may be found acceptable in the context of "lazily curved", "planted at formal intervals", "terminated in woodsy 
little squares" and "divided by a planted median" (Kunster 1993). Although modern and traditional developments have similar curvilinear systems, it is the absence of formally planted trees that distinguishes modern subdivisions from their traditional counterparts. Kunster (1993) further argues it is this absence of street trees and terminal points that add to a state of confusion in modern subdivisions by the loss of pedestrian-scaled space and an absence of visual direction. Lynch (1960) also finds clarity and legibility as essential to the visual quality of urban settings.

In his description of Oak Park, Illinois, architectural critic Philip Langdon (1994) identifies the importance of tree-lined streets as critical to the success of neighborhood business districts. Similarly, Langdon believes wide planted boulevards and planter strips along the curb to be essential instruments for safe and attractive pedestrian use. Unwin (1909) saw "grass margins" and "paved footways" essential to a "well made track". The addition of on-street parking further facilitates a psychological sense of well being by providing a broad buffer separating pedestrians from moving vehicles (Langdon 1994; Lerner-Lam et al 1992). So too, Calthorpe (1994) finds redefinition of the street essential to its resurgence as an enjoyable element within the public domain. From this reordering, the street becomes usable for a variety of activities as well as serves as a memorable feature within the neighborhood. Accomplishing this task is achieved when "streets are narrow, with sidewalks and tree-lined" (Calthorpe 1994; Lerner Lam et al 1992). 
Contrasts between modern suburbs and communities based on traditional design principles are found also in the alignment of roadways. Originating from the suburban cemetery planning movement of the nineteenth century, curvilinear roadways were widely used subsequent to the 1869 design of Riverside, Illinois by American landscape architect Frederick Law Olmsted. Even though the lazily curved alignment of these roadways is considered tranquil by many, both visitors and residents also view them as a source of confusion and disorientation (Langdon 1994). Some Traditionalists see the circuitous and complex system of streets arising from Olmsted's design as a deterrent to an impressionable street environment, and thus, an impediment to widespread pedestrian use (Calthorpe 1994). However, Unwin (1909) acknowledged the usefulness of curved roads in affording the opportunity for "an ever-changing picture" of building groups, but also warned designers must resist the desire to "produce aimlessly wandering lines".

Instead, Traditionalists regard "clear, formalized, and interconnected street systems" as a more direct and legible network of travel (Calthorpe 1994). This preference is founded on the belief that the rectilinear pattern is a form readily understood by the traveler. It is also a pattern where imposition of landmarks can define a more memorable experience by creation of a street vista, and with the imposition of more landmarks, the process of finding one's way is enhanced with the emotional security essential to those traversing an otherwise featureless terrain (Lynch 1960). In describing these closed vistas, Unwin (1909) proposed a technique for imposing a succession of "picturesque street pictures". The 
terminal feature framed by a closed vista becomes significant in reducing the visual monotony of the straight street.

\section{Comparative Relationship of Building to Street}

A distinguishing characteristic between Modernism and Traditionalism is found in the relationship between building and street. Traditionalists regard this relationship as essential to mutually reinforcing a sense of place and identity (Kunster 1993). They believe the loss of identity in the modern subdivision is a consequence of ever-changing focus found on the typical curvilinear street as one navigates through a succession of identically spaced and scaled structures having insignificant variation of scale or importance (Kunster 1993). Uncommunicative facades dominated by large garage doors and driveways also contribute to a loss of contact between street and structure, and as houses retreat from the street, further disconnection results (Langdon 1994).

Perhaps the only exception to increased isolation in the modern subdivision is found in the cul-de-sac. The cul-de-sac, so prevalent in modern suburbs, offers opportunities for what environmental psychologists term desirable levels of contact. It is in this pattern that Traditionalists contend that houses clustered around a single focus go beyond desirable levels of contact, to unwanted intrusion and neighborhood surveillance (Langdon 1994). In contrast, Zehner (1970) concluded persons living on cul-de-sacs report greater neighborhood satisfaction than those living in linear neighborhoods because vehicular and pedestrian access by those living outside the neighborhood is reduced. 
From a Traditionalist point of view, the supportive relationship between building and street must occur through a psychological restoration between public domain and adjoining structure. This restoration occurs when streets are narrowed and driveways and garage doors are replaced by "porches, balconies and entries" (Calthorpe 1994). Privacy, diminished by the absence of cul-de-sacs, is restored by layers of space, where elements such as porches, street-walls and grade differences help to physically separate public from private space, while still maintaining a sense of visual connection (Katz 1994). This relationship is defined as one shaped by "house, lot, sidewalk, grass strip, curb, and vehicular way" (Duany and Plater-Zyberk 1991). In this relationship, setback depths in lowdensity subdivisions range from five to twenty feet, and garden walls are required when setback depths exceed twelve feet (Duany and Plater-Zyberk, 1991). It is also a proportional relationship in which adjacent building heights and street widths mutually work together to support the comfort and safety of pedestrian and vehicular travel. Lower density residential development within the Traditionalist plan could be considered appropriate on rights-of-way not exceeding 50 feet in width; with setbacks varying between 0 and 25 feet; where automobile travel lanes do not exceed eight feet in width; and where buildings two stories in height are permissible. High density residential developments in the Traditionalist pattern allow buildings three stories in height, reducing setback requirements to five and fifteen feet, while maintaining right of way widths at 50 feet (Duany and Platter-Zyberk, 1991). 
Further definition between private and public domains in a traditional plan occur by the use of landscape features. Low picket fences, street-walls and hedges are used to define the line separating yard from the street beyond (Calthorpe 1993). Separation also is fostered by establishing the vertical presence of buildings in relationship to the adjoining streets. This separation is accomplished, first, by restoring a formal entry, and then, by establishing its prominence by elevating it minimally two feet above adjoining roadways (Duany and Plater-Zyberk 1991).

Contrast these dimensions with those of modern suburbs and it becomes apparent that Traditionalism emphasizes compactness in the arrangement of buildings in relationship to each other and to the street. Typical requirements within modern low-density suburbs establish minimum setbacks that may range from 25 to 75 feet, while high-density patterns allow minimum setbacks ranging between 15 and 25 feet. This same emphasis extends to typical roadway and right-of-way requirements of modern suburbs. Right-of-ways in modern auto suburbs are usually no less than 60 feet with recommended pavement widths not less than 24 feet. Greater compactness in traffic systems found in the traditionalist pattern also is seen in curb radii usually no greater than 15 feet and in the modernist pattern no less than 25 feet (Duany and Platter-Zyberk 1991). The typical 60 to 70 foot wide lot in the modern suburb is cut in half by a traditional plan where tightly spaced structures create a wall, affording a sense of enclosure and refuge (Calthorpe 1993). Unwin (1909) considered enclosure 
essential to the definition of place, and one resulting from a "fairly continuous frame of buildings".

\section{Comparative Relationships of Land Uses}

A key component of Traditionalism is diversity. Jacobs (1961) describes the stringent order of Modernism to be as maligned as utter chaos. Desirable levels of disorder rely on diversity found in the mutual sharing of space by pedestrians and cars, but also in the diversity found by a variety of building types and spatial arrangements (Calthorpe 1993; Lerner-Lam 1992). Much of the complaint that modern automobile suburbs are ugly and monotonous stems from what Traditionalists call "market segmentation" (Langdon 1994). Segmentation in the modern suburbs has led to a pattern of pods that cluster similar housing types into distinct social, economic or geographical areas. The resulting uniformity offers little opportunity for inciting a sense of visual prospect and anticipation. Furthermore, the homogenous arrangement of similar looking buildings contributes to a loss of spatial identity.

Traditionalists suggest that instead of a regimented arrangement of similar buildings in segmented pods, roadway layouts should be "the equivalent of a musical score....with a sequence of visual experiences" (Langdon 1994). Such a score allows the grouping of similarly scaled buildings and landscape features in a rhythmic pattern with varying stimulation so that a sense of sequence and progress establishes identity along the roadway environment. Unwin (1909) felt that relief from monotonous regimentation occurs by breaking the frame of the building line to create forecourts, but also cautioned that excessive gaps and 
breaks lead to disorder and a loss of dignity within the streetscape. He also recognized that the break in a building line or a change in a roadway should acknowledge the relationship between place and building. Over-large places dwarf insignificant buildings, while dominant structures require places proportional to their height (Unwin 1909). Since Unwin was not averse to lazily curved streets, he suggested breaks in the building lines be considered at the roadway bend to provide opportunities for terminal features in the more expansive green areas created by these breaks (Unwin 1909). Civic buildings, such as churches, clubs and schools are placed at the end of streets to establish a vista termination (Lerner-Lam 1992).

\section{$\underline{\text { Summary Comparison }}$}

For this research, two dimensions represented by Traditionalism and Modernism will be used to compare visual preference in neighborhood development. Fulton (1996), in his critical evaluation of New Urbanism, acknowledged success of the movement is not achievable solely by its ability to solve social, cultural and economic problems of the suburbs, but rather by its capacity to alter the "physical arrangement of neighborhoods". Crucial to its ability to induce change is the capacity of New Urbanism not only to understand who is the market, but to determine what it wants (Fulton 1996). Understanding the attributes of these two dimensions is seen as a way to establish preference in the spatial arrangement of the public realm. In summary, the comparative attributes of Traditionalism and. Modernism, as applied to the visual 
characteristics of the physical and spatial arrangement of the street are described in Table 1 below.

Table 1

Comparison of Physical and Visual Attributes

Of Traditional and Modern Development Patterns

Within Neighborhood Street Environments

Traditional Development Pattern

Modern Development Pattern

Streets with regularly planted trees

Streets with no trees or trees

Streets having sidewalks

separated by a planted median

planted in an irregular pattern

Rectilinear streets

Streets with no sidewalks or planted median

Rectilinear streets

Curvilinear streets

Streets with on-street parking

Cul-de-sac streets

Narrow streets 16 -feet in width

Streets without on-street parking

Narrow setbacks less than 15-feet in width

Wide streets 24-feet in width

Variable setbacks and building heights

Wide setbacks greater than 25 feet width

Regimented setbacks and building heights

Buildings elevated two-feet above Buildings at the same elevation the adjoining street as the adjoining roadway

Streets with narrow lot frontages Streets with wide lot frontages not exceeding 30 -feet in width

Streets having spatial separators

Streets without front driveways

Streets having terminal features not less than 60 -feet in width

Streets having no spatial separators

Streets with front driveways

Streets with no terminal

features 


\section{Dimension Hypotheses}

Given the evidence cited heretofore, the following hypotheses propose visual preference will favor one of these two development patterns. For the purposes of this research, visual preference is generally defined as that which enhances one's survival and increases one's sense of comfort and competence in the spatial environment (Kaplan and Kaplan 1982). The literature review of this researcher finds no conclusive evidence that visual preference favors either traditional or modern development patterns. For this reason, two propositions are possible:

H1: Visual preference by the subject group surveyed by this research will favor visual attributes of traditional development patterns.

H2: Visual preference by the subject group surveyed by this research will favor visual attributes of modern development patterns.

The null hypothesis proposes that visual preferences do not distinguish between traditional and modern designs, and is expressed as $u_{1}=u_{2}$, where $u_{1}$ is the population mean expressed for stimuli representing the traditional dimensions and $\mathrm{u}_{2}$ is the population mean expressed for the modern dimension.

\section{Characteristics of Visual Preference}

A key motivation for this research is developing better understanding of how people experience the environment. Critical to this understanding is the component of preference, which causes environmental design professionals their greatest fear. This fear originates from concern that the public will prefer that which is foreign to extant designs, and a mindset that determination of environmental beauty is a highly personal attribute for which no pattern exists. 
Appelton (1975); however, argued there is "something" common in all things of beauty. The psychophysical landscape preference model developed by Shafer et al (1969) found patterns to respondent's preferences for landscape images.

Findings throughout the literature continually support the notion that visual preference is neither random nor arbitrary, particularly as it relates to attributes of familiarity, complexity and coherence.

Santayana (1910) described beauty as a preference pattern in which a cooperative effort of the senses defines the emotional elements of pleasure found in the quality of an object. He treated aesthetic judgment as a universal trait generalized by our own opinions. In describing this construct in the image of the home, he regarded it as a pleasurable object materialized by a mental picture of cottage and garden. Furthermore, he found these mental images reflecting our own lives. In the formulation of those life experiences, he regarded the spatial capacity of sight as one of our most significant senses for determining pleasure (Santayana 1910).

\section{The Psychophysical Approach}

Interest in matters of beauty, and more particularly scenic-preference, are increasingly a psychological component in design and planning decisions (Kaplan 1982). If space is the canvas in which objects such as cottage and garden are to be placed, then it also becomes a way in which aesthetic perception can be applied. The classical account of visual space defines the observer as not merely an entity that view objects in space, but rather as an object immersed in a scene. 
This participatory landscape integrates the viewer through paths and boundaries regulated by the objectivity of distance (Berleant 1970).

The doctrine of perception depends on our ability to have sensations. Campbell (1974) considers this capacity to develop a percept, not only with input from the senses, but a collection of previous experiences. It is from sensations of color, sound, taste, touch, and smell, that mental capacity is employed to develop images of object or thing. Considering the mind of a child as a blank page, experiences establish the sensory map enabling response to stimuli. This theory of perception acknowledges stimuli as the raw material for building knowledge of the physical environment.

Although believed to be a process attributable to association and inference, how humans go about building an image of the world is not well understood. Nevertheless, humans generally accept perception as not exclusively determined by physical stimuli, but also by personal contributions drawing upon our individual contact with the world (Gibson 1950). If it is recognized that perception combines stimuli with personal experience, then the age-old question of whether beauty is found solely in the object or only in the mind of the beholder can be addressed, and again one can conclude "neither". It is the combination of both mind and object that establishes a structure of personal preference (Woodcock 1982).

Gibson (1986) described this perceptual system as one in which the surrounding environment is not merely seen with the eyes, but experienced by the entire body. Visual perception as described by Gibson (1986) begins with a two 
dimensional retinal image and develops depth with the input of visual cues.

Depth to the visual field occurs with the addition of "linear perspective, apparent size, superposition, light and shade, relative motion, aerial perspective, and convergence." These psychological cues are essential to Gibson's (1986) ground theory, which as a theory of surface layouts, suggests that humans cannot even begin to understand space as merely Cartesian points plotted in air, but instead, must rely on "places and objects, together with other features."

In contrast, Kaplan (1975) in describing the information-process theory supported distinction between object and setting and the need for stimuli and senses to be used in tandem as a way to associate object with location. At its most elemental level, this association includes merely an object against a contrasting background. At its highest level, the object takes on a symbolic meaning connected by association to an understanding much deeper than that represented by the object itself. The ability to organize multiple bits of data into concepts is a process useful for arranging large quantities of information, but also a process that distinguishes individuals and cultures (Rapoport and Hawkes 1970). The complexity of the perceptual system is found not only by recognizing the object, but by associating it to the larger picture that surrounds it. From these correlative pictures, humans establish a pattern of stored images extracted from prior experiences (Kaplan and Kaplan 1982).

\section{Familiarity as a Construct of Preference}

Kaplan and Kaplan (1982) described the collection of spatial knowledge as a system of cognitive maps and recognition of patterns. Such maps provide 
relational properties enabling determination of proximity, distance, order, and sequence. The spatial framework provided by cognitive maps uses distinct representations identifiable by mental landmarks. The interconnection of a succession of patterns provides the capacity of people to function smoothly in the spatial environment by being able to anticipate what to expect in the next succession of events (Kaplan and Kaplan 1982). Stea (1969) characterized these maps as relative descriptions of the real world as opposed to actual descriptions, by which we preserve order, sequence, relative size, and other specifiable conditions. In short, the cognitive maps represent human ways of approximating the environment (Kaplan 1978).

Information necessary for way finding is most prevalent in the visual sense (Woodcock 1982). To that end, humans continually gather visual information referencing location using both objects and space to facilitate understanding of surroundings. The need for visual-spatial order in a person's world dominates the theoretical basis to explain environmental preference and remains a central theme to designers wishing to incorporate human needs into their decisions (Kaplan and Kaplan 1982; Frey 1981; Peterson 1965). The capacity of designers to improve visual quality of a neighborhood must first assume distinction between the attractive and unattractive before it can isolate specific attributes contributing to preference (Lansing and Marans 1969).

Theoretical characterization of environmental preference attempts to explain these universal attributes, yet acknowledges their variability. Innate theories propose that commonalties in environmental preference have emerged 
from development of the human nervous system. Much the same as humans feel warmth from a fire, they also feel pain if thdy come in contact with the flame (Gibson 1986). Such innate theories rely on a common theme that humans continually search for information to better understand their surroundings. Gibson (1986) called these events "affordances", describing them as environmental offerings necessary to facilitate an understanding of our surroundings. As individuals see an object approach, they may view it either as an opportunity for contact or as a threat for collision. Appelton (1975) characterized the pleasurable sensations of the environment to be a result of inputs crucial to biological survival. In this manner, humans use perception as a means for not only gathering information about the environment, but more importantly, as a way of gleaning information about its possibilities. In so recognizing environments in which humans thrive, individuals view preference of an environment by its potential to be supportive to their purposes (Kaplan 1979).

The second set of preference theories considers preferential differences resulting from personal experiences. The so-called historical theories, while most strongly emphasizing differing preferences for nature, also have application to the built environment. Turner (1977) found surprising satisfaction by persons living in substandard housing as a reflection of their sense of fit and a byproduct of their familiarity with that environment. Peterson (1965) determined that preference toward visual scenes of the urban environment varied between subjects in Utah and Chicago because of the level of familiarity subjects had with those scenes. Thus, Mormon subjects participating in his study had greater preference for urban 
scenes depicting church buildings. Linton's (1968) research on natural resource assessments in Scotland found persons from the western highlands preferred mountain landscapes because of their familiarity with such terrain. Frey (1981) established familiarity as an important consideration of visual preference, particularly in neighborhoods having unusual characteristics. Kaplan (1977) used familiarity of the visual environment in her assessment of drainage improvements.

Rapoport and Hawkes (1970) proposed that cultural and personal factors are instrumental in determining whether information in a particular scene is useful. Herzog et al (1976) found positive correlation between familiarity and preference by subjects viewing scenes of buildings in Grand Rapids, Michigan. Naser (1984) found preference by subjects for street scenes of their own immediate neighborhood when contrasted to scenes from other neighborhoods. Although Gulick's (1969) research is not in the realm of visual preference, he found affinity for urban images in Tripoli to be partially attributable to knowledge of and familiarity with their social significance. Kaplan and Herbert's 1987 cross-cultural preference study of American and Australian students on the surface suggests no apparent linkages exist between visual preference and familiarity. However, further interpretations of their findings reveal differences between American and Australian cultures so inconsequential as to yield no significant variation in preferences.

\section{Familiarity Hypothesis}

Kaplan and Kaplan (1982) believed a significant amount of research in the area of environmental cognition has been driven by a desire to know how people 
experience the environment. Although understanding preference may not be an overriding objective of this interest in environmental cognition, the Kaplans would argue that understanding preference "is essential if the true scope of experience is to be understood." To that end, they would also propose that visual preference of the environment comes about by human understanding and use of evaluative codes

Evaluative codes guide one's ability to assess the environment in the present tense so that we can respond adequately to conditions in the future. Positive correlation between familiarity and preference is a consequence of reduced dependency on environmental information. Human evaluative codes formulate cognitive maps used in making decisions and finding the way in the spatial environment. They contribute to one's preference by allowing one to direct oneself toward what one likes and avoid that which one does not like. When applied to the context of visual preference, the ability to see, in advance, a need to respond allows the time to prepare for the ensuing event (Kaplan and Kaplan 1982).

While the ability to anticipate the future visually can contribute to one's sense of well being, one must also recognize the cognitive steps necessary to react to those conditions. Therein is where familiarity becomes an important link to establishing the evaluative codes necessary to develop a cognitive map. Kaplan (1973) found that people prefer what they know. He further believed that familiarity increases one's self-confidence to draw upon the cognitive maps one has developed in the past to guide one in the decisions on how one wishes to 
proceed in the future. He concluded that people are most uncomfortable "in circumstances where no previously learned map is pertinent." Familiarity with an environment allows one to rely on mental maps as a way of navigating through a particular setting. These cognitive maps represent the collective storage of experiences that are distinctively ours, and lend support to historical theories that acknowledges the belief that preferences vary between individuals and cultures (Kaplan and Kaplan 1982).

Despite how readily one can embrace the notion that familiarity contributes to one's preference of an environment by allowing one to understand and react to environmental conditions, the relationship between familiarity and preference may not always be straightforward. One can look at the times in our lives when one was most satisfied and find it may have been when one was most challenged. Without a desire to experience new challenges, how could one explain the motivation to travel and participate in the environments beyond one's surroundings? Entire industries have been developed based on the need to recreate, be amused and entertained.

Kaplan and Kaplan (1982) suggest that one's ability merely to make sense of our environment may not be enough and describe humans as "rather restless creatures, often looking for trouble when they are not busy avoiding it." Humans look forward to the opportunity to expand their horizons so that they can add to their evaluative code and build longer and more seamless cognitive maps. Just as human use experiences as a way to anticipate the future, they also search for ways to improve that well being by becoming more familiar with the environment that's 
beyond their grasp. Humans may be prepared best as a species when they can draw quickly upon a lengthy cognitive map to respond to the conditions of the environment that lies ahead and into the future. The Kaplans would propose that the need for familiarity and the need for challenge work simultaneously to influence environmental preference, and when expressed as a matrix, it may resemble that depicted below.

\section{Figure 1}

Familiarity - Preference Matrix

\begin{tabular}{|l|l|l|}
\hline & Low Preference & High Preference \\
\hline Low Familiarity & Confusion & Visual Excitement \\
\hline High Familiarity & Boredom & Comfort \\
\hline
\end{tabular}

Kaplan and Kaplan (1982)

Much of the research proposed by this dissertation is directed to understanding the influences of visual preference better particularly as those influences pertain to preference for residential neighborhoods. In relation to the visual preference of residential neighborhoods, one can begin to see the potential application of the Kaplans' research on familiarity and preference. Many people have found themselves in situations where the inability to make sense of a neighborhood readily causes discomfort. One may attribute this confusion to an absence of landmarks, a confusing network of roads or simply an environment in which they have had little experience. Because of the inability to come to terms 
readily with that visual environment, one may in turn develop a negative opinion of that visual environment.

On balance, one can relate also to experiences of residential neighborhoods where the sense of sameness becomes an overpowering attribute. Whether it is the similarity of the homes, the straightness of the street, the repetition of landscape and site features, or simply one's complete familiarity with the visual environment, one finds that his / her ability to comprehend the visual environment readily contributes to a frustrating sense of boredom. This frustration may originate from human need to re-create, to build upon evaluative codes, and to expand our cognitive maps.

Despite the competing human needs for both familiarity and challenge in the visual environment, it is the belief of this researcher that people initially gravitate toward that with which they are most familiar. Only when they feel secure within that visual environment do they begin to search for new stimuli that can assist them in building upon their evaluative code. Since this research proposes to use two-dimensional stimuli, the second step toward expanding the cognitive map is severely constrained and perhaps may not be achieved.

With this background it can be hypothesized that visual preference of a scene is increased by familiarity. Expressed more fully this hypothesis reads as follows:

H3: Visual preference for a scene is directly related to the amount of familiarity a subject has with the dimensions of that scene. 


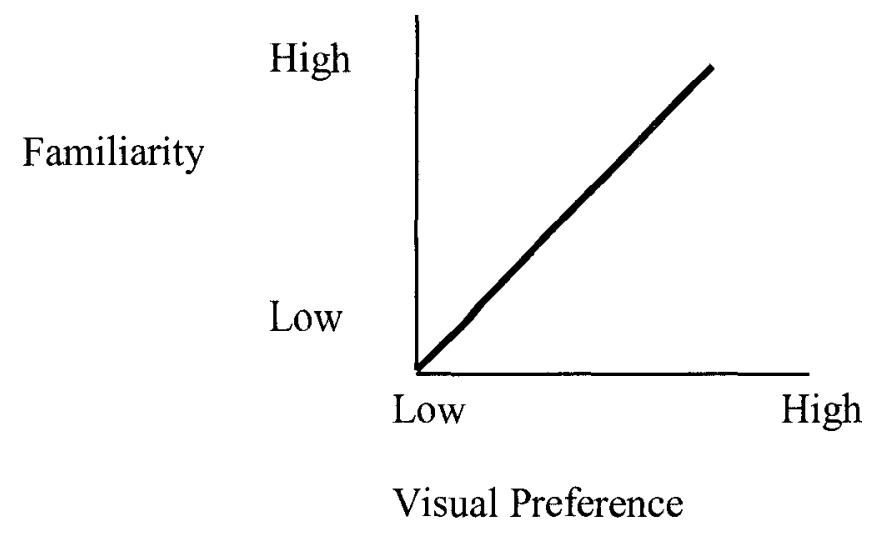

\section{Theories on Coherence and Complexity}

Exploratory theories are a third set of preference theories that help to explain variability of visual preference, particularly as it relates to coherence and complexity. Because building in complex and illusive ways is within the realm of interest of designers, such building represents the theoretical basis having greatest application to preference and environmental aesthetics (Rappaport and Kantor 1967). Lynch (1960) believed complexity of the urban environment requires that environment to be limited to readily definable terms. Through nodes, paths, edges, districts, and landmarks, the process of way finding in the urban milieu, to Lynch, becomes more manageable. Naser (1987) found evidence that moderate complexity and high coherence of commercial signs are considered most pleasant to shoppers. Other studies indicated a certain amount of complexity as a predictor of preference in both nature and the urban environment (Kaplan et al 1972).

Preference research continually emphasizes the balance between human need to make sense of the visual environment and the need for visual involvement. The need to make sense of an environment is a result of innate 
human needs to maintain spatial bearings and to understand of one's surroundings. Involvement responds to other innate needs for stimulation, to the extent that humans can react to information the environment has to offer.

Translated into a dimensional realm, these two purposes are represented by components of complexity and coherence. Involvement, represented by the complexity component, is measurable in terms of how much is occurring within a particular scene. Lansing and Marans (1969) described interest as being elements necessary to maintain curiosity, and further defined by variations in architectural style, vegetation, landscape, topography, and spatial character. The "making sense, coherence" component is measurable in terms of the organizational characteristics of a scene and human capacity to arrange information in the most understandable and memorable pattern possible.

\section{Coherence}

Most people find the environment to be completely satisfactory in terms of security and subsistence. Yet, that same environment does not challenge one until one is confronted with visual images that arouse his or her curiosity. Kaplan (1975) and Lozano (1974) suggest coherence is a reliable predictor of preference by its capacity to foster survival, yet acknowledge complexity as essential to the visual arousal required for spatial assessment. Lozano (1974) used this understanding to formulate his hypothesis that human needs in the visual and spatial environment rely on low-order and easily understandable stimuli to provide orientation, while allowing more complex, high-order stimuli to fulfill the need for anticipation. Kaplan's (1977) drainage improvement study found 
respondents in a high end socioeconomic continuum found preference for images having greater natural complexity, while respondents with limited economic resources preferred scenes with a general impression of neatness.

Steinitz (1968) defined coherence as congruent physical activities arranged in a predictable manner. He demonstrated that congruent places and activities tend to be the most known and identifiable. Naser's (1987) selection of complexity and coherence as dimensions of commercial sign preference borrowed from earlier research of Ward and Russell (1981), which concluded three aspects of environmental preference are consistently attributable to pleasantness, excitement and calmness.

In his commercial sign study, Naser (1987) found coherence is the making-sense dimension defined by its degree of organization, patterning and unity. Lozano (1974) suggested that this need for coherence in the contemporary urban environment is just as essential to survival as in the wild. While maybe not threatening, disorientation within an incoherent and hectic urban environment is, at best, stressful. Moderation of stress and frustration within an incoherent urban environment occurs by a cognitive structure facilitated by prior knowledge and familiarity, but also with orientation inputs (Stenitz 1968). Kaplan and Kaplan (1978) suggest that for a scene to make sense it must first appear as if it belongs. It then must hang together by its continuity of textures and repetition of elements.

\section{Complexity}

The involvement dimension, found in complexity, is characterized by the amount of variation in a scene. The degree of pleasantness or beauty influenced 
by complexity can be represented by an inverted " $U$ " in which optimal scene complexity is found somewhere between when monotony ceases and chaos (Naser 1987). Research by Naser in Knoxville and Chattanooga, Tennessee (1988) revealed consistent findings of visual preference for coherence by both residents and visitors. The most disliked areas of those communities lacked coherent styles or were otherwise characterized by "chaotic signs, billboards, poles, and wires." Groat's (1984) research also supported this finding, and she concluded reduction of visual nuisances' facilitated visual preference.

Kaplan and Kaplan (1982) suggested the challenge in cleaning up complex urban environments may not have so much to do with the objects themselves, but rather with the background against which they appear. Monotony and disorientation resulting from low-level visual order described by Lozano (1974) may just as readily be a consequence of complex foregrounds superimposed on equally complex backgrounds. Such is the case with the modern commercial strip, in which object recognition is obliterated by noisy and confusing backgrounds.

\section{Prospect-Refuge Theory}

Further analysis of visual perception concepts by Appleton (1975) reveals involvement in terms of mystery. Mystery serves as an attribute in which additional way-finding information becomes possible. The artistic use of this technique as a component to enhance preference is found in the partially obscured view intended to entice the viewer's further exploration of a scene, with prospects of obtaining additional information about the environment that exists beyond the 
canvas. Its legibility and capacity to deliver a prediction of other attributes of the space find the making-sense component found by the third dimension. The legible scene allows humans to readily draw upon cognitive maps in the visualspatial understanding of the surrounding environment (Appleton 1984).

Appleton (1984) used the third dimension to formulate his prospect-refuge theory. This theory proposes both prospect and refuge as necessary ingredients for optimal visual preference. The refuge component suggests that symbols of shelter, as found in vegetation, entry, canopy, and enclosure, reinforce legibility by their capacity to cause feelings of safety, well being and familiarity. In the context of neighborhood design, the application of refuge symbols may be found in tree canopy, porches, recesses, and entry gates. Appleton (1975) suggested the cul-de-sac as a strong refuge symbol by its single point of access and total enclosure. Refuge is also found in the form of buildings on both sides of a street, particularly if these buildings have penetrations and other refuge symbols such as steps, large overhangs, upper levels, and vegetative screens. Shadows emanating from these elements also help to establish a greater sense of refuge (Appleton 1975).

The prospect component is supportive of any affordances that may be offered by a scene. It is a result of visual access and what can be learned about the surrounding environment. Open and smooth surfaces, such as deserts and meadows, offer great panoramic prospects (Appleton 1975). Likewise, apertures such as windows and doors work to frame distant views and add to the prospect component. Prospect imagery in the street scene is facilitated in a number of 
ways. First, a descending roadway grade establishes an expanded view of the surroundings. Visual access to a horizon, particularly one that is partially wooded or obscured creates potential for greater involvement by the viewer. Repetitive elements, such as trees and light standards serve as vistal elements of the prospect-dominant street scene. Patches of light additionally help to induce visual prospect (Appleton 1975).

Appleton (1975) suggests prospect-refuge images have to be used in tandem to create common features of so called "calendar pictures". In Venice, as an example, symbols of both prospect and refuge work together to complement the other. The richly detailed alleys and narrow streets of that city provide refuge dominant symbols establishing vistas to more panoramic views afforded by open squares. Within these squares, ample penetrations through buildings support a sense of entry and provide paths to other successions of alleys and open spaces. It is this alternating system of canalized vistas and panoramic views, that the observer is offered the security of lateral cover in combination with an expectation of gaining visual advantage and orientation (Appleton 1975).

\section{Optimal Perceptual Rate}

In the context of environmental aesthetics, "optimal perceptual rate" as defined by Rappaport and Kantor (1968) is achieved when the right amounts of complexity and ambiguity are found in the intricacy of design. Berlyne (1960) found subjects pondered visually complex stimuli longer than those more readily understood at a glance, while Kaplan and Kaplan (1978) concluded human response speeds are dependent upon clear interpretation of the environment. This 
concept supports conclusions of Rappaport and Kantor (1968) that subtle increases in ambiguity can result in nuances that facilitate orientation in otherwise monotonous or overly complex visual environments. Naser's (1987) sign complexity study also found the independent variable of pleasantness to be significantly higher for moderately complex signscapes when contrasted with images having low or high complexity. These findings suggest that highest preference may be found near the top of an inverted U-shape curve when visual preference is measured in terms of variable complexity. Rappaport and Kantor (1968) concluded that orientation and variety are closely correlated.

Seemingly, it would be easy to conclude that disorientation in an incongruent urban environment is readily resolved by simplification. In fact, Lozano (1974) found that lower levels of orientation are a consequence of simple visual organization. This conclusion takes into consideration sensorial deprivation resulting from monotony as well as dependency on visual messages necessary to facilitate navigation. Lozano (1974) further characterized low-level order as attributable to modern urbanism epitomized by work of Le Corbusier and the Bauhaus. While clearly Le Corbusier is a master of the Modern Movement, the visual organization of lesser designers associated with that Movement oversimplified it to the extent that conscious perception ceased. Most people have experiences of traveling regularly through low-level visual environments without being cognizant of physical attributes of that environment until some functional reason demands our understanding of such spatial details. Some 
suggest prolonged exposure to monotony leads to perceptual difficulties so severe as to cause hallucinations (Rappaport and Kantor 1968).

Lozano (1974) found that low-level order offered by modern urbanism produces sensorial deprivation and monotony. Sensorial deprivation, in turn, reduces the potential for orientation by eliminating affordances necessary for comprehension of the visual environment. Because these visual messages are essential to provide directional cues in their simplest form, the oversimplifying by the Modern Movement ignores the psychological needs of humans for visual interest. Response by Modernists to this criticism has given way to the New Picturesque movement considered by many a superficial design approach marked by loosely held form. The winding roadway pattern evolving from this trend makes it nearly impossible to develop a cognitive map of the urban pattern. In contrast, Lozano (1974) embraced the simplistic form as found in the "Manhattantype grid" in which main streets are clearly understandable by their repetitive patterns and regular quadrants.

In the realm of neighborhood design, Lozano (1974) contrasted medieval town planning with conventional subdivision design. The Medieval town characterized by him is distinctive by its system of orienting landmarks found in highly organized and repetitive plazas. Urban structure in the medieval town used subtle changes in building heights and lot size to establish a hierarchy that further facilitated direction and orientation. In contrast, the sweeping simplification of the Modern Movement relies on wandering residential streets aimlessly configured to avert monotony in residential subdivisions. While Lozano (1974) 
suggested winding streets create interest, such a pattern makes it nearly impossible to develop the cognitive map essential to orientation.

Another contributing problem to disorientation in the modern subdivision comes about by its lack of relief. The sprawling ranch style house, symbolic of suburbia, seldom provides a vertical reference useful in establishing distances (Lozano 1974). Rappaport and Kantor (1968) found that dramatic vertical relief of San Francisco's grid affords greater perceptual information than would otherwise be available from a similar grid on flat terrain.

Relevant to the dimensions under consideration by this research is a belief that clarity and simplicity are hallmarks of Modernism. Rappaport and Kantor (1968) contended that the sensory output of contemporary urban environment falls to such low levels those levels fail to satisfy minimal needs for involvement. Gestalt designers recognize the value of perceptual quality, not in terms of its ambiguity, but by closure found with its brevity, simplicity, neatness, and roundness (Rappaport and Kantor 1968). Frey (1981) however, found the orderliness and homogeneity emphasized by modern land use controls, such as zoning, contrast to psychological needs for diversity and variety in our environment.

\section{Complexity-Coherence Hypotheses}

The aim of contemporary urban design to clean up the visual / spatial world to such an extent that it can be understood effortlessly was a point of discontent with Jacobs (1961). Instead, she asserted that the ambiguous and arbitrary character of life itself is by far the reason humans prefer incongruent and 
surprising attributes in the urban environment. The modernist trend toward efficiency and productivity is a contributing factor to this decline in visual diversity (Kaplan and Kaplan 1978). What seems apparent is that most visually successful environments depend on complexity to fulfill human need for visual inputs. Yet, human need for complexity must also be tempered by coherent, rhythmic patterns that serve to orient. With this reasoning, it is hypothesized optimal visual preference for a scene is found in optimal amounts of complexity and coherence.

H4: Visual preference for a scene is directly related to its complexity until an optimal level is achieved, whereupon it becomes inversely related to each additional increment of complexity.

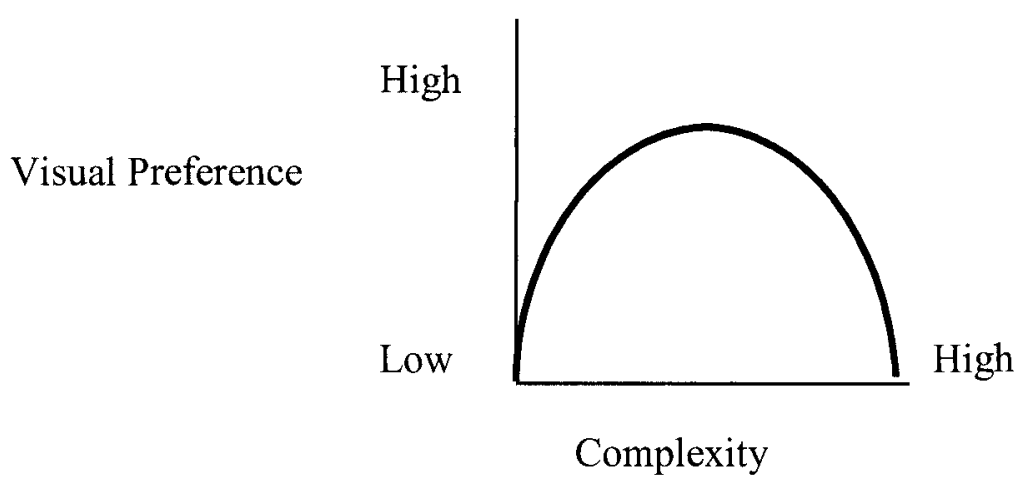

H5: Visual preference of a scene is directly related to its coherency until an optimal level is achieved, whereupon it becomes inversely related to each additional increment of coherency. 


\begin{abstract}
High
Visual Preference

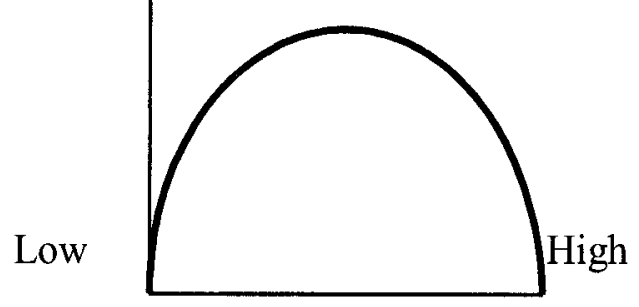

Coherency

With these hypotheses, it can be concluded that within the dimensions of Traditional and Modern neighborhoods, each type has the potential to contribute to visual preference. Traditional neighborhood designs contribute by their capacity to be complex through greater mixture of uses, building types and orientation inputs. Modern neighborhoods contribute by their capacity for coherent uses, building types, setbacks, and patterns. Each dimension has facets that are potentially complementary to one's visual experience of the street environment. Just as the attributes of coherence and complexity are not mutually exclusive, dimensions of Traditionalism and Modernism each have varying degrees of these attributes. For this reason, it is further hypothesized an optimal value of complexity and coherency is applicable to each dimension.
\end{abstract}

H6: Visual preference for a scene is directly related to an optimal amount of coherence as represented by the Modern dimension and an optimal amount of complexity as represented by the Traditional dimension. 


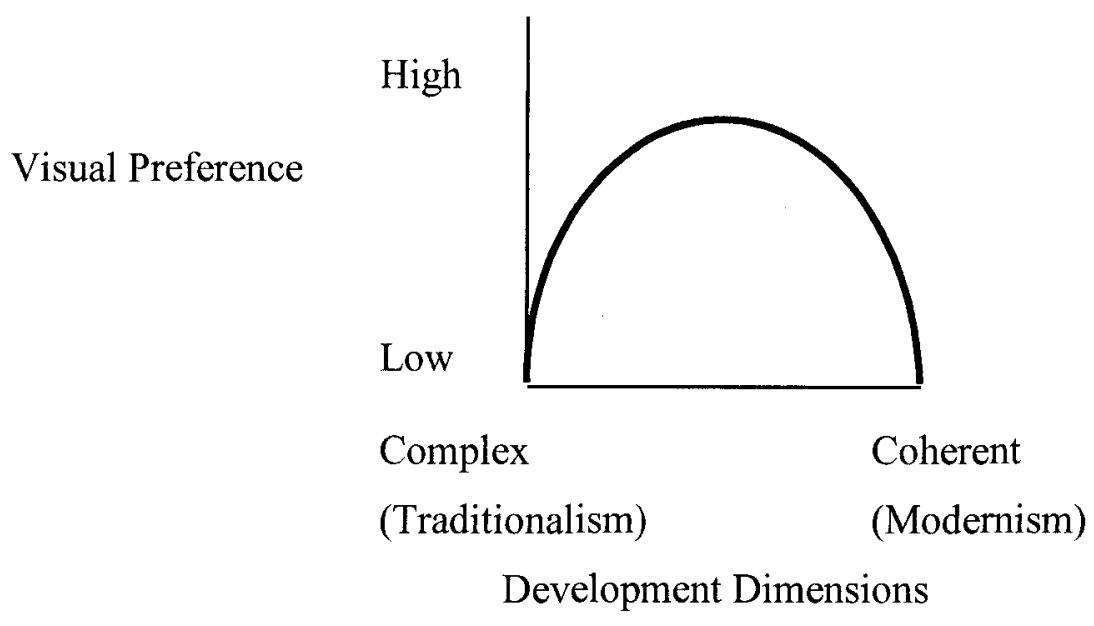

\section{Data Visualization}

The manner by which planners and urban designers communicate concepts is mostly visual. The need to visualize urban data is important on the basis of three premises. First, visual information enables designers to understand the consequences of design decisions from multiple viewpoints prior to their implementation. Second, it facilitates our visual understanding of complex urban problems. And finally, it increases the ability to communicate potentially complex concepts readily in an interactive manner (Langendorf 1992). Understanding more about that third and final premise remains crucial to the research proposed herein.

Increasingly, visualization is recognized as a computational process allowing for the transformation of symbolic design constructs into geometric form (Langerdorf 1992). Human needs to see complex urban and regional environments has made computer visualization significant for management of the visual-spatial realm. The use of such techniques has the potential for social and 
natural scientists as well as designers to assess impacts of land management decisions on the physical environment readily and accurately. Such techniques are beneficial in bridging the gap between experts and the public. In the area of environmental resource management, such techniques have been successful in assessing impacts of air pollution on the visual character of the Grand Canyon (Malm et al 1981) and of the impression insect infestations leave on the forest environment (Orland et al 1990).

Daniel (1992) suggested data visualization is essential for decision support, because of its "accurate and verifiable representation of existing and projected environmental conditions." Given the range of such techniques from use of simple charts to fully animated computer simulations, the challenge of any visualization method remains with its ability to avoid misrepresentation (Daniel 1992). To that end, many so-called experts suggest the process by which data representations are translated into environmental images remains largely unexplored (Daniel 1992; Perkins, 1992; Orland 1992; Oh 1994; Bishop 1997).

Orland (1992) contended visualization techniques used in environmental management must be capable of conveying real-time change in an accurate and graphical manner. He further recommended a regimen of research to assess issues of validity and accuracy of such techniques to address common, everyday questions about environmental resource management. Perkins (1992) questioned how image quality relates to perceived realism. Appleyard (1977) suggested simulations of any type must focus on critical aspects of reality as applicable to a particular purpose. Bishop (1996) promoted the rigorous research and validation 
of computer visualization techniques to insure their results are defensible in both research and practice.

Langendorf (1992) suggested the digital character of visual data makes the data adaptable to the spatial realm. The strength of digital visual data is found in the suitability of that data for storage and management in a computer environment; by its suitability to be readily edited, transformed, recombined, linked, and merged; by its capacity for greater interaction with users; by offering broader access through network systems; and by removing barriers between separate research tasks such as collecting, storing, retrieving, and analyzing.

Such strengths go beyond purely academic interest, extending to the public realm and the representational quality necessary to elicit a reliable public response. Daniel (1992) proposed the power and expense of the technology used in decision support must coincide with the purpose for which it is intended. He recognizes a simple two-dimensional map may be perfectly acceptable for a planimetric problem, while more complicated and realistic simulations may be necessary to the understanding sensory preferences. Most would agree the strength of computer-aided visualization is found in its capacity to organize, analyze, design, and communicate in a complex, multidimensional world (Langendorf, 1992).

Oh (1994) considered visual assessment techniques crucial to almost any design preference decision. To that end, Grob (1991) found complex visualization techniques essential for convincing authorization agencies in assessing industrial plant locations. Faust (1994) considered visual terrain 
analysis useful in assessing aesthetic and material value of visually dependent real estate. Naser (1987) successfully manipulated photographic images in his visual preference research on urban signs. Wherrett's (1999) image analysis of Scottish landscapes used ArcInfo Data Models to develop vector coverage for manipulating spatial zones and land covers necessary to validate Shafer's (1969) Landscape Scenic Preference Model.

In a comparative study of data visualization techniques, Oh (1994) assessed computer-based simulations to portray accurately as-built conditions of a building on the University of California Berkley campus. In his research, four static computer simulation methods were compared by their capacity to portray the completed building attractively and credibly. These methods included wire frame; surface models; surface models with scanned photographic images; and image processing. A comparison of mean scores for the attractiveness dimension revealed image processing products (mean $=3.01$ ) to be most like the real image of the as-built structure (mean=4.23). For the credibility dimension, image processing (mean=4.32) again was considered to be most like the as-built structure (mean=4.93). In short, Oh concluded simulations such as those based on image processing can be effective in soliciting user opinions if they are attractive and credible, and further concluded that simulation techniques must have the capacity to display color, texture, shading, and realistic details such as human figures.

Levy (1995) explored the use of Computer Aided Design (CAD) as a visualization technique in two urban design problems. In his computer modeling 
approach of the City of Geneva (New York) lakefront, he used AutoCAD for mapping and physical inventory of the study limits. Imaging and modeling capabilities of AutoCAD helped to identify key concerns and readily permitted examination of a variety of visions for the development area. ArchiCAD 4.10 was evaluated by Levy in a similar urban design problem for the City of Cochrane (Calgary). ArchiCAD provided a way to generate plans, elevations, perspectives, and isometric projections easily allowing examination of issues of architectural massing, scale, setbacks, and building materials. Greater detail to the images used in the Cochrane study necessitated use of Adobe PhotoShop to provide specialized colors, textures and architectural detail for public presentation of color slides of screen images. Levy concluded CAD visualization techniques are useful to community planners by permitting multiple perspectives of complex urban problems and by serving as an agent in data organization.

Smith et al. (1998) explored the application of digital management of visual data using both standalone and network applications such as the World Wide Web (WWW). In their research, a comparison of dynamic and static media was made in these two applications. They found that while Virtual Reality Modeling Language allows users to walk around a scene, photorealistic media enable users to access static photospatial scenes more readily. This attribute of photorealistic media allows urban information systems to be studied using less powerful and more economical computer systems. Such a visual communication system has been successful in the Massachusetts Institute of Technology (MIT) 
"Virtual Streetscape" program by allowing users to access real world planning data with a visual interface from the street.

Bishop (1997) used twelve photographically altered images to study visual impacts of built objects introduced into a landscape scene. Of specific interest to Bishop was the ability to estimate the degree to which an object, such as a tower or chimney, is noticeable in a landscape. Using Robertson's (1977) CIELAB model as a basis, Bishop employed Adobe Photoshop as a way to manipulate tagged image file formats (TIFF) in the assessment of color contrast between adjoining pixels. He concluded that Geographic Information Systems and rendering-based computer software provide a defensible model for assessing of visual impacts.

Based on the conclusions of Bishop (1997) and those of Oh (1994), Levy (1995), Wherrett (1996) and, Smith et al. (1998), it is hypothesized:

H7: Preference for computer-generated images positively correlates with the actual photographic image.

\section{Visual Modeling Using the World Wide Web}

The World Wide Web offers new and exciting possibilities as a research tool for assessing visual environments. To that end, this study proposes using the Internet as way to gather data for analyzing other hypotheses proposed herein.

The web has the capacity to provide direct access to vast and diverse audiences in a highly graphical, multi-media context. In social research, Carver et al (1997) found that the World Wide Web has advantages in its ability to access 
increased sample sizes; its potential to target samples; and the interactive capability afforded within the computer environment. Carver et al. further concluded that there is a need for greater understanding of the strengths and pitfalls of web-based research. Similarly, they acknowledged the need for welldesigned web interfaces, which not only stimulate responses, but also encourage participation in the Internet environment. They also recognized that Internet research may require outside media sources to encourage participation.

Schmidt (1997) found psychological research using the World Wide Web to be efficient by its ability to reduce publishing and distribution costs normally associated with conventional survey methods. Data entry costs and errors can be reduced by software interfaces that enable direct download of data to statistical programs. Coomber (1997) found Internet research offers the opportunity to reach much wider populations than traditional survey techniques. Because Coomber's Internet research anonymously surveyed drug dealers, it more importantly facilitated response by a target group who would not ordinarily participate in traditional survey methods.

Wherrett (1997), Carver et al (1997) and Bishop (1996) performed graphic-dependent research using the World Wide Web. Wherrett demonstrated how extensive use of a graphic interface can be performed successfully on the web. In her research, she was able to quantify relative public preference for natural landscapes, thus enabling assessment of alterations to the landscape caused by man-made and natural events. Wherrett's research used the graphical interface of the web in conjunction with more traditional paper-based data 
collection methods, finding no difference in results from either of these two media.

Carver (1991) developed a simple PC-based decision support system to facilitate public interaction in the location of sites for disposal of Britain's nuclear waste. The World Wide Web enabled Carver et al (1997) to access a wider audience than a standalone system. Their Internet decision support system was supported by easy-to-use links, buttons, check boxes, and maps to progress through a five-step process comprised of:

1. Initial site selection.

2. Evaluation of data sets.

3. Data set selection and weighting.

4. Site search modeling and evaluation.

5. Final site selection.

The strength of this web site was found in its interactive capacity, which enabled participants to use geographical, social and political information to make spatial decisions. The decision support process offered by Carver's web-site allowed researchers to better understand the paths participants use in assessing their knowledge of a particular problem; problem assessment; and methodology in making difficult spatial decisions (Carver 1997).

Bishop (1996) performed research testing perception of color variation in towers and chimneys introduced into a landscape. Because of problems inherent in finding participants in perceptual research, Bishop recognized the potential of the Internet in recruiting and exposing test groups to perceptual stimuli under experimental conditions. In his experimental environment, subjects used their 
computer screens as the medium for assessing color variations of objects imaged into a landscape. Within the confines of their own environment, subjects progressed at a pace conducive to their individual schedule. Bishop's web page provided a brief introduction of the research objectives; an overview of the twelve images being assessed; a detailed explanation of the nine-point rating scale; individual rating of the twelve images; and submittal information. Bishop concluded that the Internet serves as a convenient medium for small experiments not requiring specific participant profiles.

Bishop's conclusions recognized inherent biases attributable to Internet research. Use of the Internet as a way of sampling general population conditions is precluded for obvious reasons. First, such a research medium necessitates access to a computer and the World Wide Web. Second, it requires that respondents possess adequate technical skills to enact computer commands necessary to elicit a response. Finally, technical and operational problems prevent complete assurance that targeted population groups are indeed the actual respondents (Coomber, 1997). Despite these limitations, the research reported herein assumed positive correlation between conventional and Internet responses.

\section{Summary of Literature Findings and Re-Statement of Hypotheses} In summary, the literature provides a foundation for the proposed research by:

1. Establishing a link between the visual / spatial environment and human psychological senses.

2. Defining the diverging principles and visual / spatial differences between Traditionalism and Modernism. 
3. Reviewing determinants of visual preference.

4. Defining scene familiarity as a construct to visual preference.

5. Defining complexity and coherence as constructs to optimizing visual perception and interest.

6. Establishing precedence for digital data being used as a medium for visual understanding of complex urban problems.

7. Establishing a basis for Internet-enabled research.

Throughout this literature review, hypotheses have been developed supporting the research objectives proposed herein. To that end, propositions have been made about visual preference for either Traditional or Modern development patterns. Other propositions have been made as to the consequence of scene familiarity on visual preference and the impacts scene complexity and coherency can have on visual preference. Finally, hypothetical statements attempt to isolate how technology can be used to articulate visually the urban environment accurately, as well as a way to gather data. In summary, the following hypotheses are to be tested by this research:

H1: Visual preference by the subject group surveyed by this research will favor visual attributes of traditional development patterns.

$\mathrm{H} 2$ : Visual preference by the subject group surveyed by this research will favor visual attributes of modern development patterns.

H3: Visual preference of a scene is directly related to the amount of familiarity a subject has with the content domain of that scene.

H4: Visual preference of a scene is directly related to its complexity until an optimal level is achieved, whereupon it becomes inversely related to each additional increment of complexity.

H5: Preference for computer-generated images positively correlate with actual photographic images. 


\section{Methodology}

Widespread use of photographs in environmental simulation experiments suggests the importance of visual and spatial information in human experience of environment. The power of visual stimuli such as photographs, slides, models, and simulated images in the research context simplify the need for actual experience of an environmental setting, and comparison of responses consistently demonstrates that responses to a particular simulated landscape are similar to responses to its photographic counterpart (Shafer and Brush 1977). Hertzog et al (1976) found the power of a mental picture to be so profound that the medium itself added little when the setting was sufficiently familiar to be recognized by name. Without ever seeing a picture of the White House, one's mental image of that setting may range from extreme pride to total disgust depending on the events of the day; one's political persuasion; and our personal experience and knowledge of the scene. Naser's (1988) research on community appearance in Knoxville and Chattanooga relied on such mental images and verbal descriptions of highway view corridors, to develop composite evaluative maps depicting community image.

\section{$\underline{\text { Stimuli }}$}

As in many visual preference surveys, this research proposes to use photographs as stimuli. Herzog et al (1976) used photographs in an preference prediction study of urban scenes in Grand Rapids, Michigan. Peterson (1965) found that rating distributions of photographic stimuli are valid in assessing housing quality in both Chicago and Salt Lake City, noting, "photographs 
consistently show central tendencies and expected distributions on preference scales". His study concluded that a photo test is reliable in the order of ninety to ninety-five percent. Studies by Hershberger and Cass (1974) indicated high correlation between photographs and visual experiences of the real environment.

Frey (1981) found visual appearance an important consideration in assessing desirability of neighborhoods in Ann Arbor, Michigan, using photographs not only as stimuli for determining preference, but also as a way of determining similarity with neighborhoods of those participating in the study. Woodcock (1982) used photographic slides in determining preference ratings of natural habitats he calls biomes. Photographs were used by Kaplan and Kaplan (1982) to determine preferences for alternative drainage improvements.

The Center for Livable Communities (1999) found visual preference surveys useful in transferring knowledge about community preference for built and natural environments. Such areas of interest include streetscapes, land uses and densities, site designs, roadways, building types, and public open space. Community preference surveys allow participants to develop a collective opinion of preferences by providing a pallet for professional assessment of elements contributing positively or negatively to the visual environment. Such visual research surveys have been successful in Portland, Vancouver, Santa Fe, and Carson City by identifying options for enhancing new development and solutions for solving existing visual problems (Center for Community Living, 1999).

Zajonic (1980) and Canter (1977) found preference ratings to be a useful format for exchanging information between respondent and researcher, and a 
process by which most subjects quickly and easily respond. However, their experience with preference surveys also found that subjects experienced difficulty in explaining reasons for their like or dislike of a visual scene.

A. Nelessen and Associates (1999) extensively used visual preference surveys as a way to simulate a viewer's visual experiences of the roadway. Photographs and photographic images from the public realm established an array of scenes depicting varying development patterns, land uses, building types, and streetscapes enabling a collective opinion of preference to which measures of central tendency were later applied.

Simulated visual images have been successful also in determination of preference. Naser's (1987) research on the effects of sign complexity and coherence on perceptual quality relied on simulated images of street scenes taken from a scaled model of a business district. These images enabled alterations in size, shape, contrast, and color to establish varying degree of complexity and coherence. Wherrett (1997) used digital images of Scottish landscapes to develop a predictive model of landscape preference. Images in her study were developed from a photographic library and altered to establish a comparative area and perimeter as well as to establish the three distant zones vital to her research. Goodfellow and Aubin (1995) viewed computer visualization technology as essential to the "collaborative design process to bring community members into the design loop." Their computer visualization techniques have been useful in assessing impacts of development proposals on Bermuda's visual resources. Simplified models have been effective also in human cognition studies by 
providing a generalized medium for transferring knowledge about the visual environment (Kaplan and Kaplan 1982).

\section{$\underline{\text { Stimuli Characteristics }}$}

Early landscape preference techniques developed by Shafer and Brush (1977) used black and white photographs to isolate variables for predicting aesthetic quality. Photographic selections in these early studies identified specific landscape zones; tonal variables; and composite variations of water, land and sky to establish ten landscape dimensions. Later studies by Zube et al. (1983) used fifty color photographs to establish prediction variables associated with twentythree landscape dimension groups in combinations with test preference patterns.

The Grand Rapids preference study by Hertzog et al (1976) used 86 scenes taken in the city and surrounding areas. Since the emphasis of this study was directed at determining prediction preference for familiar urban places, criteria for scene selection included the presence of a recognizable object or structure identifiable by name or location. Selected scenes embodied a variety of functional categories such as civic and government, education, religious, entertainment, health care, retail, and office. The presence of people in scenes was specifically avoided on the basis that they are "powerfully distracting stimuli in studies of this type" (Herzog et al 1976).

Groat's (1984) study of contextual compatibility of infill architecture used twenty-five color photographs of recently completed buildings constructed in established urban environments. Scene selection clearly embraced both infill buildings and several adjacent structures necessary to establish constituent 
physical attributes in her study. Attributes were predefined by Groat through a review of design literature; design review guidelines; and literature covering site organization, massing and facade design.

A cross-cultural visual preference survey of urban arterial scenes by Naser (1984) used 24 slides of arterial roadways found in major U.S and Japanese cities. Color slides obtained with a wide-angle lens were taken at ten-second intervals to depict scenes of arterial systems as observed from the driver's vantage point in a motor vehicle. Arterial roads in both countries exemplify highly traveled, wellknown systems traversing core areas of the eight study cities. A panel of judges consisting of graduate students in architecture made scene selection for this study. This panel of judges also established seven-point, bipolar, adjective scales for survey purposes.

Research by Kaplan (1983), Kaplan (1977), and Kaplan and Talbot (1983) showed natural scenes to be preferred by humans to urban scenes. Based on those findings, Hertzog (1984) used photographic research to isolate specific attributes of nature that may be introduced into urban environments to make them preferred. One hundred colored slides of field and forest environments of Lower Michigan were used and arranged on a continuum from largely open to mostly vegetated. Scenes with any human activity were avoided.

Orland's (1988) study of rural landscape preferences used photos taken at quarter mile intervals along a ten-mile stretch of rural Arizona roadway. A total of 110 natural and fifty human-influenced scenes were included in this study. Human influences ranged from fence posts to commercial buildings. Kaplan and 
Herbert (1987) used 55 slides to perform a cross-cultural preference survey of diverse landforms located in Oakland County Michigan. Here again, the slides did not show people and avoided specific details of houses.

Peterson (1965) selected scenes attempting to determine which subjective values are useful in assessing the appearance of residential neighborhoods. As such, scenes were not randomly selected; rather scenes representative of features and differences considered meaningful to the valuation process were used. In his study, twenty-three photographs were used of various street scenes, seventeen of which are exclusively taken during the winter while the remaining six are a mix of winter and summer scenes. These mixed photos revealed summer scenes to be comparatively more desirable; more private; safer; more expensive in appearance; closer to nature; and generally, more beautiful. Peterson further concluded that preferences for seasonal influences were more representatives of the effects of vegetation and greenery as opposed to the impact of seasonal change. For this reason, he suggested the amount of greenery is a consideration in comparative scene selection.

Frey's (1981) research on urban neighborhood preference in Ann Arbor involved a process of identifying neighborhoods suitable for study. Aerial photographs and local maps were used to define residential densities and land uses, while planning and real estate data assisted in determining population characteristics. Windshield surveys identifed and recorded other characteristics compliant with the control variables established for the study. Frey uses forty photographs in tandem with a verbal categorization of neighborhood preferences 
included in the research. Of particular interest to the Ann Arbor study was obtaining a representative sampling of land uses; housing styles, size and age; and setbacks.

Kaplan et al (1972) considered visual preference research on variably complex scenes by Wohlwill (1968) as limited by its inclusion of only 14 slides. As such, their follow-up preference research included 59 slides categorically divided into scenes representing natural and urban environments. A third category included scenes with mixed elements of nature and urban environments. Slides used in that research were intentionally ordinary and representative of scenes found on the University of Michigan campus. Urban scenes were taken in Detroit and Ypsilanti of street intersections, factory buildings, stores, and tall buildings. Close-up shots of people and animals were explicitly avoided in scene selection. Similarly, selection of slides avoided those lacking consistent photographic quality and content.

Woodcock's (1982) selection of 72 photographic slides matched three biomes considered by him to be meaningful to human preference. Slide selection included those of East African savannas; rain forest of Uganda and West Central Africa; and deciduous forest of Appalachia and the Midwest. Each biome used as part of his research represented areas considered accessible to large human populations for multiple generations. Likewise, selected slides had to be significantly different in terms of the six hypothesized affordances he wished to contrast. Other factors considered to force preference judgment were also eliminated from the stimuli. Slides with particularly noticeable attributes such as 
people, animals, artifacts, weather effects, and prominent physical features were eliminated from consideration. The time of day for the photographs used in the research was limited between mid morning and mid afternoon.

In research similar to that proposed herein, Naser (1988) used wide-angle color photographs and slides to evaluate residential street scenes in Pittsburgh, Pennsylvania. Eight land-use categories were evaluated in the study, for which twelve separate observation points and viewing directions were photographed. Biases in photographic techniques were controlled by selecting days with similar sunlight conditions; taking photographs at eye level; excluding cars from the left side of the roadway; and orienting scenes with sunlight to the back of camera.

The Local Government Commission (1999) used 40 photographic slides in their Community Image Survey. All slides were taken from the public realm, during the same season, and during similar weather conditions. Communities conducting the survey established committees to advise the Commission on the geographic scope and image issues to be included in the survey. Image issues served to identify adjective pairings for scenes representing both good and bad examples affecting community image. Lexicons of images then were photographed for use in the survey.

Wherrett (1997) used the World Wide Web to model preference for photographs of Scottish landscapes collected by her over several years. Ten photographs were incorporated into the survey. Photographs with extreme variation in weather and seasonal conditions were eliminated from the survey. Using the psychophysical landscape preference model developed by Shafer and 
Brush (1977), specific attention was given to three distinct distance zones and three land-cover types to evaluate how proportions of each parameter contribute to scenic preference.

\section{$\underline{\text { Panel Ratings }}$}

While contrast between traditional and modern neighborhood design has received considerable attention in the late 1990's by both professional journals and community planning literature, few people outside those in specialized design-related fields could cite specific examples of each. For this reason, panel ratings were used in this study to identify examples of these two planning constructs as they exist in and around the Louisville Metropolitan Area.

Panel ratings are used throughout visual preference research for scene selection and descriptive labeling of stimuli. Woodcock (1982) used a panel of three judges to rate slides of the six affordances of particular interest to his research. During four sessions, judges used a five-point Likert scale to rate slides on their capacity to satisfy stated definitions of the visual characteristics of each affordance pertinent to his research.

Groat (1984) used two pairs of experts having familiarity with architectural research to mediate terms of the three design components in her research. In determining appropriateness of stimuli used in her research, panel judges established criteria representing (1) the broadest possible range of material of interest to her strategy; and (2) clarity, consistency and quality of the stimuli.

Naser's (1984) cross-cultural preference study of urban streets used graduate students with training in architecture to assess physical characteristics of 
study scenes in four U.S. and four Japanese cities. Student judges assessed VHS tape and slides of urban street scenes using a seven-point bipolar adjective rating system developed by Naser. Inter-observer reliability scores resulting from these panel ratings resulted in reasonable consistency among the four judges.

Naser et al (1983) used eight graduate students in city and regional planning to refine adjective ratings of an emotional response experiment of Appleton's (1975) prospect and refuge theory. Eighty-one professional planners, architects and upper-level students were used by Naser (1988) to construct labels for random dimensions defined in his perceptual research on Pittsburgh street scenes. Orland's (1988) research in aesthetic preference for rural landscapes employed a priori examination of color slides to establish scenic context using a panel of judges to devise four categories representing the scenic content of the study slides. Zehner's (1970) dissertation on neighborhood satisfaction used panel ratings to differentiate between highly planned and less planned neighborhoods. Frey (1981) herself selected study neighborhoods in her preference research by using published criteria and established control variables.

\section{$\underline{\text { Subjects }}$}

The underlying objective of most preference research is finding generally consistent patterns extending beyond that considered a matter of personal taste. An essential construct of this research assumes visual preference is neither random nor idiosyncratic, but rather, representative of common understandings in judgment. Groat's (1984) contextual compatibility research found relatively high compatibility in preference judgments among diverse respondent groups. In her 
study, two main subject groups were represented as either expert, being those in the design professions, or non-experts. Twenty-four experts and seventy-three non-experts were accepted strictly on the basis of convenience from referrals and non-targeted written requests.

Daniels and Vining (1983) found university students to be an acceptable proxy for the general public in landscape aesthetics research. Building on their findings, Orland (1988) engaged lower division psychology students from the University of Arizona as participants in an experiment assessing rural landscape preference. Rural counterparts in this experiment were selected from a civic group in Young, Arizona. A similar cross-cultural landscape preference experiment by Kaplan and Herbert (1987) had 97 University of Michigan students contrast preferences for Michigan landscape scenes against 122 students from the University of Western Australia.

Research by Herzog et al (1976) on preference prediction patterns of familiar urban scenes involved 121 introductory psychology students fulfilling course requirements at Grand Valley State College. In a similar preference study, Herzog (1984) engaged 247 introductory psychology students at Grand Valley State College to participate in rating 100 scenes of field and forest environments. Munsinger and Kessen (1964) sampled 617 college students having varying artistic backgrounds in a rating of random, variably complex sequences of visual forms. Kaplan et al (1972) have 88 introductory college students at the University of Michigan as subjects in preference research on variably complex scenes of natural and urban environments. Woodcock (1982) used 200 undergraduate 
students at the University of Michigan as subjects in his environmental preference research.

Naser's (1987) sign study randomly interviewed 21 subjects in a ten block commercial district in Columbus, Ohio to assess the effects of signscape features on coherence. Subsequently, 92 interviews were performed to evaluate signscape preference further, again randomly drawing from the same ten block commercial district. His 1988 image evaluation of Knoxville and Chattanooga included random interviews of visitors and residents about their visual perceptions of these two communities. In that study, Naser interviewed 220 residents by phone and 180 visitors in person to ascertain opinions about visual preferences within these two communities. One hundred and four individuals selected from six neighborhood groups participated in Naser's evaluation of residential streets in Pittsburgh. Using slightly different procedures, Naser et al (1983) interviewed sixty university students in assessment of Appleton's (1975) prospect and refuge theory. Assessment procedures entailed interviews conducted at specific observation points representing varying degrees of openness and protection.

Peterson (1965) interviewed 110 people from the Chicago area and thirty from Salt Lake City in his assessment of visual preference for neighborhood environments. Peterson's original intent was to select a random sample of the population in both communities. Unwillingness of randomly selected respondents to participate necessitated instead that interviews be collected from a diverse group of respondents willing to participate in such a study. 
Wherrett (1997) assessed graphical environments using the World Wide

Web. Over 700 logins to an online questionnaire were recorded from diverse sources and contrasted to paper-based surveys completed by the staff at the McCauley Land Use Research Institute in Aberdeen, Scotland. Analysis showed no significant differences between the paper- and web-based responses.

\section{$\underline{\text { Procedures }}$}

The research herein described attempts to address growing concerns about environmental aesthetics by potential inclusion of such aesthetics into a decision-making system. While normative-rational models are inherent to planning and land management fields, aesthetics has not been a concern of environmental models or methodological studies affecting local land use policy (Sancar 1985). Psychophysical research by Zube et al. (1982) and Shafer et al. (1969) recognized the value of identifying and manipulating environmental features so that subjective estimates of aesthetics could be defined. Through such an approach of evaluating public preferences using survey methods, results may be analyzed to ascertain a consensus of aesthetic acceptability potentially useful in development of visual policy based not only on objective fact, but also on human behavior.

Hertzog et al. (1976) in rating 86 urban scenes in Grand Rapids for familiarity, preference and complexity successfully used such survey methods. In this survey, subjects used a five-point scale to rate the subjects' opinions of each variable. Two random orders were used by Hertzog et al. to analyze and remove the effects of ordering. In similar research by Kaplan et al. (1972), three random 
orders accounted for ordering effects. Slides presented in that experiment were of urban and natural scenes and were rated on the basis of complexity, preference, excitement, and intrigue. A five-point scale again was used in which a rating of one represented "not at all" and five rated as "a great deal" Kaplan et al (1972). Research by both Hertzog et al. (1976) and Kaplan et al. (1972) research included procedures where instructions were read and practice slides were presented to the subjects. Practice slides remained on the screen for an indefinite period of time allowing subjects to freely ask questions about the requested task.

Wherrett (1997) had a seven-point scale for rating scenic preference of ten Scottish landscape scenes in her preference research using the World Wide Web. In Wherrett's research, respondents read an introduction and instructions. In a manner similar to the procedures used in Herzog et al. (1976) and Kaplan et al. (1972) research, subjects were then allowed to practice rating a scene. Wherrett (1997) also presented ten images included in her study enabling respondents to browse the range of images prior to initiating the actual scoring in order to reduce the effects of ordering.

Naser's (1984) cross-cultural evaluation of urban streets in the United States and Japan used a seven-point bipolar scale to assess adjective characteristics: closed-open, simple-diverse, chaotic-orderly, dilapidated-well kept, vehicles prominent-vehicles not in sight, and nature (greenery) not in sightnature prominent. A panel having training in the design fields performed initial adjective ratings. A second adjective rating, again using a seven-point bipolar scale, was performed by a larger, more diverse group of subjects measuring 
aesthetic responses found in pleasantness-unpleasantness and interestinguninteresting (Wohlwill, 1976).

The Center for Livable Communities (1999) survey of community image used a scale of -10 to +10 ( 0 being neutral) in adjective rating of scenes on the basis of how much each scene was liked or disliked. Using these initial survey results, the Center personnel isolated scenes having the highest and lowest averages. Scenes having the greatest consensus among respondents were presented a second time in which respondents were given the average scores and asked why ratings depicted a consensus of likes or dislikes.

Peterson's (1965) seven-point rating of 23 photographs was based on that developed by Morris (1956). The scale consisted of seven descriptive categories ranging from "I like it very much" to "I dislike it very much". Subjects in Peterson's experiment rated photographs based on nine attributes determined to be contributors to residential neighborhood amenity (Chapin and Weiss 1962).

Woodcock's (1982) biome preference research involved a five-point Likert scale enlisting responses by the 200 participants in his study. Preference responses ranged from 1 "not a bit" to 5 "a great deal". The same scale measured respondents' level of difficulty in determining preference. As with similar research, ordering effects were reduced by different slide arrangements being presented to various subject groups. These effects were also minimized by an initial presentation of all slides in the set prior to their being rated by respondents. In summary, Woodcock's 46-minute procedure involved nine steps: consent and material distribution; instructions; first rating session; respondent questionnaire; 
second rating session; environmental preference questionnaire; third rating session; environmental experience questionnaire; and respondent feedback.

Frey (1981) also used a five-point scale to rate photographs included in her urban neighborhood preference research. A rating of "1" represented a low assessment of preference or similarity to the respondents' neighborhood, while " 5 " suggested a strongly positive assessment of preference or similarity to the respondents' neighborhood. In contrast to other visual preference research, photographic stimuli in Frey's research were distributed as part of a questionnaire to 891 households in thirty-eight separate neighborhoods. Selection criteria for questionnaire distribution were established by residential types; i.e., if a third of the housing types in a neighborhood were represented by multi-family units, a third of the questionnaires were distributed to households representing that unit type. Individual questionnaires were distributed by the research team, delivering between seventeen and twenty-four to each of the targeted Ann Arbor neighborhoods. Photographic material was accompanied by a brief introductory letter and instructions on how the rating was to be used in the assessment. Selfaddressed stamped envelopes were enclosed with the questionnaires to encourage participation.

Groat's (1984) contextual compatibility study had both expert and nonexpert respondent groups rank order twenty-five photographs strictly on the basis of preference for contextual relationships. In psychophysical fashion, respondents were asked to express rankings on their "idiosyncratic 'taste"”. Similarly, Naser's (1987) sign study entailed rank order of nine images establishing relative degrees 
of coherence and complexity. In that study, simple reshuffling of photographs prior to each interview averted ordering effects. Similar rank ordering procedures were used by Naser to ascertain respondents' perceptions of pleasantness, excitement and calmness.

Naser's (1983) perception study of residential streets grouped sixty photographs in accordance with physical features of housing depicted in those scenes. Respondents in the study were asked to categorize photographs having similar characteristics. No limit was placed on the number of possible categories to which the photographs could be sorted. Multi-dimensional scaling was used by experts participating in the study to establish labels for main dimensions determined through the initial sorting. Each dimension was then analyzed by a broader group of non-expert respondents evaluating the scenes on a seven-point, bipolar, adjective rating assessing: unpleasant-pleasant, interesting-boring, and desirable-undesirable.

Fenton (1985) also used color slides in his aesthetic response study of natural settings. Subjects in this study were presented twelve slides grouped in sixty-six pairs. Using a seven-point bipolar rating, each pair was judged in terms of similarity. Respondents were then asked to evaluate preference for the twelve photographic stimuli using the same seven-point bipolar rating scale.

Two hundred and forty seven subjects evaluated 100 slides in Hertzog's (1984) preference study of field and forest environments. Subjects used a fivepoint rating system to evaluate individual slides on the basis of six environmental preference predictors. 
Naser et al. (1983) performed an emotional quality study of scenes and observation points using actual field locations in lieu of photographic and simulated images. In this experiment, subjects were directed to four observation points on the University of Ohio campus. Using Kasmar's (1970) lexicon of environmental descriptors, subjects rated each scene as: interesting-boring, uglybeautiful, safe-unsafe, attractive-unattractive, dislike-like, repelling-inviting, relaxed-tense, excited-calm, and insecure-secure. A seven-point scale was used by respondents in rating emotional responses to both view and observation point.

Orland (1988) used the same behavioral approach to quantify respondent evaluations of rural Arizona landscapes. Two groups, one representing university students residing in urban Tuscon, and another of rural residents, viewed 110 natural and fifty human-influenced scenes of the Arizona countryside. The two sets of scenes were projected one at a time and rated using the Scenic Beauty Estimation method developed by Daniel and Boster (1976). This method is a tenpoint rating scale with 1 being low scenic beauty and 10 representing high scenic beauty. Randomness of slides was employed by Orland to reduce effects of ordering.

The fifty-five slides in Kaplan's and Herbert's 1987 experiment of crosscultural preference for rural landscapes used a five-point preference scale. Three practice slides served to orient participants to the rating system. The rating form in this experiment was numbered to sixty despite having only fifty-five slides in order to avoid ordering and end effects. Slides in this experiment were presented individually for ten seconds each. 


\section{$\underline{\text { Analysis }}$}

Preference ratings are becoming increasingly popular ways to blend psychological components into an objective study of the physical environment. The psychophysical approach relies on survey methods to assess preferences of the general public. Survey results are analyzed to derive a consensus of aesthetic acceptability defensible in a public venue. In question here is the reasonableness of aggregating individual states of mind into a preference response representative of the public at large. Clearly, such an approach requires statistical verification of models, theories, dimensions, and domains posed by the researcher in an attempt to depict regularities in public preference for visual characteristics. Yet, it is carried out in the realization that deriving a collection of individual states of mind into an aggregation completely and fairly representing the public remains a logical impossibility.

\section{Dimensional Determination}

Most attempts at aggregation in visual preference research entail a twostep approach. The first step involves dimensioning of scenes into domains, while a second phase analyzes specific prediction patterns (Nasar 1987; Kaplan and Herbert 1987; Fenton 1985; Woodcock 1985; Hertzog 1984; Frey 1981; Herzog et al. 1976; Kaplan et al. 1972; Shafer, Hamilton and Schmidt 1969). In their prediction preference study of familiar urban places, Herzog et al (1976) classified randomly presented urban scenes using non-metric factor analysis. From this dimensional analysis, five content domains were identified for further statistical verification of preference. Kaplan et al (1972) used Guttman-Lingoes 
Smallest Space Analysis (Lingoes 1973) to ascertain relative degree of urbanism in their preference study of urban and natural scenes. They then applied correlation analysis to rate preference statistically with degrees of urbanism and complexity.

Psychophysical research continues to rely on objective specifications and techniques to define perceptual dimensions (Fenton 1985). Frey (1981) used Guttman-Lingoes Small Space Analysis to compute a correlation matrix for rank ordering of seven visual preference dimensions for urban environments. With these independent variables established, she then applied statistical analysis to evaluate relationships between independent and dependent variables.

Woodcock's (1982) biome study also used small space analysis and cluster analysis to establish correlation dimensions of preference. As opposed to a priori determination of urban and natural scenes, Kaplan et al. (1972) used GuttmanLingoes Smallest Space Analysis III to define relative degrees of natural and manmade environments. Kaplan et al (1972) identified content categories from mean preference ratings by extracting preference patterns from non-metric factor analysis. Hertzog (1984) used the same procedure to categorize field and forest environments into three content categories. Oostendorp and Berlyne (1988) used multidimensional scaling techniques developed by Carroll and Chang (1970) to determine common architectural dimensions for conducting pair-wise similarity ratings of buildings.

Other studies have treated physical settings themselves as main determinants to preference. In these studies, the tendency was to view the 
environment in more subjective personal terms. Naser (1990) used evaluative maps to assess visual preferences in Knoxville and Chattanooga. The evaluative map showed physical locations; preference assessments; and reasons for a particular evaluation. By using evaluative maps, Naser found a consensus of perceived quality and visual dislikes to the extent that dimensions of each were determinable. Naser pre-selected complexity and coherence as independent variables in a 1987 study of perceived visual quality for commercial signs. Naser's (1984) cross cultural preference study of urban street scenes measured preference for environmental properties established by empirical evidence supporting their contribution to environmental preference. Four pre-selected conditions were considered by Naser et al (1983) in evaluation of emotional quality found in various scenes and observation points on the Ohio State University campus. Later research by Naser (1988) reverted to more objective measures by using multidimensional scaling and similarity ratings to determine perceptual dimensions in the evaluation of residential streets.

Other determinants in preference studies have relied on more normative judgment and empirical findings in lieu of strict objective quantification. Peterson (1965) pre-selected nine physical qualities for measurement of housing quality. From these selected dimensions, he statistically analyzed mean judgment, social value measurements and subjective values. Wherrett (1997) used pre-determined landscape domains established by Shafer et al (1969) and Brush (1981). In the Wherrett study, the degree of each domain within a photographic scene was measured with a grid to derive objective assessment of the landscape distant zones 
and cover types. In a more subjective manner, the Center for Livable

Communities Community Image Survey (1999) presented adjective pairings of what it considered "good" and "bad" examples of visual community image. Orland (1988) used a priori categorization by a panel of judges to establish four content domains from slides of rural Arizona landscapes.

\section{$\underline{\text { Statistical Verification }}$}

Environmental preference research attempts to determine if preference follows a consistent and predictable pattern or merely represents personal taste shaped by the events of one's life. Kaplan and Kaplan (1972) argued that preference is statistically verifiable thus challenging conventional wisdom that beauty remains in the eyes of the beholder (Purcell 1986). Naser (1988) also argued that humans can evaluate scientifically something as personal as one's qualitative judgment of community appearance. Within this realm of social science, there are methods to observe human response to stimuli in an attempt to bear out patterns of preference. The application of these methods examines hypotheses necessary for advancing theory about unexplained phenomena to a more reliable level of knowledge.

As with most research, the hypotheses represented herein lean toward a conservative path, not necessarily seeking proof beyond a shadow of doubt, but allowing simple statistics to rule out the null hypotheses. Aforementioned sections of this work have stated basic constructs and theoretical interests of the research. As well, they have involved literature to provide operational definitions for fuzzy concepts about traditionalism, modernism, complexity, coherence, and preference. 
Operational definitions, in turn, enable the validation of relationships between constructs and measurable indicators as well as relationships between the constructs themselves. For instance, does greater complexity within a scene incite greater visual preference, or does this relationship provide an indication of other constructs not previously considered?

The visual features of this study represent the independent variables, while emotional responses of the participants are dependent variables. This dependency is predicated on the assumption that when adequate numbers of ordinary people consistently indicate their preference for something, it may serve to achieve wellfounded and reliable base of knowledge. In this and other environmental preference research, a stimulus-response format is used whereby an internal cognitive and perceptual process enables statistical determination of probabilistic relationships between subjects and the environment.

Herzog et al. (1976) used such a stimulus-response format in a preference prediction study of buildings in Grand Rapids, Michigan. In that study, mean ratings were established for five content domains. Analyses of variance found preferences for five content domains to be considerably different $F=23.24, \mathrm{df}=4$, $92, p<0.001$, where $F$ is the $F$ test value measuring the analysis of variance between two independent samples, $\mathrm{df}$ is the degree of freedom and $\mathrm{p}$ is the critical region for the test. Similarly, analyses of variance among these content domains finds considerable difference in measures of familiarity $(F=26.50)$ and complexity $(F=9.21)$. 
Naser et al. (1983) used analysis of variance for assessing variation in respondent assessment scales used to evaluate the emotional quality of scenes and observation points on the Ohio State University campus. For the safety scale, he found male students indicated a significantly higher level of safety $(\mathrm{s}=2.18)$ than did female students $(\mathrm{s}=2.90)(\mathrm{F}=7.94, \mathrm{df}=1, \mathrm{p}<.01)$. Open views in this study were determined to be safer $(\mathrm{s}=2.2)$ than closed views $(\mathrm{s}=3.0)(\mathrm{F}=8.18, \mathrm{df}=1$, $\mathrm{p}<0.01)$. Interactive effects of observation points contrasted with views indicated feelings of safety are more closely associated with a protected than unprotected view $(\mathrm{F}=3.93, \mathrm{df}=1, \mathrm{p}<.06)$. Interactive analysis also revealed opposing preferences by female and male students toward protected views over unprotected views $(F=3.67, \mathrm{df}=1, \mathrm{p}=.06)$.

T-test analyses of variance were used by Kaplan et al (1972) in preference and complexity ratings of natural and urban visual material. In this stimuliresponse study, four dimensions identified by multi-dimensional analyses revealed consistent preference for natural over urban scenes $(t=8.45, \mathrm{df}=34, \mathrm{p}<$. 001). The study also revealed consistent patterns of urban scenes being considered more complex than nature scenes $(\mathrm{t}=3.38, \mathrm{df}=34, \mathrm{p}<.01)$.

Naser (1987) performed two statistical studies in his evaluation of urban street signs. The first assessed effects of signscape features on coherence. A rank ordering of nine signscapes was made on the basis of their coherence. In this first study, two independent variables, represented by contrast and complexity were evaluated by their influence on the dependent measure of coherence. Friedman's two-way analysis of variance was used by Naser to rank scores of coherence for 
varying signscape conditions. Summary statistics for the analyses indicated coherence to be highest for the least complex signs $\left(\mathrm{x}^{2}=5.94,2 \mathrm{df}, \mathrm{p}<0.05\right)$ and highest for the most contrasting signs $\left(x^{2}=5.86,2 d f, p<0.05\right)$.

The second signscape study performed by Naser (1987) evaluated rank order emotional responses to sign pleasantness, excitement and calmness. Using Spearman's rank order correlation, this second study compared responses of various groups including residents versus visitors, male versus female and young versus old. The effects of complexity and coherence were tested using Friedman's two-way analysis of variance to compare median rank order scores by compensating for adjective scales of unpleasant-pleasant, boring-exciting and distressing-calming. Naser finds pleasantness was rated highest for the most coherent sign alternatives; excitement was rated lowest for the most coherent signs; and calmness was rated highest for the most coherent signs. Interactive effects of complexity and coherence suggested an inverted U-shaped relationship, where moderate complexity and high coherency is rated most pleasant $\left(x^{2}=108.6\right.$, $8 \mathrm{df}, \mathrm{p}<0.01)$ and calming $\left(\mathrm{x}^{2}=138.44,8 \mathrm{df}, \mathrm{p}<0.01\right)$, and where excitement is highest for the most complex and least coherent alternatives $\left(x^{2}=345.24,8 \mathrm{df}\right.$, $\mathrm{p}<0.01)$. The inverted $\mathrm{U}$-shape relationship suggests the graphing of visual preference would increase incrementally with each marginal increase of complexity or coherence, but that beyond a certain point, each incremental increase of either complexity or coherency results in declining preference.

Frey (1981) used Guttman-Lingoes Small Space Analysis to determine dimensions resulting from her verbal and photographic preference surveys. The 
dimensions yielded by the multi-dimensional analysis were subjected to an analysis of variance and Student-t tests, to evaluate relationships between independent and dependent variables by separate respondent groups. Naser's (1984) cross-cultural study of urban streets in the United States and Japan assessed average scores for bipolar measures of interesting-uninteresting and pleasant-unpleasant. The reliability of these two measures as a composite scale of aesthetic response were examined further by their correlation, for both U.S. subjects $(\mathrm{r}=.71,23 \mathrm{df}, \mathrm{p}<.001)$ and Japanese subjects $(\mathrm{r}=.85,24 \mathrm{df}, \mathrm{p}<.001)$. Correlation was also used to determine positive preference patterns of U.S. and Japanese subjects to photographic stimuli used in the study $(\mathrm{r}=.54,23 \mathrm{df}, \mathrm{p}<.01)$. Naser used analysis of variance to determine if subjects from each country exhibited higher preference for foreign scenes than preference for native scenes $(\mathrm{F}=3.95,1,44 \mathrm{df}, \mathrm{p}=.05)$.

Correlation was used by Naser (1988) to assess bi-polar appraisals of residential street scenes, again using scales of unpleasant-pleasant, interestingboring and desirable-undesirable. In this study, positive patterns emerged with increases of ornamentation $(\mathrm{r}=0.59)$, upkeep $(\mathrm{r}=0.56)$ and prominence of vegetation $(r=0.52) . R^{2}$ stepwise regression then was used to find relationships between mean scores of predictor variables and mean scores of criterion variables. Here again, Pearson's product-moment correlation was used to find similarity between predicted scores and those actually obtained for two predictor models developed by regression procedures $(r=0.72, p<0.001$ and $r=.68, p<0.001)$. A Chow analysis of variance test found no significance difference between the two 
regression equations $(\mathrm{F}=1.8, \mathrm{df} 4,52, \mathrm{p}<0.05)$. The final regression equation of Naser's (1988) research yield:

Favorable evaluation $=2.8+0.66$ Ornamentation +0.35 Upkeep 0.38 Ambiguity -0.22 Closed

Preference assessment of modern apartment complexes by Kaplan (1983) used a five-point scale to assess views from apartment buildings. Mean preference scores were evaluated to determine stronger preferences for wooded views than views of large mowed areas. Similar assessment of mean scores enabled determination of view preference for natural spaces when contrasted with views having intervention by man made objects. Herzog (1984) also assessed three dimensions of field and forest environments using mean preference ratings. Mean preference ratings and analysis of variance were used to determine sizable differences in preference between these dimensions $(\mathrm{F}=23.75, \mathrm{df}=2,226$, $\mathrm{p}=<.001$ ). Mean preference ratings and analysis of variance were used also to determine if longer $(15 \mathrm{sec})$ duration views of natural scenery were preferred over shorter duration ( $20 \mathrm{msec}$ and $200 \mathrm{msec})$ viewing times $(\mathrm{t}=2.37, \mathrm{df}=113, \mathrm{p}<.025)$. Correlation between the mean predictor variables and mean preference ratings was used further by Herzog (1984) to determine positive preference for identifiably ( $(\mathrm{r}=.55)$, coherence $(\mathrm{r}=.47)$ and spaciousness $(\mathrm{r}=.45)$.

Orland (1988) used ANOVA to establish interclass correlation coefficients of preference by two respondent groups for familiar rural Arizona scenes characterized as predominately natural $(r=.92)$ or human-influenced $(r=.95)$. In a second experiment, preference for content domains of unfamiliar landscapes were 
analyzed further using interclass correlation to determine strong agreement between the two respondent groups and two pre-selected content domains $(r=.90)$. Two-way analysis of variance between two content domains and respondent groups revealed no effects between respondent origins and stimulus sets; however, significant differences $(\mathrm{p}=.033)$ were observed between the subjects' rural and urban backgrounds. Analyses of means were used to further to classify preferences of more specific content domains considered predominately natural or human influenced. Further analyses used one-way ANOVA to isolate significant preference variation between predominately natural content categories $(\mathrm{p}<.05)$, while differences between respondent groups were negligible. Of the human influenced content domains, one way ANOVA revealed differences in preferences among urban and rural respondents for content domains characterized by grasslands $(\mathrm{p}<.05)$.

Familiarity and preference research by Kaplan and Herbert (1988) assessed preferences for rural Michigan scenes by students attending the University of Michigan and the University of Western Australia. Findings of the study suggest similar preference assessments by these two separate samples with a positive correlation (.84) and mean preferences for all 55 slides being 3.29 $(\mathrm{SD}=.48)$ for the American subjects and $3.08(\mathrm{SD}=.52)$ for the Australian subjects $(\mathrm{t}=3.06, \mathrm{p}<.01)$. Further cross-cultural preference research looked at relationships between the ratings using non-metric factor analysis to establish four dimensions. These dimensions were further assessed by preference means for the American and Australian subjects using separate data sets developed by each. Rank order 
preferences for each subject group and each data group yielded strongest preference for manicured landscapes.

Wherrett's (1997) scenic preference model using the World Wide Web assessed preferences for scenes having varying degrees of dimensions and distance zones established in earlier landscape preference research by Shafer et al (1969) and Brush (1981). Wherrett evaluated results from an Aberdeen University (Scotland) pilot questionnaire using analysis of variance and found effects of image order to be insignificant $(\mathrm{F}=0.28, \mathrm{df}=6, \mathrm{p}=0.941)$, while the image content was a highly significant source of variation $(\mathrm{F}=7.53, \mathrm{df}=19$, $\mathrm{p}=0.000$ ). An analysis of means was used by Wherrett to assess 81 international responses received from the main questionnaire posted on the World Wide Web. An analysis of variance performed by Wherrett found insignificant variation in gender, age and nationality on mean scores provided by Internet respondents.

Woodcock (1982) assessed preferences for biome categories using analyses of means. Correlation then was used in his research to assess associations among six affordance theories and three main biomes isolated as savannas, rain forest and hardwood forest. These two statistical steps enabled Woodcock to use stepwise regression to identify which affordances served as the best preference predictors. In a similar stimuli response study, Peterson (1965) assessed mean preferences as a way of comparing statistical differences in scene attributes, and found statistical significance in attributes related in photo content and effects of season. A correlation matrix is then used by Peterson to investigate 
commonality among the photographs in order to reduce sources of variability to a smaller number of independent factors.

\section{Summary of Research Objectives and Contributions}

In summary, this research can improve the skills of community design professions in determining consensus about visual preference. It accomplishes this by isolating the issue of visual preference for either traditional or modern development patterns. The research also determines how contextual dimensions found in complexity and coherence influence visual preference, and how familiarity with a scene influences visual preference. Finally, it is hoped that this research assesses the effectiveness of digital imaging techniques in correlating with photographic images. The objectives of this research are intended to address the following problems:

1. To determine if there is a method for community design professions to derive consensus about visual preference.

2. To determine if visual preference favors conventional suburban development patterns or traditional neighborhood development patterns.

3. To determine if scene complexity or coherency affects visual preference.

4. To determine if familiarity of scene content affects visual preference.

5. To determine if visual preference for a simulated scene correlates with its photographic counterpart.

These objectives contribute to the field of psychophysical research by:

1. Supporting Naser's (1998) recommendation for further research on how plans achieve a sense of "coherency and compatibility". 
2. Continuing Groat's 1984 research on how redundant surface elements affect compatibility between structures.

3. Isolating specific components of scene complexity (Naser 1998).

4. Determining "popular preferences" on how "city designers can guide the image of the city toward becoming more likable, meaningful, and livable" (Naser 1998).

5. Defining specific predictors of neighborhood satisfaction (Zender 1970).

6. Affirming Peterson's (1965) objectives to "describe and measure qualities of residential neighborhood appearance toward which preference potential tends to direct human behavior".

7. Supporting the recommendations of Rapoport and Hawkes (1970) for "experimental validation" to determine if complexity is a desirable quality of the urban environment.

8. Addressing Naser's 1987 recommendation for experimental validation to determine if complexity is a desirable quality of the urban environment.

9. Continuing the research of Kaplan, Kaplan and Wendt (1972) for more domain separation studies that manipulate the amount of complexity and coherence of streetscapes. 


\section{CHAPTER THREE}

\section{METHODOLOGY}

\section{$\underline{\text { Research Objectives }}$}

The research objectives proposed by this dissertation are as follows:

1. Investigate links between the visual / spatial environment and human psychological response.

2. Define the diverging principles and visual / spatial differences between Traditionalism and Modernism.

3. Attempt to understand determinants of visual preference better.

4. Define scene familiarity as a construct to visual preference.

5. Define complexity and coherence as constructs to optimizing visual perception and interest.

6. Understand the potential application of digital medium for visual understanding of complex urban problems.

7. Establish a basis for Internet-enabled research.

These research objectives have led to the development of the following hypotheses:

H1: Visual preference by the subject group surveyed by this research will favor visual attributes of traditional development patterns.

H2: Visual preference by the subject group surveyed by this research will favor visual attributes of modern development patterns.

H3: Visual preference for a scene is directly related to the amount of familiarity a subject has with the content domain of that scene. 
H4: Visual preference for a scene is directly related to its complexity until an optimal level is achieved, whereupon it becomes inversely related to each additional increment of complexity.

H5: Preference for computer-generated images positively correlates with preference for actual photographic images.

It is these hypotheses that have shaped the experiment and research methodology used in this study. Chapter Three describes in detail the experiment and research methods that have been used to prove or disprove the proposed hypotheses.

\section{$\underline{\text { Research Problem }}$}

Throughout the 1990's considerable attention was given in the literature to the subject of neighborhood planning; particularly as it relates to traditional neighborhood design. For many architects, and architectural critics, Traditional Neighborhood Design had the potential to re-shape the pattern of development in this country, and therein, improve the quality of life within our communities (Fulton 1996; Langdon 1994; Katz 1994; Calthorpe 1993; Duany and PlaterZyberk 1991).

While Traditional Neighborhood Design embodies many principles beyond the scope and emphasis of this research, it strongly emphasizes the ability to achieve a preferred visual environment (Duany and Plater-Zyberk 2000; Katz 1994; Langdon 1994; Calthorpe 1993; Kunstler 1993). The commitment of Traditionalist to improve the visual quality of our neighborhoods establishes an interesting question about the key determinants of visual preference. That question is whether the claims by Traditionalist of a preferred visual environment are in fact true, and if so, can those claims be proven? 
It was from that desire to understand the essential dimensions of visual preferences better that this researcher initiated a photographic library of residential streets throughout the Louisville and Cincinnati metropolitan areas. The development of this photographic library was strictly informal and random and possessed none of the characteristics of a true photographic survey. Yet, it affirmed that the basic elements contributing to visual quality of a neighborhood are indeed elusive and difficult to isolate.

While in many respects the informal photographs made at the outset of this study were of little value, they did aid in developing an appreciation for the multiple attributes that potentially contribute to scene preference. Leafing through these photographs in an attempt to pinpoint essential constructs that shape the character of visual preference is immensely frustrating. The frustration was made even more exasperating by the belief that as a professional responsible for the layout of numerous residential streets, such understanding should be almost second nature. It was from this inability to define such a pattern, or for that matter to even understand the essential dimensions of visual preference, that this research problem was founded.

\section{Methods}

\section{$\underline{\text { Stimuli }}$}

The photographic library assembled between 1994 and 1997 served well as a starting point for this experiment; if for no other reason than to begin a thought process about how people determine visual preference. These early photographs were of even greater value because they provided impetus to 
determine how photographic materials have been used successfully in similar research, as well as how it could be used to accomplish the objectives of this study.

A number of studies provide adequate examples of photograph images being used as a practical substitute to actual viewing a scene in person (Kaplan and Kaplan 1982; Woodcock 1982; Frey 1981; Herzog et. al 1976; Hershberger and Cass 1974; and Peterson 1965). Of greater relevance to this experiment are findings in which photographic images were used to determine visual preference of building, streets and neighborhoods (The Center for Livable Communities 1999; A. Nelessen and Associates 1999). Based on these findings, the use of photographic images to study visual variables was considered well established to the extent that it is a credible option for this experiment.

In February and March of 1999, approximately 200 slides were taken of residential streets throughout the Louisville and Cincinnati metropolitan areas. Unlike the scattered approach mentioned earlier in this chapter, the 1999 photographic images were planned and targeted toward neighborhood streets which, in the opinion of the author, were distinct by their ability to conform to traditional design characteristics or by their ability to match well with modern principles. At this point in the research, considerable review of the literature allowed clear characterization to be made between these two design movements.

The literature offered examples of two traditional neighborhoods within the Louisville and Cincinnati study area. The Park Duvalle neighborhood, currently under development in west Louisville, serves as a unique example 
because it represents a new development being constructed in the pattern of traditional principles (Steuteville 1999). The other local example is Mariemont, a suburb city of Cincinnati. Mariemont is patterned after the traditional design of France's Beaux-Arts school of Architecture and founded in the American City Beautiful Movement (Fulton 1996). Local access to both Park-Duvalle and Mariemont provided tremendous opportunity to include these traditional neighborhoods in the experiment.

Because the initial experiment proposed that subjects be presented the material in a group format by using a slide projector, the photography was made with Kodak Ektachrome slide film. Slides were made using a fairly inexpensive Fujifilm Discovery $31235 \mathrm{~mm}$ camera. Subsequent to completion of the camera work, and upon consensus of the research advisory committee, the approach was slightly altered; actual photographic prints were used in lieu of slides. A Tamarack 2400FS film scanner converted the slides into a digital format so that they could be more easily cataloged and made ready for other phases of the experiment.

The photographic images were made on select days in February and March of 1999 prior to any visible evidence of new vegetative growth and before spring flowering. Because vegetative growth in the study areas is so profuse, significant consideration was given to the time of year when the photographs could be made in order to insure reasonable visual penetration into the scenes. Timing also was important so that flowering trees did not distract overly from the scenes. For the same reason, scenes with people, dogs and other similar features 
were avoided. Scenes with automobiles, fences, sidewalks, utilities, signs, or other like attributes that could be considered inherent to either of the development patterns were not avoided or cropped from the scene.

Careful consideration was given to the time of day and weather conditions. All the photographic images were made between ten in the morning and three in the afternoon. Here again, the selection of this time frame was made to avoid overly long or deep shadows that would either serve as a distraction or otherwise reduce visual penetration into the scene. All photographs were made on sunny days, and every attempt was made to avoid unusual cloud or sky conditions. If at all possible, photographs were taken in such a manner as to have shadows cast away from the vantage point. Photographs were made with the vantage point primarily in the center of right of way and with the camera settings, angle and height the same for each image.

The importance of defining these parameters had little to do with artistic composition of the photographs, but rather, achieving as much consistency as possible. If vehicles were parked along the roadway, they were included in the image. If mailboxes or street signs were present in actual scene, they were also captured in the photograph. Composition of the scenes was avoided; instead emphasis was placed on depicting the scene in a clear, accurate and honest manner.

\section{Categorization of Stimuli}

After obtaining over 200 images of neighborhood streets, the next step entailed sorting the images in order to assemble the 60 most suitable for use in the 
panel ratings. Images that were excessively light or dark were removed from consideration. Images that had a particular distraction, such as an unusual sky or cloud condition, also were removed. Relative consistency among the photographs became an overriding determinant for consideration in subsequent phases of the research.

It was during this selection process that images were being evaluated also on the basis of relative values of the homes which they depicted. Early in the preparation of this proposal, it was determined that the research would be served best by considering a broad array of property values. The camera work performed in February and March of 1999 planned for this consideration, and included a variety of neighborhoods representing both traditional and modern development patterns, but also representing a broad range of values.

The photographs made in early 1999 include neighborhoods located in two metropolitan areas, three states and five counties. Photographs taken in the Louisville metropolitan area included neighborhoods in Clark County, Indiana and Jefferson County, Kentucky. Photographs from the Cincinnati metropolitan area included neighborhoods in Hamilton County, Ohio and Campbell and Kenton counties in Kentucky. Official property valuation records available through these five county jurisdictions were used to determine property values. For Jefferson and Kenton counties in Kentucky, property valuation records were available online by access to their respective property valuation administration websites. The Hamilton County Auditor also had property valuation records available online. Property values for neighborhoods in Clark County, Indiana and 
Campbell County, Kentucky were obtained by actual review of the records available in property valuation offices within those jurisdictions.

As consistent an approach as possible was made to establish average values of the homes depicted by the photographs. Values were determined for only single family residential units. Structures that were being used for multiple units or mixed uses were not included in the averaging. Values were obtained as far as practical for all the eligible properties visible in the image. If there were other similar nearby properties not visible in the photograph, they were included if considered useful in establishing an average value for the neighborhood.

The 60 neighborhood images presented in the panel ratings included a broad range of values (Appendix A). Year 2000 home values within neighborhoods considered traditional ranged between $\$ 41,000$ and $\$ 312,000$. Year 2000 home values depicted by images of neighborhoods considered modern ranged from $\$ 34,000$ to $\$ 433,000$. By formatting the neighborhoods represented in the photographs from lowest to highest values, images were placed into three price groups of twenty photographs each. The lowest property values represented ten traditional neighborhoods and ten neighborhoods considered modern. The value of homes in this price group ranged from $\$ 41,000$ to $\$ 81,000$ for the traditional examples and from $\$ 34,000$ to $\$ 79,000$ for modern examples. The middle price group included nine neighborhoods considered traditional and eleven that were considered modern. Average home values of the traditional examples were from $\$ 89,000$ to $\$ 161,000$. Modern examples in this group ranged from $\$ 89,000$ to $\$ 162,000$. The highest value group included twelve neighborhoods 
considered traditional and eight that had characteristic of modern development patterns. Home prices of traditional examples in this group ranged from $\$ 172,000$ to $\$ 312,000$. Modern examples in this group ranged in price from $\$ 198,000$ to $\$ 433,000$.

\section{Panel Ratings}

The description of methods used in this research thus far has been done with care to identify the photographic images as representing neighborhoods considered either traditional or modern. The characterization of a neighborhood as either traditional or modern, up to this point, has been a determination made by the researcher using the literature as a basis for distinctions between the two development patterns. Therefore, a crucial part of this experiment is the use of panel ratings as a way of: (1) validating the opinion of the researcher, and (2), selecting the best photographic examples of each.

Panel ratings have been used extensively in other visual research (Orland 1988; Naser 1988; Naser 1984; Groat 1984; Naser et al 1983; Woodcock 1982; and Zehner 1970). In these studies, panels were comprised of people considered knowledgeable about a subject, and who could offer judgments affirming or differing from that of the researcher. The literature provides examples of panels comprised of experts in the subject on which they are passing judgment (Groat 1984). In Groat's 1984 example, the panel was comprised of "two pairs of judges, all of whom had some familiarity of architectural research," and who were given the assignment of evaluating photographic stimuli to determine their suitability for further evaluation by two major respondent groups. Naser (1984) 
used graduate students in city and regional planning to assess scenes used in his cross cultural preference study of urban street scenes. Naser (1988) also used 81 professional planners, architects and upper level students in these fields to specify design dimensions of photographic slides used in a preference study of residential street scenes.

The panel in this study was comprised of five people considered to be knowledgeable of traditional and modern development patterns. Three of the raters were urban planners certified by the American Institute of Certified Planners, who have considerable experience with the design, review and/or preparation of regulations related to both modern and traditional developments. All three were involved in the preparation of the Louisville and Jefferson County Traditional Neighborhood Design Strategy. The panel also included a licensed architect, who had considerable experience in both traditional and modern neighborhood design through his experience as a member of the Louisville and Jefferson County Planning Commission and employment with the Louisville Development Authority. The other member of the panel was a principal with Triad Development Company. Triad is the primary entity responsible for the development of Norton Commons, a traditional plan designed by the firm of Andres Duany and Elizabeth Plater-Zyberk and being developed in eastern Jefferson County, Kentucky. While Norton Commons is Triad's most notable development, the firm also has considerable experience in the development of several other modern style subdivisions throughout the Louisville metropolitan area. 


\section{Measurement of Traditional and Modern Dimensions}

In the fall of 2000, the five panelists were mailed information needed by them to rate photographic images of residential streets throughout the Louisville and Cincinnati metropolitan areas. Each of the panelists had been contacted previously by the researcher to inquire about their willingness to participate in the ratings, but that initial contact did not include any instructions or details concerning the research. The information mailed to the panelists included a cover letter explaining the purpose the research and instructions on how to complete the ratings (Appendix B). Three 13-inches by 19-inches photo glossy prints were also included in the mailing (Appendix C). Superimposed on each 13-inch by 19-inch print were 20 photographs of residential street scenes depicting development patterns considered to be either traditional or conventional suburban. The prints were separated into the three price groups previously described, and the numbering and ordering of each photograph was randomly established by literally pulling a number out of a hat. The photographs on the print were 2.2-inches by 3.4-inches size. Standard vertical and horizontal spacing between the photographs was established and an identification number placed at the lower right corner of each photograph. In addition, panelists were provided a form on which they could rate the 60 photographs, as well as an addressed and postmarked envelop for returning the survey.

A five-point bipolar scale was used by the panelists to rate the sixty images on whether or not the images had characteristics of either traditional or 
conventional suburban development patterns. For simplicity, the panelist questionnaire response form (Appendix D) was comprised of three sheets having 20 lines each. This arrangement not only permitted a very legible format, but also enabled each sheet to readily correspond with the three 13 -inches by 19 -inches photo glossy prints. For legibility, the form was arranged so that ratings could be made simply by checking a box right or left of a neutral column. A check mark directly left of the neutral column indicated that the panelist rated the photograph as depicting slight characteristics of traditional development patterns and was scored as -1 . A check mark directly right of the neutral column indicated that the panelist rated the photograph as depicting slight characteristics of conventional suburban development patterns and was scored as $a+1$. The distance left or right of the neutral column indicated the relative degree in which the images depicted characteristics supportive of traditional or conventional suburban development patterns. A mark on the far left side of the neutral column indicated that the panelist rated the photograph as representing a strongly traditional neighborhood street scene and was scored as a -5 . A score on the far right side of the neutral column indicated that the panelist rated the photograph as representing a strongly conventional suburban street scene and was scored $a+5$. A check in the neutral column indicated that the photograph had no strong visual characteristics of either development pattern.

A simple analysis of means was used to isolate photographs that best represented either the traditional or conventional suburban patterns (Appendix E). Appendix E also indicates reasonable consensus among the panelists was found in 
the selection of the photographs ( $\sigma=0$ to 1.02$)$. From these ratings, nine traditional and nine conventional suburban examples were selected for use in the broader sample. The nine photographs selected for each development dimension included three from each of the three price groups. In summary, eighteen photographs were selected; nine from each development dimension. All three of the price groups were equally represented for each development dimension.

\section{Digital Imaging}

An objective of this research is to establish precedence for the use of digital data as a medium for visual understanding and communication of complex urban issues. This objective recognizes that the design professions are heavily dependent upon visual media as a way to convey ideas. Increasingly, visual communication by design professionals is being accomplished in a digital environment facilitated by faster personal computers and more sophisticated software. Digital data have been found to be particularly adaptable to understanding space better, and hence, the ability to support decisions affecting the spatial realm (Langendorf 1992; Daniel 1992). However, future and more widespread use of digital techniques as a way to communicate complex urban concepts may hinge on the capacity of those techniques to be accurate. The research thus far has been directed more to the potential application of these techniques and less to their potential to be accurate (Wherrett 1999; Smith et al 1998; Levy 1995; Faust 1994; Oh 1994; Grob 1991; Naser 1987).

This study evaluates how well digital images correlate to photographic images of the same scene. Two photographic scenes were chosen from the 
eighteen selected during panel ratings. Both photographic scenes were from the middle price group; one photograph depicts a scene identified by the panelist as a traditional neighborhood and the other is a photograph identified as a conventional suburban scene. Both photographs were of neighborhoods inside the City of Louisville.

Inside the City of Louisville, digital mapping of the neighborhoods was available from the Louisville and Jefferson County Information Consortium (LOJIC). LOJIC is the community based geographic information system (GIS) for Louisville and Jefferson County and uses ArcInfo GIS and mapping software available from ESRI. The GIS mapping provided from LOJIC is compatible with AutoCAD 2000 and can be manipulated successfully in that environment. Used within AutoCAD, LOJIC served well as a scaleable base map that provided reasonable horizontal and vertical information for preparing the digital images of the selected neighborhoods.

\section{Three Dimensional Graphics Technology}

Numerous three-dimensional (3D) modeling, rendering and animation tools are currently available to design professionals, and with reasonable certainty it can be assumed that many new and improved products will follow. Three such tools have been explored during the course of this study in terms of their ability to represent most accurately, in a digitally created format, scenes depicted by the selected photographs. The simplest and most economical product used as part of this study was EasySite. Developed by Cad Easy Corporation, EasySite is a presentation tool specifically targeted for use by site and civil design professions 
to create and render 3D site models. The value of this program as a simple and economical 3D modeling tool is limited by its inability to produce a convincing rendered image.

The inability to prepare compelling renderings using EasySite necessitated further review of other 3D rendering tools. A more advanced (and expensive) 3D modeling and rendering tool is 3D Studio VIZ. VIZ is advanced visualization software developed by Autodesk. As an Autodesk product, VIZ provides a direct link to AutoCad files allowing two-dimensional drawing files to be used in the preparation of 3D models. An advanced material editor and specialized lighting effects enable VIZ to produce credible renderings of 3D images. While only static images were used as part of this study, VIZ also can be used as an animation tool allowing virtual walk-through or flyovers of a three dimensional model.

A final visualization tool reviewed as part of this research was Maya 4.5 as developed by Alias Wavefront. Alias Wavefront products have been associated most closely with the development of 3D graphics technology used for film, video, video games, interactive media, and industrial design. In these realms, the graphics technology developed by Alias Wavefront has been used in the creation of animated scenes for movies such as those seen in Jurassic Park. The 3D graphics technology has been used also in the automobile industry and in the creation of video games for companies like Atari.

The use of Maya 4.5 in this research arose by association with the Louisville imaging firm of Xerxes. Xerxes uses Maya 4.5 as an animation tool 
for local advertisers, but also uses the software in the evaluation of impacts associated with roadway and transportation improvements. Because Maya was developed primarily for the production of $3 \mathrm{D}$ animation used in the entertainment industry, it is capable of producing highly realistic images. Xerxes use of the Maya in the study of proposed transportation improvements included projects such as planned roadway widening, installation of noise barriers and construction of an inter-modal transportation corridor. The use of Maya by Xerxes to create these highly realistic digital animations also created a similar interest by them in how to accurately create digital images comparable with photographs. As such, Xerxes agreed to assist the researcher in developing the digital images used in this study.

As an alternative to Easysite and VIZ images, the images prepared using Maya were by far the most realistic and credible. Some of this credibility can be attributed to the power of this software to create highly realistic digital scenes. However, a large portion of the realism revealed by the two digital images used in this study can be credited to the skill of the Xerxes modelers who assisted in their preparation.

\section{$\underline{\text { Statistical Verification }}$}

Environmental preference research has been used successfully to verify statistically visual preference patterns (Naser 1988; Purcell 1986; Kaplan and Kaplan 1972). Used in this context, such research typically relies on the measurement of human responses to stimuli in order to ascertain patterns of preference. Such psychophysical research relies on traditional survey methods to 
assess public preference in an attempt to develop a consensus about aesthetics. Yet, the challenge with this type of research remains with aggregating personal preferences into a response that is clearly defensible as representing the community at large.

A primary objective of this research is to attempt to understand better the determinants of visual preference, particularly as they may apply to divergent dimensions found in traditionalism and modernism, complexity and coherency and familiarity and unfamiliarity. To that end, the research proposes that survey methods will ascertain clearly if a subject group favors Traditional development patterns over Modern development patterns, or vice versa. Similarly, the research proposes to determine how scene complexity as well as familiarity with a scene influences preference.

\section{Questionnaire Design}

Early in the preparation of this proposal, it was determined that the Louisville based market research firm of Horizon Research International would be retained to assist in the design and distribution of a questionnaire needed to conduct this study. The decision to use Horizon Research International was based on two primary reasons.

The first reason was their capacity to support a primary research objective of this study by exploring a basis for internet-enabled research. Carver et al (1997) found that the World Wide Web was an advantageous research tool by its ability to access increased sample sizes; its potential to target samples; and the interactive capability afforded within the computer environment. Wherrett (1997) 
used the World Wide Web as a way to record diverse opinion about graphical environments, and successfully demonstrated that web-based responses were no different than paper-based responses. The opportunity presented itself in this study to ascertain further how internet-enabled methods could serve as a practical way to gather data, by using a well established population sample of internet respondents already assembled by Horizon Research International.

The second reason was the practical limitations and high costs of obtaining results through more conventional survey methods. This study proposed to sample at least 300 subjects in order to verify statistically the five hypotheses proposed herein. Conventional survey methods, such as direct interviews or mailings, represented time-consuming and expensive propositions. Particularly the cost of printing and mailing represented a major expense. In order to secure the 300 responses proposed by this study, approximately 3,000 questionnaires, including 60,000 photographic images, would have to be prepared and mailed. The ability to access a population sample by electronic mail provided an efficient way of establishing contact with serious subjects willing to participate in this study.

During the winter of 2003, considerable time was devoted to the final implementation of this questionnaire. Over 400 booklets were assembled. Each booklet included the 18 photographs selected from the panel ratings conducted in November of 2000. Nine photographs were of street scenes identified by the panelists as best representing Traditional neighborhoods. Nine other photographs identified by the panelists as best representing Modern neighborhoods also were 
included. The nine photographs of Traditional neighborhoods and the nine photographs of Modern neighborhoods each included three photographs from the three economic price groups selected during the panel ratings. The questionnaire booklets also included the two digital images that were modeled using Maya.

In summary, the 400 booklets prepared for this questionnaire included twenty images. Eighteen were photographic images; nine each from the two development dimensions being studied. Two others were digital images; one photograph depicted a scene identified by the panelist as a traditional neighborhood and the other was a photograph identified as a conventional suburban scene. Both images were digital models of photographic scenes taken from the middle price group.

The twenty photographic images were enlarged to an 8 -inch by 10 -inch standard image size using Adobe Photoshop 4.0. The photographic images also were identified randomly by placement of a number (1-20) at the right hand corner of the canvas. Images were bound sequentially, one through 20, along the left margin. All photographic images were arranged so that they were oriented toward the bound edge.

Considerable thought was given to whether the actual booklets should be established in three randomly ordered sets so as to obviate any effects attributable to ordering. By using this approach to offset ordering effects, the capacity to download easily the results would be hampered. As such, ordering effects were addressed in the questionnaire itself (Appendix $\mathrm{H}$ ) by simply directing subjects through the photographic survey in random sequences. 


\section{Questionnaire Distribution}

In Mid-March of 2003, Horizon Research International emailed a recruitment request to its online database of r-E-respondents. Horizon's online database includes a population sample in the five-county metropolitan Louisville area of Jefferson, Oldham and Bullitt in Kentucky, and Floyd and Clark in Indiana. The initial appeal produced 350 respondents who agreed to participate in the survey and another 150 respondents indicating a willingness to participate if required during this phase of the research.

The final selection of the respondents attempted to balance the study participants with a cross section of the population within the Louisville Metropolitan Statistical Area. Appendix H depicts the demographic profile of the respondents who participated in the survey with the same population categories found in 2000 census information. Although every effort was made to have the respondents closely compare with the Louisville population, it is believed that the participant profile under-represented the very poor, the very wealthy and the elderly. The very poor were identified as under-represented by not having convenient access to a computer and the internet. The very wealthy were identified as under-represented by not having the inclination or time necessary to complete such a survey. The elderly were under-represented by not having the technical skills or inclination necessary to complete such a survey.

The respondents who were eventually selected were offered five dollars for their willingness to participate in the study and were made eligible for one of 
two drawings, each in the amount of $\$ 450.00$ as an incentive to complete the survey by the specified date.

The initial email enabled a remote database to be compiled by the research team for the 350 potential respondents which included the respondents mailing address and phone number. The addresses compiled in this remote database were later used to prepare mailers. The mailers included a cover letter (Appendix F), the booklet of 20 photographic images (Appendix G) and a five dollar bill. The cover letter provided some basic instructions and the URL link and priority code required by the subject to access the survey site.

Once online and at the survey site (Appendix H), subjects were again provided some general information; instructed to enter their respondent password; and directed to begin interview. The survey consisted of sixty questions, three questions applicable to each of the twenty images contained in the booklet. Considerable attention and pre-testing was given to the exact wording of the three main questions so that they not only would be clear to the respondents, but also would build as much as possible on applicable definitions previously established by the literature (Kaplan and Kaplan 1982; Kaplan 1973; Kaplan et al 1972). The pre-testing engaged the help of acquaintances of the researcher who were willing to participate in a initial review of the instructions and questionnaire. The initial efforts of this group of volunteers assisted in identifying definitional issues, particularly as it related to the meaning of complexity and familiarity.

The question format was programmed using a five-point click and go rating scale that permitted the subjects to evaluate each of the 20 images on the 
basis of preference, complexity and familiarity. A final section of the questionnaire was devoted to obtaining a demographic profile. 


\section{CHAPTER FOUR}

\section{ANALYSIS AND CONCLUSIONS}

\section{$\underline{\text { Review of Findings }}$}

Five hypotheses have been developed and explored by this research in an attempt to understand better the links between the visual / spatial environment and psychophysical senses, and more specifically, determinants of visual preference. Two urban development dimensions, defined as Traditionalism and Modernism, were displayed in twenty photographic images and presented to 304 subjects who participated in this experiment. Other research objectives were formulated to improve understanding of how scene content, such as complexity and coherence, as well as familiarity with a scene, influence visual preference. The questions of scene complexity, coherence and familiarity also were posed to the subjects who participated in the experiment. Finally, the research investigated whether image from a digital medium extensively being used by design professions correlate with actual photographs of a scene, and whether such media can serve as reliable visual representations of an existing or proposed environment. This chapter will review findings resulting from this experiment. 
The Question of Visual Preference for Traditional vs. Modern

\section{Development Patterns}

The hypotheses related to this question were:

H1: Visual preference by the subject group surveyed by this research will favor visual attributes of traditional development patterns.

H2: Visual preference by the subject group surveyed by this research will favor visual attributes of modern development patterns.

Embraced within Hypothesis $1(\mathrm{H} 1)$ and Hypothesis $2(\mathrm{H} 2)$ are the questions of whether there is a favorite first choice for the visual environment portrayed by either traditional or modern development patterns. The results of this question, as shown in Figure 2, indicate an overall visual preference for images depicting modern development patterns.

Figure 2 Overall Appeal, Modern vs. Traditional

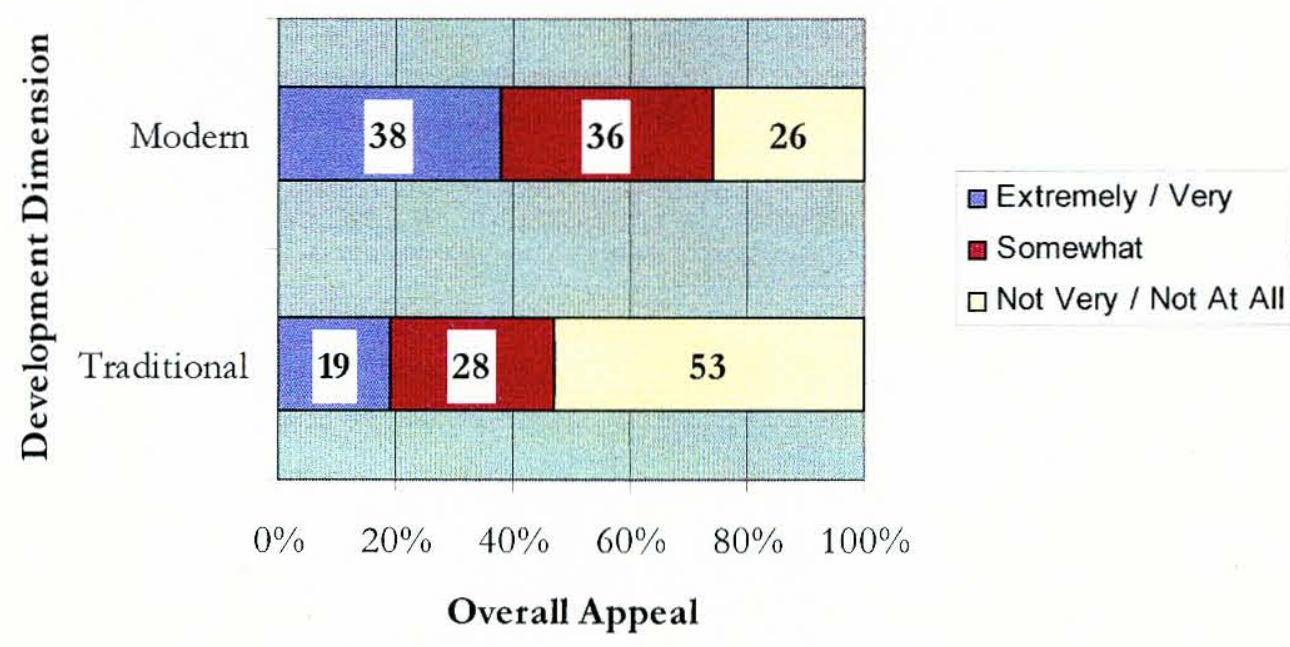


The preference for modern development patterns is statistically significant at the 95-percent confidence level when aggregate preferences for all traditional development images are contrasted with aggregate preferences for all modern development images. Not surprisingly, strong feelings of visual preference, in which over 50 percent of the respondents found the image to be extremely or very appealing, were evoked by properties mostly in the highest value groups and by scenes depicting modern neighborhoods. Similarly, responses where less then tenpercent of the respondents found the image to be appealing, were evoked by properties representing the lowest price group, in traditional neighborhoods.

\section{The Question of Visual Preference on the Basis of Scene Familiarity}

The hypothesis related to this question was:

H3: Visual preference of a scene is directly related to the amount of familiarity a subject has with the content domain of that scene.

This question explores how scene familiarity influences preference for that scene. Accordingly, it entails understanding the relationship between two different measures, and thus, enables the relationship to be measured quantitatively by the development of a correlation coefficient. In this experiment, 304 subjects rated 20 images each on the basis of scene familiarity and scene preference, thereby allowing over 6000 such comparisons to be made. Figure 3 below summarizes these responses by depicting the comparison between the percentages considered "Extremely / Very" Appealing with the percentages considered "Extremely / Very" Familiar. 
Figure 3 Relationship Between Visual Appeal and Familiarity

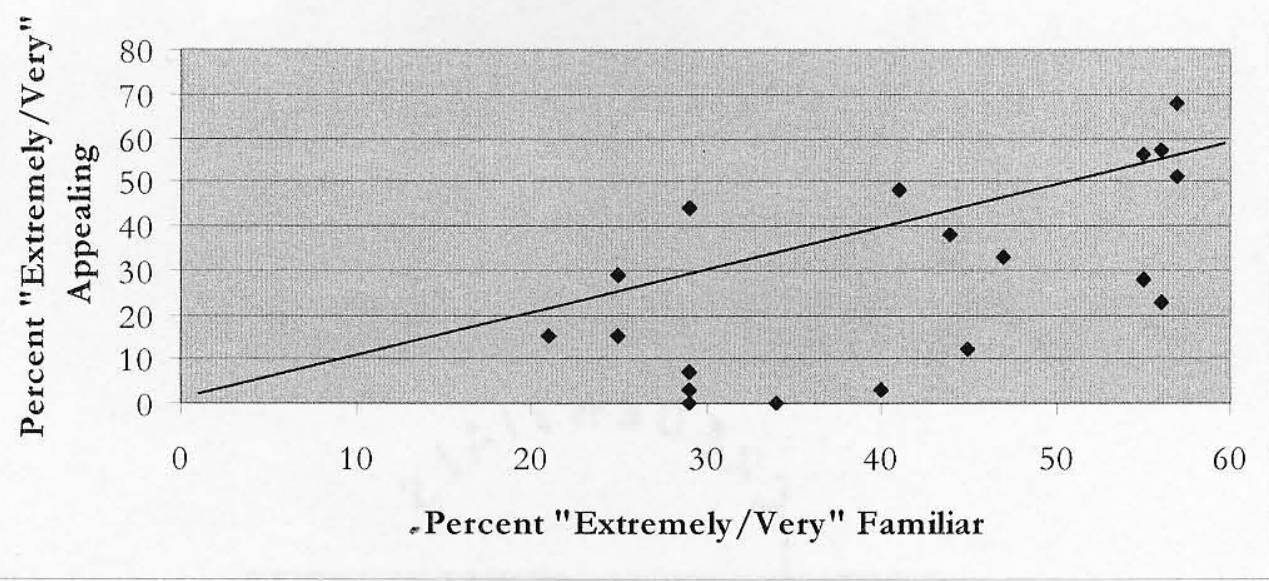

The relationships indicates a generally positive correlation $(0.342)$ between Percent "Extremely / Very".Appealing and Percent "Extremely / Very" Familiar. Because of the large sample size $(n=6080)$, a $z$-test was used to determine that this correlation was significant to the 99-percent confidence interval. Figures 4 and 5 show the correlation for "somewhat" appealing when compared with "somewhat" familiar (-0.204) and the correlation between "not at all" appealing when compared to "not at all" familiar (0.379).

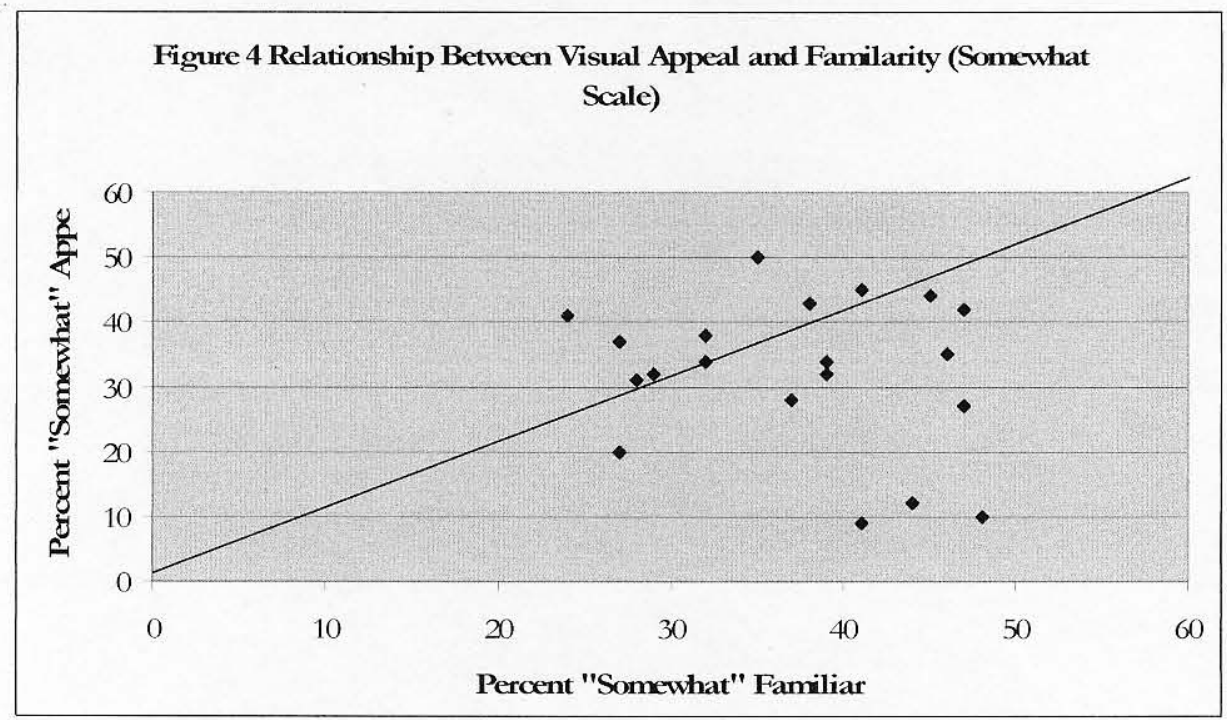




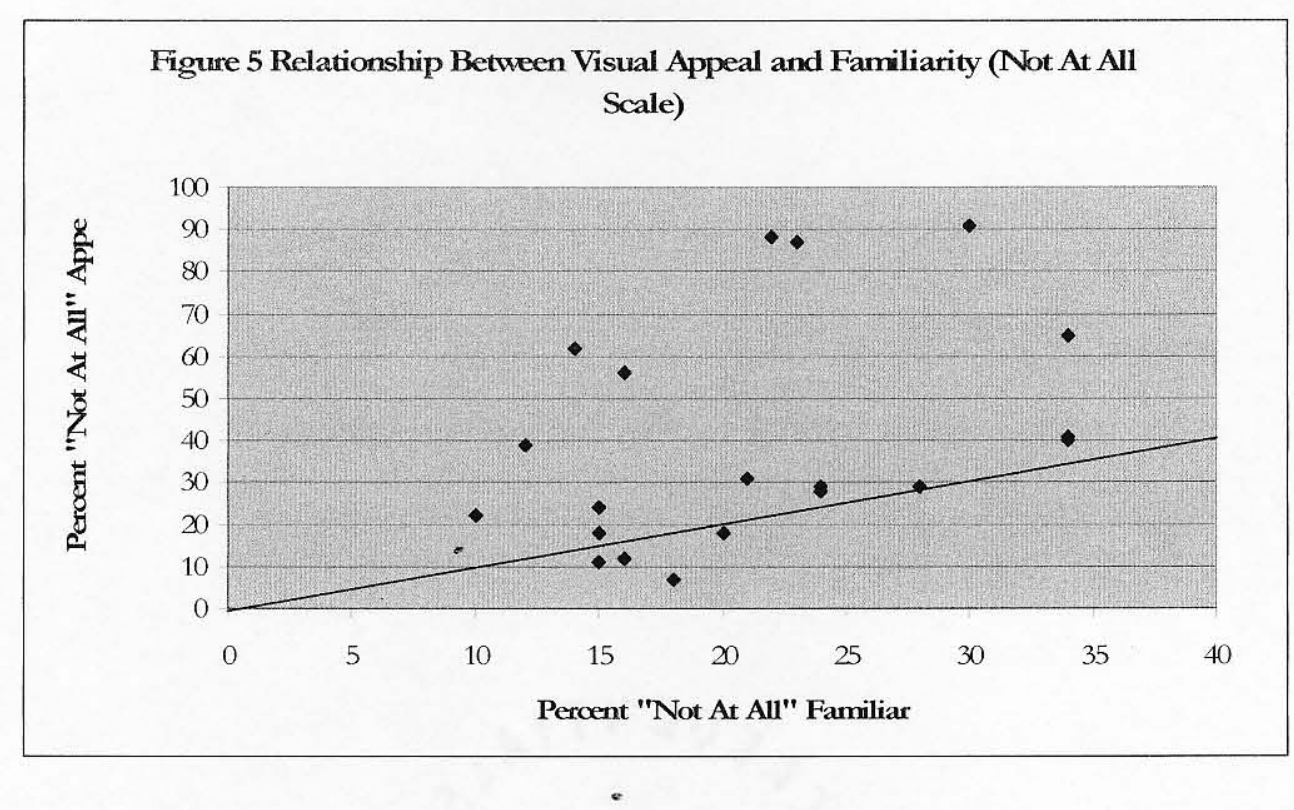

This finding supports historical theories by acknowledging the power of familiarity to shape visual preference. Kaplan and Kaplan (1982) defined familiarity patterns as an accumulation of spatial knowledge or system of cognitive maps and recognition patterns. Peterson (1965) acknowledged the power of geographic familiarity to shape preference. Turner (1977) established that even substandard housing conditions were found to be acceptable to people who had become familiar with that environment. The implication to developers and designers may be most useful by understanding that preference patterns change as people become more accustom to a new environment. An inference relative to this specific research could be made that the preference for modern suburban development patterns exhibited by the subjects who participated in this experiment may be more of a reflection of their familiarity with that particular development pattern than the traditional patterns that were presented. If 
traditional plans had been the dominant development pattern for the past fifty years, the familiarity that the participants may have had with that design dimension could have made it the preferred option. Hence, it can be argued that changes in preference patterns may be more of a function of the time that people have to become accustomed to that pattern as opposed to its characteristics.

\section{The Question of Visual Preference on the Basis of Scene Complexity}

The hypothesis related to this question was:

H4: Visual preference for a scene is directly related to its complexity until an optimal level is achieved, whereupon it becomes inversely related to each additional increment of complexity.

This question considers the relationship between scene preference and scene complexity. The hypothesis, as stated, proposes that scene complexity is a positive attribute to a certain point whereupon each marginal increase of complexity results in some marginal diminishment of preference. The experiment asked the 304 subjects to rate each of the twenty images on the basis of their visual preference for that image. Commensurately, and prior to moving forward to the next image, each subject was then asked to rate the same image on the basis of complexity. In this case, complexity also was defined as how intricate the scene appeared to be, and respondents were given a range of choices from Extremely Complex / Intricate to Not At All Complex / Intricate. Figure 6 on the following page provides a summary of these responses by depicting a comparison between the percentages considered "Extremely / Very" Appealing with the percentages considered "Extremely / Very" Complex. 
Figure 6 Relationship Between Visual Appeal and Complexity

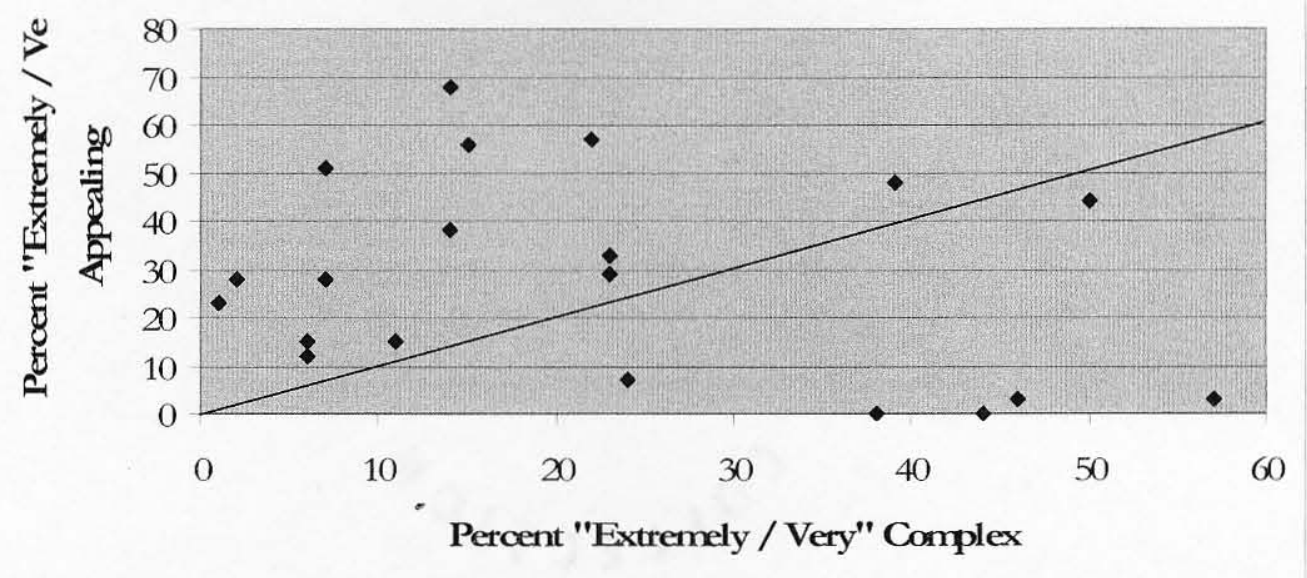

Figure 6 shows that no meaningful relationship was found to exist between scene preference and scene complexity. The correlation coefficient from the 6080 comparisons made as part of this experiment was -0.014 indicating that any conclusions resulting from these responses would be unreliable. The correlation coefficient for the comparison between "somewhat" appealing and "somewhat" complex was 0.141 (Figure 7) and for "not at all" appealing and "not at all" complex was -0.418 (Figure 8 ). The implication is that scene complexity in this experiment was an unpredictable measure of scene preference. 

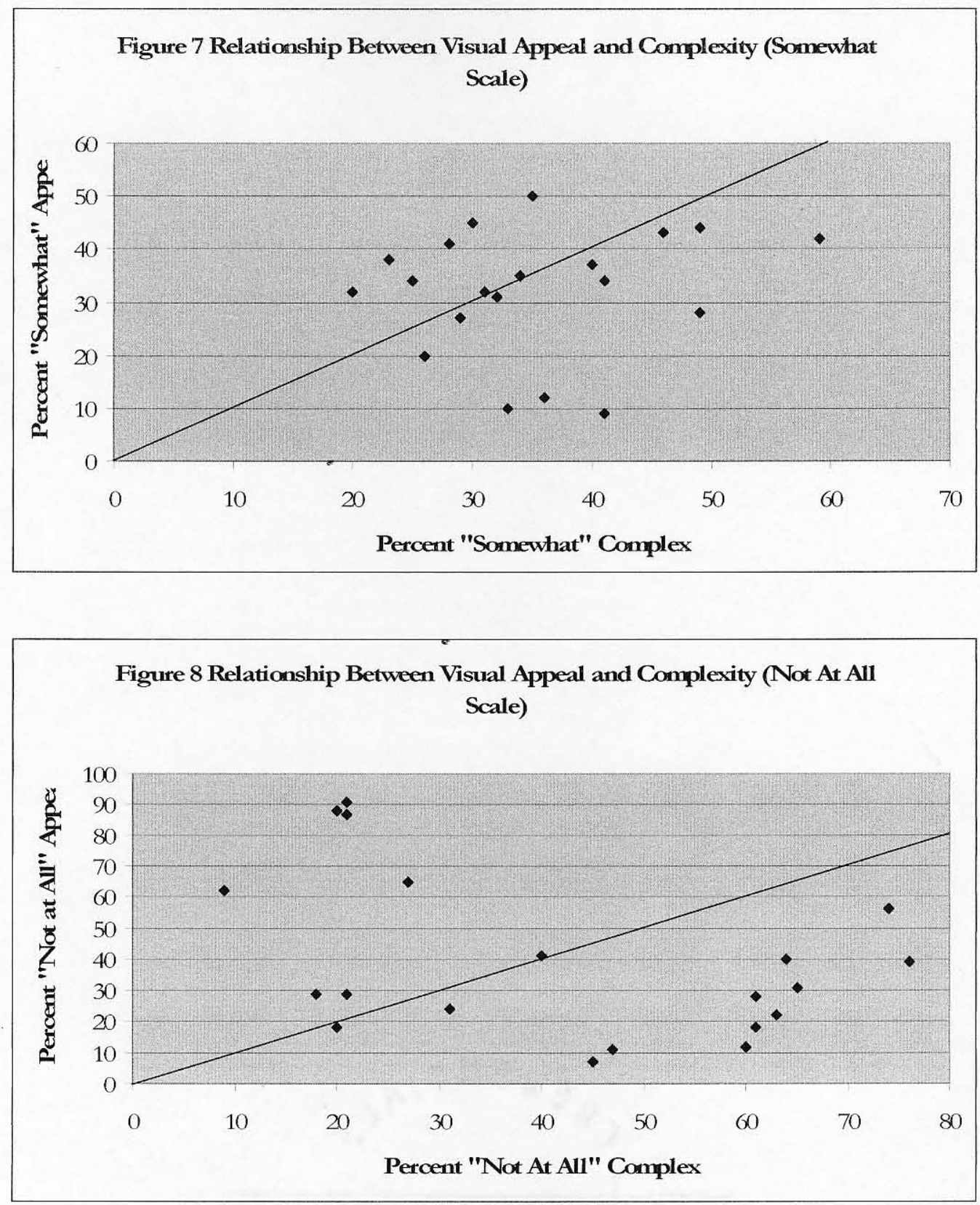

Lynch (1960) found that complexity had to be limited to definable terms in order for it to be of value. If people cannot adequately describe objects found in the visual environment then they are less aped to find them useful. The innate capacity of people to describe objects in nature may very well imply why complex, nature-dominated scenes used in this study were preferred more 
often than scenes in which complexity was an accumulation of random urban objects. The implication is that complexity must be held together in coherent and definable terms in order for it to be useful and pleasing to the eye. For the researcher, the application of understandable terminology is essential to harvesting credible information.

From a designer's standpoint, objects used to construct a scene must be done so cautiously and with such intent so that they become a supportive collaboration of individual elements that hold a scene together. A further implication can be made that much more research is needed to more fully understand the characteristics of complexity and how those characteristics support its usefulness within a scene.

\section{The Question of the Reliability of Digital Images When Compared to}

\section{Photographs}

The hypothesis related to this question was:

H5: Preference for computer-generated images positively correlates with preference for actual photographic images.

This hypothesis explores the question of whether computer-generated images can serve as a reliable visual medium when contrasted with actual photographs. Two photographs were selected and were re-created using the 3D graphics technology, Maya. The two digital images, along with the 18 photographs, were evaluated by the 304 subjects who participated in this experiment. The subjects were not made aware that the images were digital recreations of photographs included in the survey, but rather, were asked to 
evaluate them in the same manner as the other photographs. The two digital images were rated by participants in the survey on the basis of preference, familiarity and complexity. The ratings were then compared to the actual photographs to ascertain if a positive correlation existed between the photographic images and their digital counterparts.

Figure 9 graphically depicts the relationship between photographic Image 6 and its digital counterpart presented as 17 in the survey. If the stated hypothesis was that "preference for computer generated images positively correlates with preference for the actual photographic images," then it can be stated that this comparison supports the hypothesis with Pearson product-moment correlation $(\rho)$ of 0.240 . The Pearson product-moment correlation is the basic formula used to describe the how strong the relationship is between two data sets. Correlation was found to be positive also by comparing photographic Image 6 with digital Image 17 on the basis of complexity $(\rho=0.241)$ and familiarity $(\rho=0.569)$. 
Figure 9

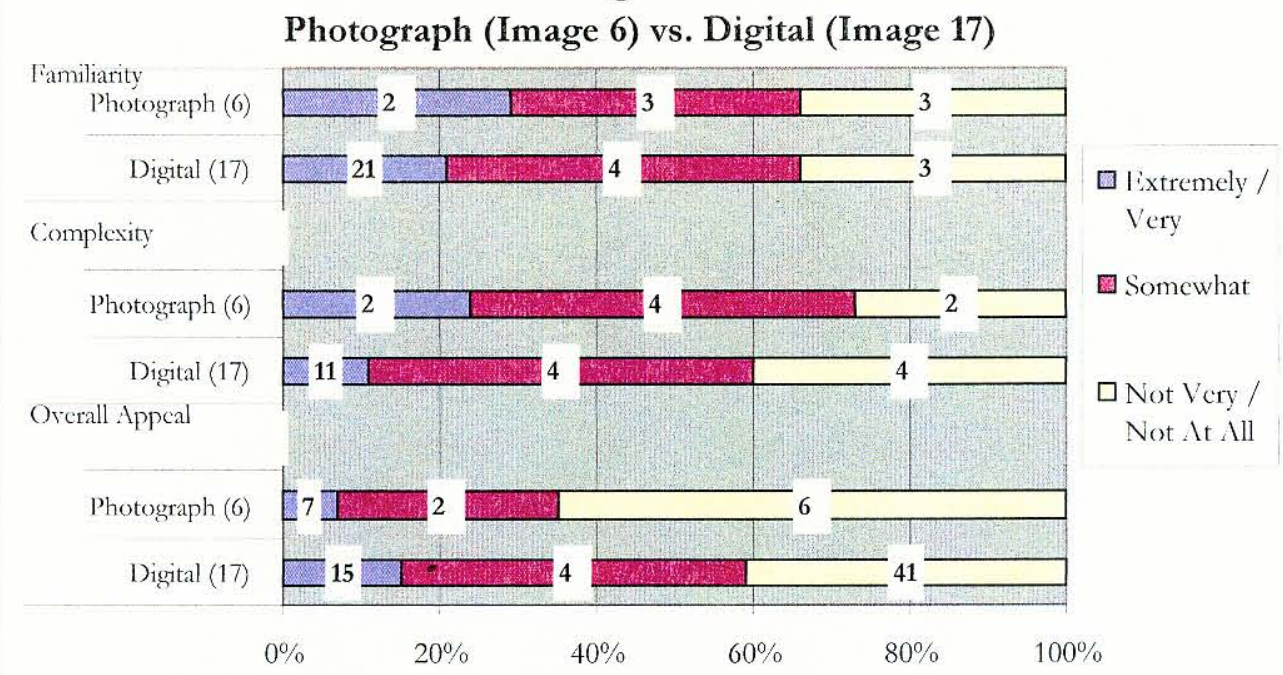

The other comparison between Photograph 14 and digital Image 7 is represented by Figure 10. In this comparison, similar results can be found supporting the stated hypothesis with $\rho-0.339$ for visual preference, $\rho=0.214$ for complexity and $\rho=0.398$ for familiarity. While both comparisons support the hypothesis, the strength of these correlations would indicate considerable progress must be made in the application and use of visualization technology in order to portray an actual scene realistically. 
Figure 10

Photograph (Image 14) vs. Digital (Image 7)

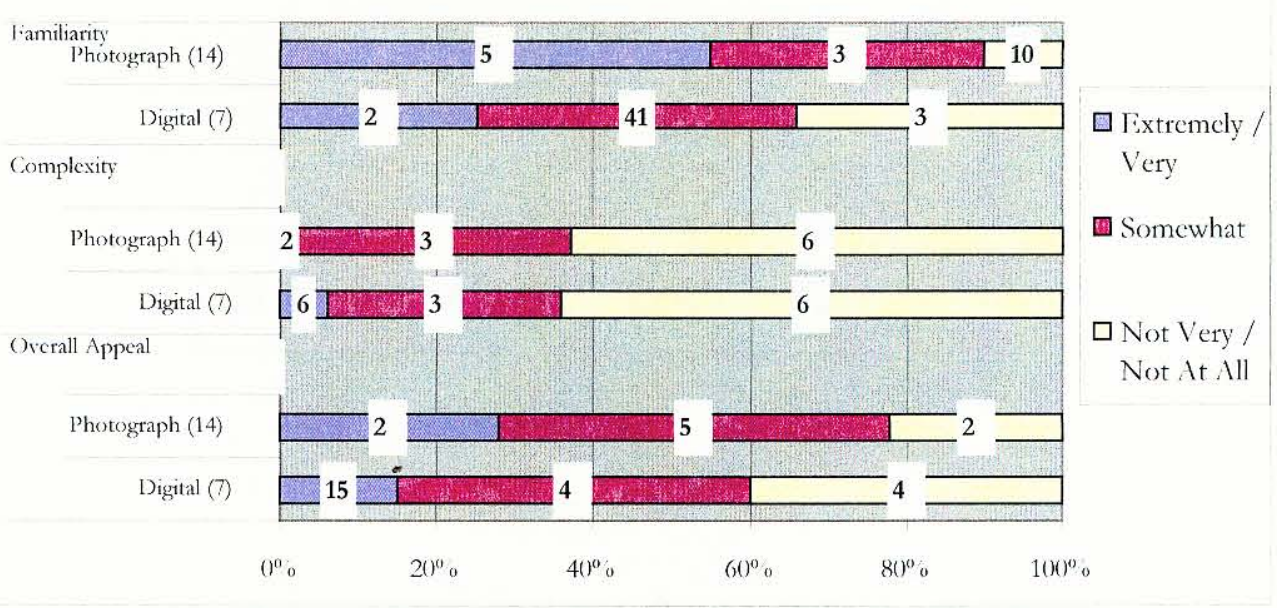

Daniel (1992) found that 3D data visualization remains largely

unexplored. Orland (1992) suggested that considerably more research needed to be performed before visualization techniques become useful in an accurate and graphical manner. Perkins (1992) questioned how image quality relates to perception. While this experiment resulted in positive correlation between digital images and their photographic counterparts, the weakness of the correlations would imply that considerable refinement and research must continue before digital visualization becomes a reliable decision-making tool. Some of this experimentation should be directed to additional testing of rapidly-changing digital medium. In this research, three different programs were trialed, with the selection of Maya being made on the basis of its being the most visually realistic. Yet, a comparison of the digital image to the photographic image reveals to both the design professional and the non-professional, that the digital images lack 
realism. Is that a result of model specific features of the software or the capability of the modeler?

Other experimentation and refinement should attempt to determine the reasonable application of digital techniques in a structured public decisionmaking environment. Are visualization techniques a more desirable option than typical plans and written reports? Do visualization techniques allow for specific design elements important to design professionals to be isolated in such a manner that they can be assessed in terms of their value in the composition of an overall scene? What are the equipment, labor and training cost associated with the use of digital techniques when contrasted to more typical plans and reports?

\section{$\underline{\text { Statistical Verification }}$}

Statistical verification of the five hypotheses is summarized as follows:

$\mathrm{H} 1$ : Visual preference favors visual attributes characteristic of traditional development patterns.

Null hypothesis

$$
\mathbf{P}=0.5
$$

Alternative

$$
\mathrm{P}>0.5
$$

Significance Level

$$
\alpha=0.05
$$

Critical Region

Critical Binomial Distribution, $p \geq 166 / 304$

This research proposed five hypotheses. Surveys were conducted to test the hypotheses. Statistical techniques were used to determine how much of the results occurred by chance. The null hypotheses assumed that the results reflect randomness that is mostly beyond the controls established by the experiment. 
The null hypotheses, expressed by $\mathrm{P}$ in $\mathrm{H} 1$ above also assumed that proportion indicating preference for either traditional or modern development patterns will be split evenly, or in other words that the results are no different than the flip of coin. Both $\mathrm{H} 1$ and $\mathrm{H} 2$ propose alternatives that indicate preference will be proportionally higher for either alternative $(\mathrm{P}>0.5)$. In this statistical analyses, a significance level, expressed as $\alpha$, will be five-percent (0.05). It has been decided that the null hypotheses will be rejected only if the results of the survey occurred by random chance less than five-percent of the time (Koosis 1997). Based on 304 subjects (n) participating in this the survey, a critical binomial distribution was calculated using an Excel spreadsheet and from that calculation it was determined that at least 166 subjects would have to indicate "Extremely / Very" appealing in order to reject the null hypotheses.

Analysis of this hypothesis reveals that visual preference does not favor attributes of the traditional development pattern. Of the 20 images included in the survey, ten were of traditional neighborhoods covering a wide range of price points. Overall, forty-seven percent of the 3040 responses related to visual preference indicated the traditional scenes to be appealing. Of the ten traditional scenes, five had greater than 166/304 favorable responses needed to evaluate visual appeal for the scene.

H2: Visual preference favors visual attributes characteristic of modern development patterns.

Null hypothesis

Alternative
$\mathrm{P}=0.5$

$\mathrm{P}>0.5$ 
Analysis of this hypothesis reveals that visual preference does favor attributes of the modern development pattern. Of the 20 images included in the survey, ten were of neighborhoods developed in the modern style, and included scenes taking into account a wide range of price points. Overall, fifty-three percent of the 3040 responses related to visual preference indicated the images of modern development patterns to be appealing. Of the ten modern scenes, only one did not have favorable responses necessary to conclude reliably that it was visually appealing.

H3: Visual preference of a scene is directly related to the amount of familiarity a subject has with the content domain of that scene.

$\begin{array}{ll}\text { Null hypothesis } & \rho=0 \\ \text { Alternative } & \rho>0 \\ \text { Significance Level } & \alpha=0.05 \\ \text { Critical Values } & z \text { distribution }\end{array}$

Analysis of Hypothesis 3 reveals a positive correlation between familiarity and preference. A Pearson product-moment correlation confirms the alternative that $\rho>0$ by having a value of 0.342 . Because of the large sample size a $z$-test was used to determine the critical value $(\sigma)$ to be $\sigma>1.96$ and $\sigma<-1.96$ at the $95-$ percent confidence level.

H4: Visual preference of a scene is directly related to its complexity until an optimal level is achieved, whereupon it becomes inversely related to each 
additional increment of complexity.

Null hypothesis

Alternatives

Significance Level

Critical Values $\rho \neq 0$

$\rho>0$

$\rho<0$

$\alpha=0.05$

$\mathrm{z}$ distribution

Analysis of Hypothesis 4 reveals that no meaningful correlation exists between complexity and preference. A Pearson product-moment correlation of 0.014 does not significantly support alternatives proposed by this question.

H5: Preference for computer generated images positively correlates with preferences for actual photographic images.

Null hypothesis

$\rho=0$

Alternative

$\rho>0$

Significance Level

$\alpha=0.05$

Critical Values

$\mathrm{z}$ distribution

Analysis of Hypothesis 5 reveals positive correlation between preferences for images generated by 3D graphics technology and preference for actual photographs of the same image. A Pearson product-moment correlation confirms the alternative that $\rho>0$ by having a value of 0.240 and 0.339 on the measure of preference. The alternative is also supported on the other measures of complexity by having relational values of 0.241 and 0.214 and on the measure of familiarity by having values of 0.569 and 0.398 . 


\section{Conclusions and Implications}

From all that has been presented by these findings, the following conclusions can be established that is useful to better understanding of the links between the visual / spatial environment and psychological senses, and more specifically, to determinants of visual preference.

First, there does not appear to be any compelling visual preference for scenes of traditional development patterns. This conclusion seems true for scenes of traditional neighborhoods representing the three price points studied when compared to modern neighborhoods.

The implications of this finding perhaps are twofold. One is that planners and designers many times become caught up in popular movements within their professions that are short lived or inappropriate to apply to a specific development condition. During the 1960 's, design professionals throughout the United States tried in their designs to emulate downtown shopping districts in Europe through the development of pedestrian walking streets (Fourth Street in Louisville is an example). The result was that, in many cases, the exclusion of vehicular traffic from downtown shopping streets may have hastened the decline of retailing in the very districts that were targeted for physical and economic improvement. Monumental changes to development must come about slowly, thoughtfully, and hopefully, with some idea of the anticipated results.

A second implication is that development patterns that are determined by a mostly free and unobstructed market seemingly result in the continuation of those 
same patterns. Land developers and those that finance developers propagate plans which are financially conservative. The massive de-concentration of American cities after World War II has been accomplished with seemingly little innovation, and the research herein finds that in the context of the visual environment, Americans tend to like it that way. The research supports the notion that people like a street scene with which they are familiar, and the post-World War II modern development patterns represent the visual environment in which they have become most accustom. The familiarity and comfort that the public can establish with an environment may in itself determine if and how long it may take for them to embrace more readily new and alternative development patterns such as those being propagated by neo-traditionalists.

It may be concluded from the research that scene complexity and intricacy has no bearing on visual preference. While it may be easy to accept this conclusion at face value, the issue of scene complexity remains one that is elusive, particularly because of how complexity is defined. For lack of any better description, the survey used "complex" and "intricate" as measures, but in reality, these terms could have multiple interpretations. Complexity could be interpreted in terms of the number and types of separate parts required to compose the scene. Others may interpret it by how understandable the scene is at first glance, which in some respects may be more a measure of scene familiarity as opposed to level of intricacy. It could be interpreted by the type of elements in the scene and how they are arranged, which in itself leads to interesting questions about why we 
prefer certain shapes, colors and patterns.

These questions touch upon innate theories researched by Woodcock (1982), who would suggest that preference for certain elements in a scene is a determinate of how humans have evolved. Or it may touch upon exploratory theories researched by Gibson (1950), who would suggest that preference for a scene is dependent upon how much can be learned from that scene. In turn, that thought procession is linked to historical theories, where personal cognitive experiences determine an individual's preference for a visual environment. Perhaps these questions touch upon all three theories; thus allowing limitless propositions for future research.

A non-statistical review of the traditional scenes used in this research indicates a tendency by study subjects to respond more favorably to complexity when it was in the form of trees, shrubs and grass than when it was in the form of overhead wires, utility poles and parked cars. Traditional scenes such as St. James Court (Image 4), Belgravia Court (Image 8), Everett Avenue (Image 16), and Oak Street (Image 18) had high preference, but also were considered complex. Comparison of these scenes with scenes of other traditional neighborhoods such as Overton Street in Newport (Image 5), Morton Street (Image 6), Second Street (Image 10), Hickory Street (Image 13), and Greenup Street in Covington (Image 20) would indicate that parked cars along the roadway, utility poles and overhead lines diminished scene preference.

One could argue that this preference phenomenon may be more a result of 
neighborhood value than of the type of complexity, and indeed, the traditional scenes that were both highly preferred and complex were of higher valued properties. However, a similar review of rated preferences for modern neighborhoods indicates modern scenes were more consistently rated with the complexity dimension across all price points. While no correlation exist between preference and complexity $(-0.29055)$ for all the scenes combined, correlations vary considerably when scenes are divided into those that are traditional and those that are modern. A correlation coefficient of -0.13059 (Figure 11) between the preference and complexity for traditional scenes would indicate there is no correlation between these two dimensions. Contrasting that finding with a correlation coefficient of 0.72704 (Figure 12) for preference and complexity of modern scenes, it would appear that complexity is a reasonably reliable dimension of preference within modern developments. 
Figure 11 Relationship Between Visual Appeal and

Complexity for Traditional Scenes

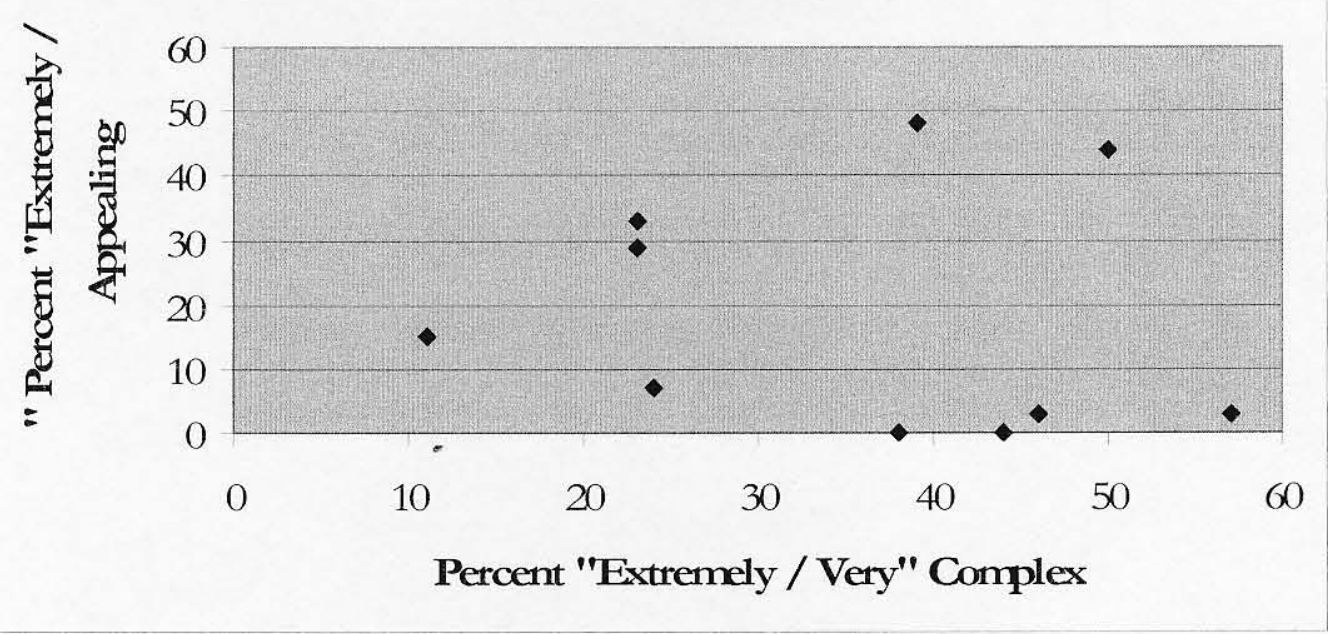

Figure 12 Relationship Between Visual Appeal and

Complexity for Modern Scenes

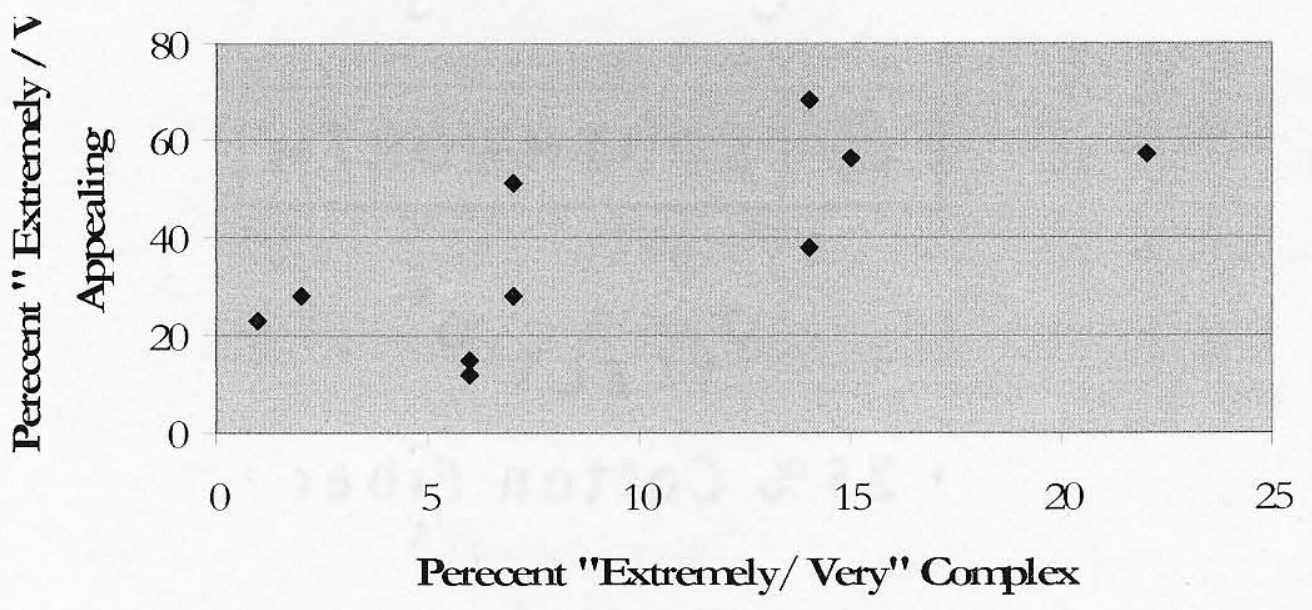

It would appear that these findings emphasize some of the unique idealistic differences between Traditionalism and Modernism. It may be that Traditionalism is a lot about visual details and having the optimal types, 
arrangement and amount of details to establish visual preference. It may be also that Modernism is about responding to the human desire for uncomplicated efficiency and the ability readily to perceive the visual environment in the manner promoted by Gropius (1970) and the Bauhaus. For now, and at least in Louisville, Kentucky, it would appear visual allegiance remains with the uncomplicated efficiency of Modernism.

This research investigated whether a preference for images produced by a digital visualization medium that is extensively being used by design professions correlates with preferences for actual photographs of a scene, and if such media can serve as a reliable visual representations of an existing or proposed environment.

While there was positive correlation between digitally-generated images and their photographic counterparts, the strength of that correlation would indicate that the digital images used in this study are not a reliable alternative to actual photographs of a scene. The inability of digitally-generated images to correlate better to their photographic counterparts may rest with the details required to create credible images, as well as internal biases of the modelers who prepare those images.

As in the conventional application of pen, paper and water colors used to prepare an image, the digital image does not capture the numerous subtle details (and perhaps flaws) that inevitably become a part of a scene. As such, uncollected leaves around a catch basin, faded pavement markings, detailed 
shadow patterns from an adjacent tree, curbside trash cans, cracks in the pavement, and other similar features never emerge into the digitally-created environment. Another internal bias to the use of digital medium is that the nittygritty details essential to producing credible images require more work and necessitate additional time. In the case of this study, that lack of detail underrepresented the complex character found in the traditional scene and overrepresented complexity in the modern image. First glance review of the digitallycreated images included in this study with the photographic images reveals the differences in these two medias. Some of the feedback received from the subjects who participated in this study also referenced the noticeable difference between digital and photographic images.

Whether using a computer or pen and paper, it remains a challenge to design professionals to represent completely and accurately their plans prior to construction. What seems to be more promising than creating an image from scratch as was done in this study, is using photographic images to depict the background on which development proposals can be superimposed to create a photomontage. The digital design environment aided by digital photography has enabled this technique to become an effective alternative. By finding or establishing visual landmarks in the field and including those landmarks in a photographic image, the designer has the horizontal and vertical references to insert a design reliably into an actual setting. For example, an architect physically can mark the corners of a proposed building in the field and from those marks 
establish the proposed floor elevations. A digitally generated photograph of that staked building site allows the architect to superimpose the digital re-creation of a building plan on the actual site, thus referencing critical impacts on the visual landscape. Likewise, an honest representation of the proposal on the actual site can be conveyed, including the type of details and features that are typically obliterated in an artistic rendering.

One final note is warranted on the implications of internet enabled research techniques. Internet enabled research similar to that performed by this study is a valuable approach for a number of reasons. First, it afforded access to an established population sample that was ready, willing and able to participate in the research. Second, access to willing participants dramatically reduced the time and expense that otherwise would have been required to secure participation of three hundred subjects through a more conventional approach. Early projections in this research effort indicated that as many as 3000 mailed questionnaires, having an estimated printing and mailing cost of $\$ 10,000$, would have been required to enlist the response of 300 willing participants. Third, internet enabled research allowed greater control of the research environment by facilitating a prompt response from those who agreed to participate. Fourth, the "click and go" electronic questionnaire required less time by the participants; allowed for the initial first reaction of the participants to be registered since changes were not permitted after a response was entered; and prevented errors by making sure that the questionnaire was completed fully prior to being returned electronically. 
Fifth, direct electronic download into a statistical program was less time consuming and more accurate.

\section{Biases and Limitations of the Research}

Every effort was made to avoid biases and minimize limitations associated

with the research, yet there were biases and limitations noted as follows:

1. The photographic material was collected from neighborhoods in the Louisville and Cincinnati Metropolitan Areas. Yet, the subjects characterized a population sample of the Louisville Metropolitan Area. A bias may have occurred by those subjects potentially having familiarity with Louisville area street scenes and not having the same level of familiarity with Cincinnati area street scenes. It would have better to include only the photographic material of Louisville area street scenes.

2. The research was provincial to Louisville, Kentucky. It mostly used photographic material taken of Louisville area street scenes. The population sample was assembled from the Louisville Metropolitan Area. Both these conditions limit the potential value and transferability of the research to other parts of the United States.

3. The survey material used 18 photographs taken of Louisville area streets. It also included two digital images of street scenes that were used in the comparison with photographs of those same street scenes. This small comparison of only two digital and two photographic images was a limitation to ascertaining more definitive comparisons between photographic images and digitallycreated images. More comparisons should have been embedded in the research.

4. The use of internet enabled research necessitates that subjects have access to a computer and the World Wide Web. Internet enabled research assumes that the subjects have the technical skills needed to operate a computer. The computer and the World Wide Web are tools inherent to modern society, thus creating the potential bias in favor of scenes depicting modern development patterns.

5. The use of internet enable research potentially eliminates a segment of the population that neither has access or the skills to operate a computer, and who may not have convenient access to the World Wide Web. This same segment of the 
population may also have the greatest familiarity with traditional inner-city neighborhoods, and hence, the strongest opinion (favorable or unfavorable) about the visual character of traditional street scenes. Similarly, internet enable research may also underrepresent the elderly because of their lack of inclination and skills to participate in an electronic survey. As well, the wealthy may not have the inclination or time to participate in a survey of this type.

6. Efforts were made to select survey respondents on the basis of closely matching the population profile within the Louisville Metropolitan Statistical Area. While reasonably close, the subject profile did not represent a perfect sample of the Louisville, Kentucky population.

\section{Summary of Contributions and Suggestions for Further Research}

In conclusion, the research provided herein contributes to the state of art and sum of knowledge in the following ways:

1. This research provided an approach to assess the visual character of alternative development patterns within a structured research environment.

2. The research confirmed the capacity of familiarity to influence visual preference, thus lending support to the historical theories and the innate need of people to construct a cognitive map as a way of managing their visual environment.

3. The research determined that complexity was a blurry construct that needs better definition in order for it to become a reliable variable for measuring visual preference and to be supportive to the exploratory theories.

4. In this particular application, the research established that $3 \mathrm{D}$ digital visualization techniques have the capability to be a reliable instrument for use in a structured decision-making process, but that continued advancements in development of visualization models and modeling techniques are needed to render more accurate portrayals of development proposals.

5. In this particular application, the research found internet enabled research to be a judicious, reliable and economical approach to accessing a population sample, and that the internet serves as a reasonably dependable approach for securing and managing research data. 
From this dissertation, other research opportunities are suggested as

follows:

1. Further research is needed to not only verify visual preferences within a setting of structured public input, but to determine if visualization techniques can be used to optimize decisions about the visual environment through a system of pair wise comparison. Much the same as an optometrist optimizes vision is it possible for planners and designers to optimize a community's vision through an exhaustive comparison of critical visual dimensions?

2. Specific to the dimension of complexity, further research is needed to devise some linguistic refinement that can enable a lexicon of terminology for the purposes of extracting predicable relationships with visual preference. To that end, this dissertation implies that the complexity as found in nature is perceived differently than that which is found in the built environment. If so, what are the patterns and characteristics that make natural complexity different than that which is found within a typical street scene? Do images of cottage and garden described by Santayana (1910) enhance nature by providing points of reference to the viewer, or are they detractions to a scene that would be even better without them?

3. The research herein implies that familiarity is a determinate of visual preference. Assuming this to be the case, what are the stages in life that people are most aware of their surroundings? Is familiarity with a visual environment most profound when a person is young and mobility limits travel to a walking or biking pace, or does the greater mobility offered as adults allow for greater comparison of alternative visual environments? What are the specific elements within those visual environments that have the greatest impact in framing the point of reference that supplements a cognitive map? 


\section{REFERENCES}

Appleton, Jay (1975), The Experience of Landscape, Chichester, Great Britain: John Wiley and Sons.

Appleton, Jay (1984), “Prospects and refuge revisited," Landscape Journal, Vol. 3, pp. 91-103.

Appleyard, D. (1969) "Why buildings are known," Environment and Behavior, Vol. 1, pp. 131-156.

Appleyard, D. (1977), "Understanding professional media: issues, theory and a research agenda," in I. Altman and J. F. Wohlwill (eds.), Human Behavior and Environment, Volume 1, New York: Plenum.

Appleyard, Donald (1981), Livable Streets, Berkeley, Calif.: University of California Press.

Beardsley, John (1997), "A mickey mouse utopia," Landscape Architecture, Vol. 87, February, 79-92.

Berleant, A. (1970), The Aesthetic Field, Springfield, Ill.: Thomas.

Berlyne, D. E. (1960), Conflict, Arousal, and Curiosity, New York: McGraw-Hill.

Biddulph, M. J. (1995) "The value of manipulated meanings in urban design and architecutre," Environment and Planning B: Planning and Design, Vol. 22, pp. 739762.

Bishop, Ian D. (1997), "Testing perceived landscape colour difference using the Internet," Landscape and Urban Planning, Vol. 37, pp. 187-196.

Brush, R. O. (1981), "Landform and scenic preference: A research note," Landscape Planning, Vol. 8, pp. 301-306.

Calthorpe, Peter (1993), The Next American Metropolis, New York: Princeton Architectural Press.

Cambell, B. G. (1974), Human Evolution, Chicago: Aldine. 
Canter, D. (1977), The Psychology of Place, New York: St. Martin’s Press.

Carroll, J. D. and Chang, J. J. (1970), "Analysis of individual differences in multidimensional scaling via an $\mathrm{N}$-way generalization of Eckart-Young decomposition," Psychometrika, Vol. 35, pp. 283-319.

Carver, S. (1991), "A prototype decision support system for siting radioactive waste disposal facilities using Geographic Information Systems and multicriteria evaluation," Northeast Regional Research Laboratory Report No.91/1, University of New Castle.

Carver, S., Kingston, Richard., and Turton, I. (1997), Review of graphical environments on the WWW as means of widening public participation in social science research, http://www.agocg.ac.uk/sosci/casestudies/carver/abstract.html

Center for Community Living (1999), The Community Image Survey, Sacramento, CA.: Local Government Commission.

Chapin, S., and Weiss, S. (1962), Urban Growth Dynamics, New York: Wiley Press.

Coomber, R. (1997), "Using the Internet for survey research," Sociological Research Online, Vol. 2, No. 2, http://www.socresonline.org.uk/socreonline/2/2/2.html.

Crane, Randall (1996), "Cars and drivers in the new suburbs," Journal of the American Planning Association, Vol. 62, Winter, 51-65.

Daniel, T. C. and Vining, J. (1983), "Methodological issues in the assessment of landscape quality," in I. Altman and J. F. Wohlwill (eds.), Human Behavior and Environment, Vol. 6, New York: Plenum Press.

Daniel, Terry C. (1992), "Data visualization for decision support in environmental management," Landscape and Urban Planning, Vol. 21, pp. 261-263.

Duany, Andres and Plater-Zyberk, Elizabeth (1991), Towns and Town-Making Principles, New York: Rizzoli.

Duany, Andres and Plater-Zyberk, Elizabeth (2000), Suburban Nation, New York: North Point Press.

Duncan, James S. (1987) "Review of urban imagery: urban semiotics," Urban Geography, Vol. 8, No. 5, pp. 473-483.

Evans, G. W., and Wood, D. (1981) "Assessment of environmental aesthetics in scenic highway corridors," Environment and Behavior, Vol. 12, 255-274.

Faust, N. L. (1995), "The virtual reality of GIS," Environment and Planning B, Vol. 22, pp. 257-268. 
Fenton, M. D. and Reser, J. P. (1987), "The assessment of landscape quality: an integrative approach," in J. L. Naser (ed.) Environmental Aesthetics: Theory, Research and Applications, Cambridge: Cambridge University Press.

Fenton, Mark D. (1985), "Dimensions of meaning in the perception of natural settings and their relationships to aesthetic response," in J. L. Naser (ed.) Environmental Aesthetics, Cambridge: Cambridge University Press.

Frey, Janet E. (1981), Preferences, Satisfactions, and the Physical Environments of Urban Neighborhoods, unpublished Ph.D. dissertation, The University of Michigan, Ann Arbor, Michigan.

Fulton, William (1996), The New Urbanism, Cambridge, Mass.: Lincoln Institute of Land Policy.

Gans, Herbert J. (1967), The Levittowners, New York: Pantheon.

Glabb, Charles N. and Brown, Theodore A. (1983), A History of Urban America, New York: Macmillan Publishing Company, Inc.

Gibson James J., (1986) The Ecological Approach to Visual Perception, Hillsdale, New Jersey: Lawrence Erlbaum Associates.

Gibson, James J. (1950) The Perception of the Visual World, Boston: The Riverside Press.

Goodfellow, D. and Aubin, A. (1995), Virtual world simulation: Bermuda, Ontario: University of Waterloo.

Groat, Linda (1984), "Public opinion of contextual fit," Architecture: The American Institute of Architects Journal, Vol. 73, pp. 72-75.

Grob, Markus (1991), "The analysis of visibility-environmental interactions between computer graphics, physics and physiology," Computer and Graphics, Vol. 15, No. 3, pp. 407-415.

Gropius, Walter (1970), Scope of Total Architecture, New York: Collier Books.

Gulick, John (1969) "Images of an urban city," AIP Journal, August, pp. 179-198.

Hall, Edward T. (1969), The Hidden Dimension, New York: Anchor Books.

Hershberger, R.G. and Cass, R. (1974), "Predicting user responses to buildings," in G. Davis (ed.), EDRA 5: Evaluation and Application, Washington D.C.: Environmental Design Research Association. 
Hershberger, Robert G. (1969), "A Study of Meaning and Architecture," EDRA 1: Proceedings of the First Annual Environmental Design Research Association Conference (Raleigh: North Carolina State University) pp. 86-100.

Hertzog, T. R. (1984), "A cognitive analysis of preference for field-and-forest environments," Landscape Research, Vol. 9, pp. 10-16.

Hertzog, Thomas R. (1984), "A cognitive analysis of preference for field-and-forest environments," Landscape Research, Vol. 9, pp. 10-16.

Hertzog, Thomas R. (1984), "A cognitive analysis of preference for field-and-forest environment," Landscape Research, Vol. 9, pp. 10-16.

Herzog, T., Kaplan, S., and Kaplan, R. (1976), "The prediction of preference for familiar urban places," Environment and Behavior, Vol. 8, No. 4, December, pp. 627-645.

Jacobs, Allan B. (1996), Great Streets, Cambridge, Mass.: M.I.T. Press.

Jacobs, Jane (1961), The Death and Life of Great American Cities, New York: Random House.

Kaplan, R. (1983), "The role of nature in the urban context," in I. Altman and J. F. Wohlwill (eds.), Human Behavior and Environment, Vol. 6, New York: Plenum Press.

Kaplan, R. and Herbert E. (1987), "Cultural and subcultural comparison in preference for natural settings," Landscape and Urban Planning, Vol. 14.

Kaplan, R., and Herbert, E. H. (1987), "Cultural and subcultural comparisons in preference for natural settings," Landscape and Urban Planning, Vol. 14.

Kaplan, Rachel (1977), "Preference and everyday nature: method and application," in D. Stokols (ed.), Perspective On Environment and Behavior, New York: Plenum.

Kaplan, S. (1975), "An informal model for the prediction of preference," in E. H. Zube, R. O. Brush and J. G. Fabos (eds.) Landscape Assessment, Stroudsburg, PA:

Dowden, Hutchinson and Ross.

Kaplan, S. and Talbot, J. F. (1983), "Psychological benefits of wilderness experience," in I. Altman and J. F. Wohlwill (eds.), Human Behavior and Environment, Vol. 6, New York: Plenum Press.

Kaplan, S., and Kaplan, R. (1982), Cognition and Environment, New York: Praeger Publishers. 
Kaplan, S., and Talbot, J (1983), "Psychophysical benefits of wilderness experiences," in I. Altman and J. F. Wohlwill (eds.), Human Behavior and Environment, Vol. 6, New York: Plenum Press.

Kaplan, S., Kaplan, R. and Wendt, J. (1972), "Rated preference and complexity for natural and urban visual material," Perception and Psychophysics, Vol. 12, pp. 354356.

Kaplan, S., Kaplan, R., and Wendt, J. (1972), "Rated preference and complexity for natural and urban and visual material," Perceptions and Psychophysics, Vol. 12, No. 4, pp. 354-356.

Kaplan, Stephen (1975), "An informal model for the prediction of preferences," Landscape Assessment: Values, Perceptions, and Resources, Stroudsburg, Pa: Dowden, Hutchinson and Ross.

Kaplan, Stephen (1978), "On knowing the environment," in Kaplan, S. and Kaplan, R. (eds.), Humanscape, North Scituate, Mass.: Duxbury Press.

Kaplan, Stephen (1979), Proceedings of Our National Landscape Conference (Berkley, Calif.: Pacific Southwest Forest and Range Experiment Station) pp. 241-248.

Kaplan, Stephen (1982), Knowledge for Design (Washington D. C.: Environmental Design Research Association), pp. 183-188.

Kasmar, J. V. (1970), "The development of a usable lexicon of environmental descriptors," Environment and Behavior, Vol. 2, pp. 153-169.

Katz, Peter (1994), The New Urbanism, New York: McGraw-Hill.

Koosis, Donald J. (1997), Statistics: A Self-Teaching Guide, New York: John Wiley and Sons.

Kunster, James H. (1993), The Geography of Nowhere, New York: Touchstone.

Lang, J., Burnette, C., Moleski, W., and Vanchon D. (1974), Designing For Human Behavior: Architecture and the Behavioral Sciences, Stroudsburg, Pa.: Dowden, Hutchinson and Ross.

Langdon, Phillip (1994), A Better Place to Live, Amherst, Mass.: The University of Massachusetts Press.

Langendorf, R. (1992), “ The 1990's: information systems and computer visualization of urban design, planning and managment," Environment and Planning B, Vol. 19, pp. 723-738. 
Lansing, J., and Marans, R. (1969) "Evaluation of neighborhood quality," AIP Journal, May, pp. 195-200.

Lansing, John B. and Marans, Robert W. (1969), "Evaluation of neighborhood quality," Journal of the American Institute of Planning, Vol. 55, May, 195-199.

Lazalde, Patricia (1998), "Hue must be joking," Time, Vol. 152, No. 18, November 2, p. 8.

Lerner-Lam, E., Celniker, S., Halbert, G., Chellman, C., and Ryan, S. (1992), "Neotraditional neighborhood design and its implications for traffic engineering", ITE Journal, Vol. 62, No. 1, January, pp. 17-25.

Levy, R. M. (1995), "Visualization of urban alternative," Environment and Planning B: Planning and Design, Vol. 22, pp. 343-358.

Lingoes, J. C. (1973), The Guttman-Lingoes Nonmetic Program, Ann Arbor, Michigan: Mathesis Press.

Linton, D. L. (1968), "The assessment of scenery as a natural resource," Scottish Geographical Magazine, Vol. 84, pp. 219-238.

Lozano, E. (1974), "Visual needs in urban environments and physical planning," Town Planning Review, Vol. 45, No. 4, pp. 351-374.

Lynch, Kevin (1960), The Image of the City, Cambridge, Mass.: M.I.T. Press.

Malm, W., Kelly, K., Molenar., J., and Daniel, T. (1981), "Human perception of visual air quality (uniform haze)," Atmosphere Environment, Vol. 15, pp. 1875-1890.

Mayo, James M. (1988), "Urban design as uneven development," Environment and Behavior, Vol. 20, September, 633-663.

Moore, G. T. and Golledge, R. G. (1976), "Environmental knowing: concepts and theories," in G. T. Moore and R. G. Golledge (eds.) Environmental Knowing: Theories, Research and Methods, Stroudsburg, PA: Dowden, Hutchinson and Ross.

Morris, Charles (1956), Varieties of Human Value, Chicago: University of Chicago Press.

Munsinger, H. L., and Kessen, W. (1964), "Uncertainty, structure and preference," Psychological Monographs, Vol. 78, No. 9.

Naser J. L., Julian, D., Buchman, S., Humphreys, D., and Mrohaly, M. (1983), "The emotional quality of scenes and observation points: a look at prospect and refuge," Landscape Planning, Vol. 10, pp. 355-361. 
Naser, Jack L. (1984), "Visual preferences in urban street scenes: a cross-cultural comparison between Japan and the United States," Journal of Cross-Cultural Psychology, Vol. 15, pp. 79-93.

Naser, Jack L. (1987), "The effect of sign complexity and coherence on the perceived quality of retail scenes," APA Journal, Autumn, pp. 499-509.

Naser, Jack L. (1988), "Perception and evaluation of residential street scenes," in J. L. Naser (ed.) Environmental Aesthetics, Cambridge: Cambridge University Press.

Naser, Jack L. (1988), "The evaluative image of the city," APA Journal, Winter, pp. 4153.

Naser, Jack L. (1998), The Evaluative Image of the City, Thousand Oaks, Calif.: Sage Publications.

Naser, Jack L. and Julian, David A. (1995), "The psychological sense of community in the neighborhood," Journal of the American Planning Association, Vol. 61, Spring, 178-184.

Nelessen, A. (1999), The Visual Preference Survey, A. Nelessen and Associates, Princeton, NJ: A. Nelessen and Associates.

Oh, Kyushik (1994), "A perceptual evaluation of computer-based landscape simulations," Landscape and Urban Planning, Vol. 28, pp. 201-216.

Oostendorp A., and Berlyne, D. (1988), "Dimensions in the perception of architecture: Identification and interpretation of dimensions of similarity," in J. L. Naser (ed.) Environmental Aesthetics, Cambridge: Cambridge University Press.

Orland, B., LaFontaine, J. and Daniel, T. C. (1990), "Visualizing alternative futures for forested landscapes," in Resource Technology 90 (Washington D. C.: American Society for Photogrametry and Remote Sensing) pp. 46-57.

Orland, Brian (1988), "Aesthetic preferences for rural landscapes: some resident and visitor differences," in J. L. Naser (ed.), Environmental Aesthetics, Cambridge: Cambridge University Press.

Orland, Brian (1992), "Evaluating regional changes on the basis of local expectations: a visual dilemma," Landscape and Urban Planning, Vol. 21, pp. 257-259.

Palen, John J. (1995), The Suburbs, New York: McGraw-Hill.

Perkins, Nathan H. (1992), "Three questions on the use of photo-realistic simulations as real world surrogates," Landscape and Urban Planning, Vol. 21, pp. 265-267. 
Peterson, George L. (1965), Subjective Measures of Housing Quality: An Investigation of Problems of Codification of Subjective Value for Urban Analysis, unpublished Ph.D. dissertation, Northwestern University, Evanston, Illinois.

Purcell, A. T. (1984), "The organization of the experience of built environment," Environment and Planning B, Vol. 11, pp. 173-192.

Rapoport, A., and Hawkes, R. (1970), "The perception of urban complexity," AIP Journal, March, pp. 106-111.

Rappaport, A. and Kantor, R., (1967) "Complexity and ambiguity in environmental design,” AIP Journal, Vol. 33, July, pp. 210-222.

Robertson, A.R. (1977), "The CIE 1976 color-difference formulae," Colour Res. Appl., Vol. 2, pp. 7-11.

Rusk, David (1993), Cities Without Suburbs, Washington, D. C.: Woodrow Wilson Center Press.

Sancar, Fahriye H. (1985), "Toward theory generation in landscape aesthetics," Landscape Journal, Vol. 4, pp. 116-124.

Santayana, George (1910), The Sense of Beauty, New York: Charles Scribner's Sons.

Schmidt, W.C. (1997), "World-wide web survey research: benefits, potential problems, and solution," Behavior Research Methods, Instruments and Computer, Vol. 29, No. 2, pp. $274-279$

Shafer, E. L., Hamilton, J. F., Schmidt, E. A. (1969), "Natural landscape preference: a predictive model," Journal of Leisure Research, Vol. 5, pp. 60-65.

Shafer, E.L. and Brush, R.O. (1977), "How to measure preferences for photographs of natural landscapes," Landscape Planning, Vol. 4, pp. 237-256.

Smith, A., Dodge, M., and Doyle, S. (1998), Visual Communication in Urban Planning and Urban Design, http://www.agocg.as.uk/sosci/casestudies/smith/references.html

Stea, David (1969), "Environmental perception and congnition toward a model for 'mental' maps," in Kaplan, S. and Kaplan, R. (eds.), Humanscape, North Scituate, Mass.: Duxbury Press.

Steinitz, Carl (1968), "Meaning and congruence of urban form and activity," AIP Journal, July, pp. 233-248.

Steuteville, Robert (1999), "Growth in TND steady, but slower; neotraditional home sales strong," New Urban News, Vol. 4, No. 5, September / October. 
Turner, John (1977), Housing by People: Towards Autonomy in Building Environments, New York: Pantheon Books.

Unwin, Raymond (1909), Town Planning in Practice, New York: Benjamin Blom, Inc.

Ward, L. and Russell, J. A. (1981) "The psychological representation of molar environment," Journal of Experimental Psychology, Vol. 110, pp. 121-152.

Wherrett, J. R. (1997), Natural Landscape Scenic Preference: Predictive Modeling and the World Wide Web, (unpublished)

http://bamboo.mluri.sari.ac.uk/ jo/publications/athens/

Wohlwill, J. F. (1968), "Amount of stimulus exploration and preference as differential function of stimulus complexity," Perception and Psychophysics, Vol. 4, pp. 307312.

Wohlwill, J. F. (1976), "Environmental aesthetics: The environment as a source of affect," in I. Altman and J. F. Wohlwill (eds.), Human Behavior and Environment, Vol. 1, New York: Plenum Press.

Wolf, Peter (1981), Land In America, Its Value, Use and Control, New York: Pantheon.

Woodcock, David M. (1982), A Functionalist Approach to Environmental Preference, unpublished Ph.D. dissertation, The University of Michigan, Ann Arbor, Michigan.

Von Hoffman, Alexander (1999), "Housing heats up: home building patterns in metropolitan areas," The Brooking Institution Survey Series, pp. 1-11.

Zajonic, R. B. (1980), "Feeling and thinking: Preferences need no inferences," American Psychology, Vol. 35, pp. 151-175.

Zehner, Robert B. (1970), Satisfaction With Neighborhoods: The Effects of Social Compatibility, Residential Density, and Site Planning, unpublished Ph.D. dissertation, The University of Michigan, Ann Arbor, Michigan.

Zube, E. H., Pitt, D. G., and Evans, G. W. (1983), "A lifespan development study of landscape assessment," Journal of Environmental Psychology, Vol. 3, pp. 115-128.

Zube, E. H., Sell, J. L., and Taylor, G. (1982), "Landscape preference: Research, application and theory," Landscape Planning, Vol. 9, pp. 1-33. 


\section{APPENDIX A \\ PROPERTY VALUES OF \\ STREETS INCLUDED IN \\ THE STUDY \\ (VALUES OBTAINED IN YEAR 2000)}

1 Legislative Way (Jeffersonville)

m $\$ 34,033.00$

2 Washington Way (Jeffersonville)

$\mathrm{m} \quad \$ \quad 37,720.00$

3 Spring Street (Louisville)

t $\$ 41,055.00$

4 Overton (Newport)

t $\$ 42,120.00$

5 Washington Street (Jeffersonville)

m $\$ 47,358.00$

6 Sylvia (Louisville)

t $\$ 51,373.00$

7 Silo Ridge (Jeffersonville)

$\mathrm{m} \$ 60,944.00$

8 Washington Street looking west (Jeffersonville)

t $\$ 61,616.00$

9 Burnett (Louisville)

t $\$ 61,732.00$

10 Lindsay (Louisville)

$\mathrm{m} \quad \$ \quad 61,918.00$

11 Freestone $\mathrm{Ct}$ (Louisville)

m $\$ 64,840.00$

12 Russel Lee Drive (Louisville)

t $\$ 71,990.00$

13 South Third Street (Louisville)

m \$ $72,450.00$

14 Eastern Ave (Cincinnati)

$\mathrm{t} \$ 73,500.00$

15 Afterglow Dr.(Louisville)

$\mathrm{m} \quad \$ \quad 74,184.00$

16 Tallow Lane (Louisville)

$\mathrm{m} \quad \$ 74,510.00$

17 Story Ave (Louisville)

$\mathrm{t} \$ 78,840.00$

18 Cranston (Louisville)

$\mathrm{m} \quad \$ 79,055.00$

19 Greenup Street (Covington)

t $\quad$ S $80,000.00$

$20 \quad$ 36th Street (Louisville)

t $\$ 81,334.00$

21 South Second Street (Louisville)

t $\$ 89,200.00$

22 Bay Pointe Ct. (Louisville)

m $\quad$ S $89,307.00$

23 Rubel (Louisville)

t $\$ 94,412.00$

24 Hollyview (Louisville)

m $\$ 102,928.00$

25 Morton (Louisville)

t $\$ 107,342.00$ 
27 Briarwood Road (Louisville)

m $\$ 117,086.00$

28 Northwood Drive (Louisville)

$\mathrm{m} \quad \$ 121,485.00$

29 Bayly (Louisville)

t $\$ 121,725.00$

30 Belgravia (Louisville)

t $\$ 135,967.00$

31 Laurelwood Road (Louisville)

m $\$ 138,796.00$

32 Andrew Ct. (Louisville)

m $\$ 146,170.00$

33 Wellington (Louisville)

$\mathrm{m} \$ 148,650.00$

34 Belmont Park Circle (Louisville)

$\mathrm{m} \quad \$ 149,410.00$

35 Kennedy (Louisville)

t $\$ 150,550.00$

36 Tusculum (Cincinnati)

t $\$ 153,158.00$

37 Linden Place (Mariemont)

t $\$ 153,567.00$

38 Sawyer Place (Louisville)

m $\$ 161,154.00$

39 Beech Street (Mariemont)

t $\$ 161,457.00$

40 Hanover (Louisville)

$\mathrm{m} \$ 162,403.00$

41 Garrard Street (Covington)

t $\$ 171,500.00$

42 Windsong Way (Louisville)

t $\$ 179,113.00$

43 Oak Street (Mariemont)

t $\$ 188,175.00$

44 Evergreen Rd. (Louisville)

t $\$ 191,870.00$

45 Lancaster Essex Ct. (Louisville)

m $\$ 197,894.00$

46 Regency Woods Way (Louisville)

m $\$ 209,414.00$

47 Everett (Louisville)

t $\$ 213,270.00$

48 St. James Ct. (Louisville)

t $\$ 216,256.00$

49 Ivybridge (Louisville)

m $\$ 222,118.00$

50 Lake Forest Parkway (Louisville)

m $\$ 222,286.00$

51 Nourbourne Blvd. (Louisville)

t $\$ 223,837.00$

52 Cherokee Rd (Louisville)

t $\$ 225,673.00$

53 St. Germaine Ct. (Louisville)

t $\$ 238,323.00$

54 Chauncey (Louisville)

t $\$ 259,210.00$

55 Cherokee Parkway (Louisville)

t $\$ 295,637.00$

56 Mt. Vernon (Mariemont)

t $\$ 311,660.00$

57 Limehouse Ct. (Louisville)

m $\$ 344,643.00$

58 Balmoral Drive (Louisville)

m $\$ 350,778.00$ 
59 Brownsboro Hill Rd. (Louisville)

m $\$ 380,960.00$

60 Golden Springs Court (Louisville)

m $\$ 432,636.00$

$\mathrm{t}=$ traditional neighborhood

$\mathrm{m}=$ modern neighborhood 


\section{APPENDIX B \\ EXAMPLE COVER LE'TTER \\ TO PANELIST}

December 2, 2000

Dear,

Thank you for agreeing to participate in this survey.

The survey is part of a Ph.D. research project entitled "Rated Preference, Complexity and Familiarity for Traditional Neighborhood and Conventional Suburban Development Patterns Using Alternative Visual Medium". The project is concerned with understanding visual preference determinants for alternative neighborhoods.

As a participant in this phase of the research, you are being asked to use your expertise in community development and urban design to distinguish between traditional neighborhoods and conventional suburban neighborhoods.

Three photographic sheets are enclosed, each depicting twenty (20) street scenes. Drawing upon your experience and expertise, please rate each scene on the basis of it having visual characteristics of traditional neighborhoods or visual characteristics of conventional suburban neighborhoods. There should be three survey forms to assist you in this task, one each corresponding to the photographic sheets. In all, sixty (60) photographs will be rated.

Using the forms, scenes should be rated on the depicted scales. A scene having strong visual characteristics of a traditional neighborhood would be checked on the far left side the scale. In contrast, a check on the far right side of the scale indicates strong visual characteristics of a conventional suburban neighborhood. A neutral rating indicates a scene has no strong visual characteristics of either development pattern. Please keep in mind this is not a rating of visual preference, but rather, a rating of each scene's capacity to satisfy your understanding of the visual characteristics of traditional neighborhoods or conventional suburban neighborhoods.

When complete, you may use the attached addressed and stamped envelope to return the survey. The three photographic sheets can be discarded.

Thank you for your willingness to participate.

With Best Regards,

Jim Mims 
APPENDIX C

RESIDENTIAL STREET SCENES

REVIEWED BY PANELIST 

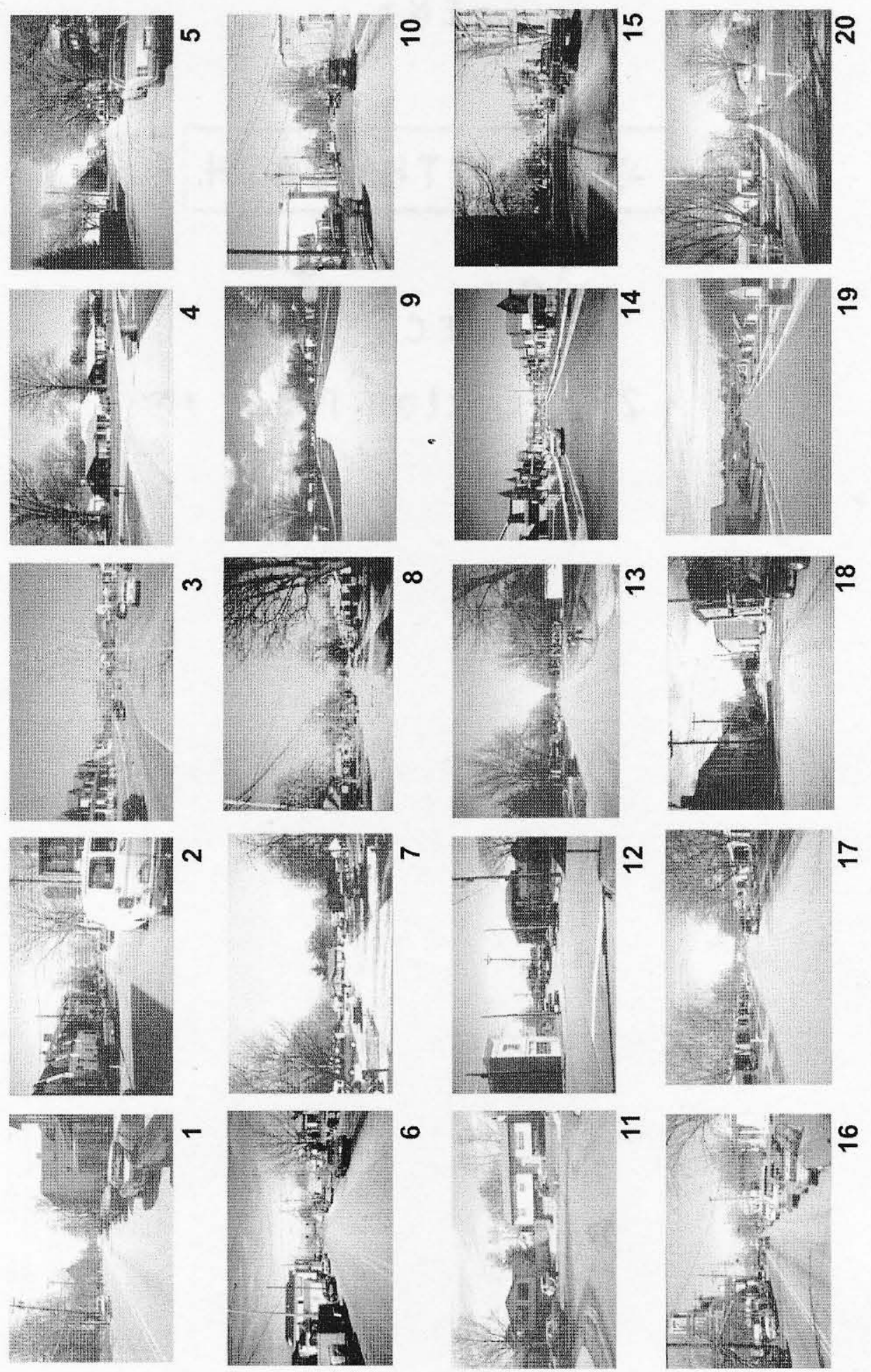

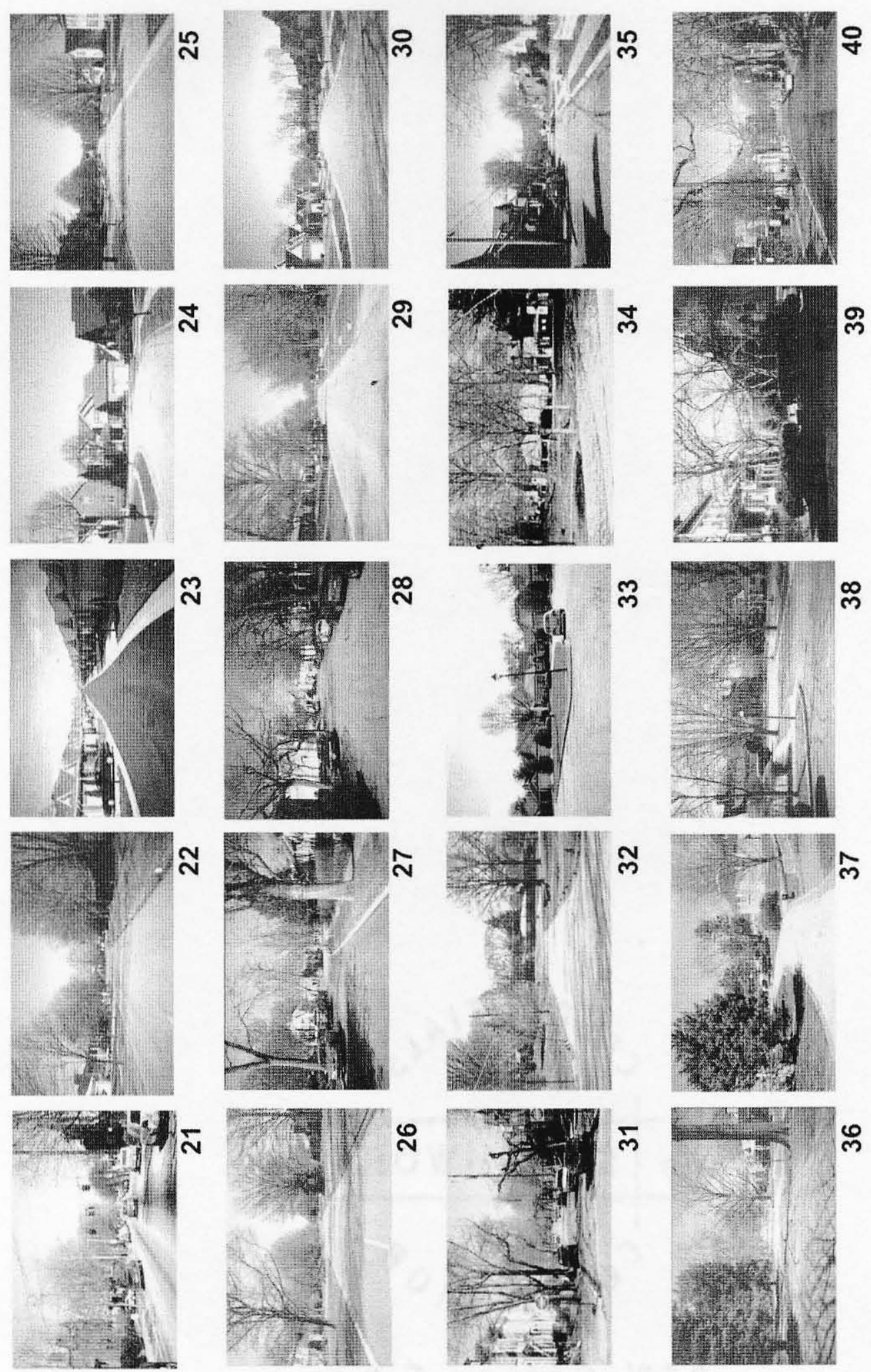

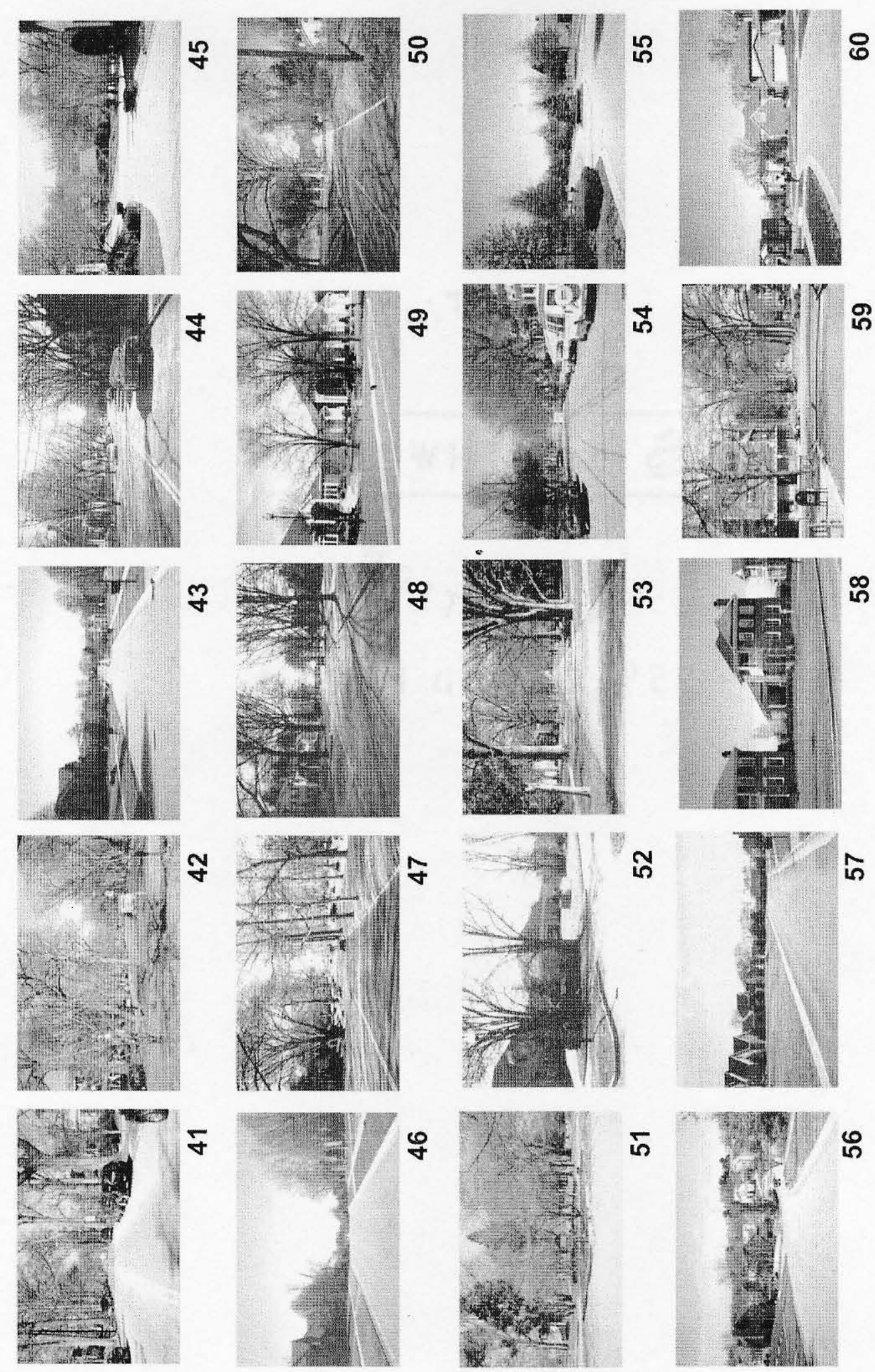


\section{APPENDIX D}

PANELIST QUESTIONAIRE RESPONSE FORM

Please rate all sixty (60) photographs by checking the appropriate box on the scales below.

Most

Traditional
Neutral

Most

Conventional

1. $\square \quad \square \quad \square \quad \square \quad \square \quad \square \quad \square \quad \square \quad \square \quad \square \quad \square$

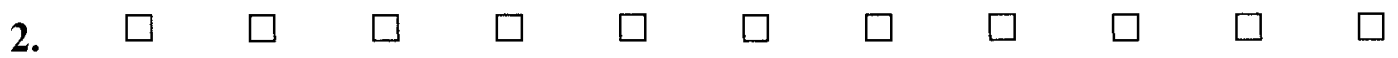

3. $\square \quad \square \quad \square \quad \square \quad \square \quad \square \quad \square \quad \square \quad \square \quad \square \quad \square$

4. $\square \quad \square \quad \square \quad \square \quad \square \quad \square \quad \square \quad \square \quad \square \quad \square \quad \square$

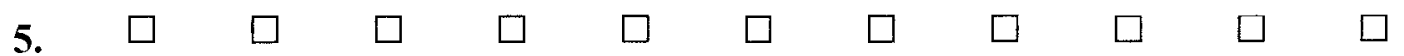
6. $\square \quad \square \quad \square \quad \square \quad \square \quad \square \quad \square \quad \square \quad \square \quad \square \quad \square$

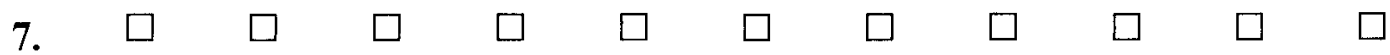

8. $\quad \square \quad \square \quad \square \quad \square \quad \square \quad \square \quad \square \quad \square \quad \square \quad \square \quad \square \quad \square$ 9. $\square \quad \square \quad \square \quad \square \quad \square \quad \square \quad \square \quad \square \quad \square \quad \square \quad \square \quad \square$

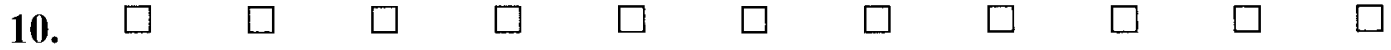
11. $\square \quad \square \quad \square \quad \square \quad \square \quad \square \quad \square \quad \square \quad \square \quad \square \quad \square$

12. $\square \quad \square \quad \square \quad \square \quad \square \quad \square \quad \square \quad \square \quad \square \quad \square \quad \square$

13. $\square \quad \square \quad \square \quad \square \quad \square \quad \square \quad \square \quad \square \quad \square \quad \square \quad \square$

14. $\square \quad \square \quad \square \quad \square \quad \square \quad b \quad \square \quad \square \quad r \quad \square \quad \square \quad \square$

15. $\square \quad \square \quad \square \quad \square \quad \square \quad b \quad \square \quad \square \quad \square \quad r \quad \square \quad \square \quad \square$ 


\section{APPENDIX E}

\section{ANALYSIS OF MEANS OF PANEL RATED PHOTOGRAPHS}

\begin{tabular}{|c|c|c|c|c|c|c|c|c|}
\hline Photo & $\begin{array}{l}\text { Panelist } \\
1\end{array}$ & $\begin{array}{l}\text { Panelist } \\
2\end{array}$ & $\begin{array}{l}\text { Panelist } \\
3\end{array}$ & $\begin{array}{l}\text { Panelist } \\
4\end{array}$ & $\begin{array}{l}\text { Panelist } \\
5\end{array}$ & $\begin{array}{l}\text { Std. } \\
\text { Dev. }\end{array}$ & Average & \\
\hline 1 & -4 & -3 & -3 & -4 & -4 & 0.489898 & -3.6 & \\
\hline 2 & -4 & -5 & -4 & -5 & -5 & 0.489898 & -4.6 & t3 \\
\hline 3 & -4 & 5 & 4 & -4 & -3 & 4.029888 & -0.4 & \\
\hline 4 & 3 & 3 & 4 & 5 & 3 & 0.8 & 3.6 & \\
\hline 5 & -5 & -1 & 0 & -4 & -3 & 1.854724 & -2.6 & \\
\hline 6 & -3 & -2 & -2 & -4 & -4 & 0.894427 & -3 & \\
\hline 7 & 5 & 3 & 4 & 5 & 4 & 0.748331 & 4.2 & \\
\hline 8 & 0 & 3 & 0 & -3 & 1 & 1.939072 & 0.2 & \\
\hline 9 & 5 & 4 & 5 & 5 & 3 & 0.8 & 4.4 & $\mathrm{~m} 3$ \\
\hline 10 & -1 & -2 & -2 & -4 & -4 & 1.2 & -2.6 & \\
\hline 11 & 5 & 5 & 3 & 4 & 5 & 0.8 & 4.4 & $\mathrm{~m} 2$ \\
\hline 12 & -4 & -4 & -3 & -5 & -5 & 0.748331 & -4.2 & \\
\hline 13 & 1 & 3 & 4 & 5 & 5 & 1.496663 & 3.6 & \\
\hline 14 & -5 & -1 & -4 & -5 & -4 & 1.469694 & -3.8 & \\
\hline 15 & -5 & -4 & -5 & -5 & -5 & 0.4 & -4.8 & t1 \\
\hline 16 & -5 & -5 & -3 & -5 & -5 & 0.8 & -4.6 & $\mathrm{t} 2$ \\
\hline 17 & 1 & 2 & -1 & 3 & 4 & 1.720465 & 1.8 & \\
\hline 18 & -5 & -3 & -1 & -5 & -5 & 1.6 & -3.8 & \\
\hline 19 & 5 & 5 & 4 & 5 & 4 & 0.489898 & 4.6 & $\mathrm{~m} 1$ \\
\hline 20 & 5 & 3 & 0 & 3 & 5 & 1.83303 & 3.2 & \\
\hline 21 & -5 & -5 & -5 & -5 & -5 & 0 & -5 & $t 1$ \\
\hline 22 & 3 & 1 & 4 & 4 & 5 & 1.356466 & 3.4 & \\
\hline 23 & 5 & 4 & 3 & -1 & 5 & 2.227106 & 3.2 & \\
\hline 24 & 5 & 4 & 2 & 3 & 4 & 1.019804 & 3.6 & $\mathrm{~m} 3$ \\
\hline 25 & 2 & 3 & 2 & 5 & 3 & 1.095445 & 3 & \\
\hline 26 & 3 & 1 & 5 & 5 & 0 & 2.039608 & 2.8 & \\
\hline 27 & -5 & -1 & -2 & -2 & -2 & 1.356466 & -2.4 & \\
\hline 28 & -5 & -3 & -4 & -4 & -3 & 0.748331 & -3.8 & \\
\hline 29 & 3 & 2 & 4 & 4 & 5 & 1.019804 & 3.6 & $\mathrm{~m} 4$ \\
\hline 30 & 5 & 4 & 4 & 4 & 5 & 0.489898 & 4.4 & $\mathrm{~m} 1$ \\
\hline 31 & -5 & -5 & -4 & -5 & -5 & 0.4 & .4 .8 & +3 \\
\hline 32 & 3 & 2 & 4 & 5 & 5 & 1.16619 & 3.8 & $\mathrm{~m} 2$ \\
\hline 33 & 5 & 3 & 3 & 0 & 1 & 1.74356 & 2.4 & \\
\hline 34 & -4 & -2 & -3 & -3 & -2 & 0.748331 & -2.8 & \\
\hline 35 & -4 & -4 & -3 & -3 & -3 & 0.489898 & -3.4 & \\
\hline
\end{tabular}




$\begin{array}{lcccccrcc}\mathbf{3 6} & -3 & 2 & 1 & 3 & 4 & 2.416609 & 1.4 & \\ \mathbf{3 7} & 3 & 4 & 2 & 0 & 3 & 1.356466 & 2.4 & \\ \mathbf{3 8} & -5 & -1 & 3 & -3 & 1 & 2.828427 & -1 & \\ \mathbf{3 9} & -5 & -5 & -5 & -5 & -5 & 0 & -5 & \mathrm{t} 2 \\ & & & & & & & & \\ \mathbf{4 0} & -5 & -5 & -4 & -4 & -4 & 0.489898 & -4.4 & \\ \mathbf{4 1} & -5 & -4 & -4 & -4 & -5 & 0.489898 & -4.4 & \mathrm{t} 2 \\ \mathbf{4 2} & -5 & -3 & -4 & -4 & -4 & 0.632456 & -4 & \mathrm{t} 3 \\ \mathbf{4 3} & 5 & 5 & 4 & 5 & 5 & 0.4 & 4.8 & \mathrm{~m} 2 \\ & & & & & & & & \\ \mathbf{4 4} & -5 & -2 & -4 & -4 & -3 & 1.019804 & -3.6 & \\ \mathbf{4 5} & 3 & 2 & 0 & -1 & 1 & 1.414214 & 1 & \\ \mathbf{4 6} & 5 & 5 & 4 & 5 & 3 & 0.8 & 4.4 & \mathrm{~m} 3 \\ \mathbf{4 7} & -5 & -3 & -1 & -4 & -4 & 1.356466 & -3.4 & \\ \mathbf{4 8} & -5 & 1 & 2 & 4 & -3 & 3.310589 & -0.2 & \\ \mathbf{4 9} & 3 & -2 & -1 & -1 & 2 & 1.939072 & 0.2 & \\ \mathbf{5 0} & -1 & 1 & 0 & 1 & 5 & 2.039608 & 1.2 & \\ \mathbf{5 1} & -5 & -2 & 0 & 0 & 0 & 1.959592 & -1.4 & \\ \mathbf{5 2} & 3 & 2 & 1 & -1 & 3 & 1.496663 & 1.6 & \\ \mathbf{5 3} & -5 & -2 & -1 & 2 & 0 & 2.315167 & -1.2 & \\ \mathbf{5 4} & -5 & -3 & -1 & -4 & -3 & 1.32665 & -3.2 & \\ \mathbf{5 5} & 2 & 3 & 1 & 1 & 3 & 0.894427 & 2 & \\ \mathbf{5 6} & 5 & 5 & 4 & 4 & 4 & 0.489898 & 4.4 & \mathrm{~m} 3 \\ \mathbf{5 7} & 5 & 5 & 4 & 4 & 4 & 0.489898 & 4.4 & \mathrm{~m} 3 \\ \mathbf{5 8} & -4 & 4 & -3 & -3 & -2 & 2.87054 & -1.6 & \\ \mathbf{5 9} & -5 & -4 & -5 & -5 & -5 & 0.4 & -4.8 & \mathrm{t} 1 \\ \mathbf{6 0} & 5 & 5 & 5 & 5 & 5 & 0 & 5 & \mathrm{~m} 1\end{array}$




\section{APPENDIX F \\ QUESTIONAIRE COVER LETTER}

March 24, 2003

«First_Name» «Last_Name»

«Address»

«City», «State» «Zip_Code»

Dear «First_Name»:

Thanks for agreeing to participate in this research project sponsored by Horizon Research International and the Platinum Panel. This is an important project and your feedback is critical to the overall success.

Enclosed you will find a booklet that contains several pictures of various neighborhoods from around the local community. It is your reaction to these pictures that we are interested in.

Please take the booklet and go to your computer. Login to the Web site listed below and enter your password to begin. The Web site will give you instructions once you login.

URL: http://www.horizonresearchint.com/surveys/ls5084

Password: «Priority_Code»

As a token of our appreciation for your participation, we have included a five-dollar bill with this mailing. This is yours to keep as long as you complete the survey. In addition, once you complete the survey, your name will be entered into one of two drawings for $\$ 450$. However, to be eligible for the drawing, you must complete the survey by Wednesday, April 9.

Thanks again for participating in this study. If you have any questions, please contact horizon@horizonresearchint.com.

Research Panel Director

Horizon Research International 
APPENDIX G

SURVEY IMAGES 


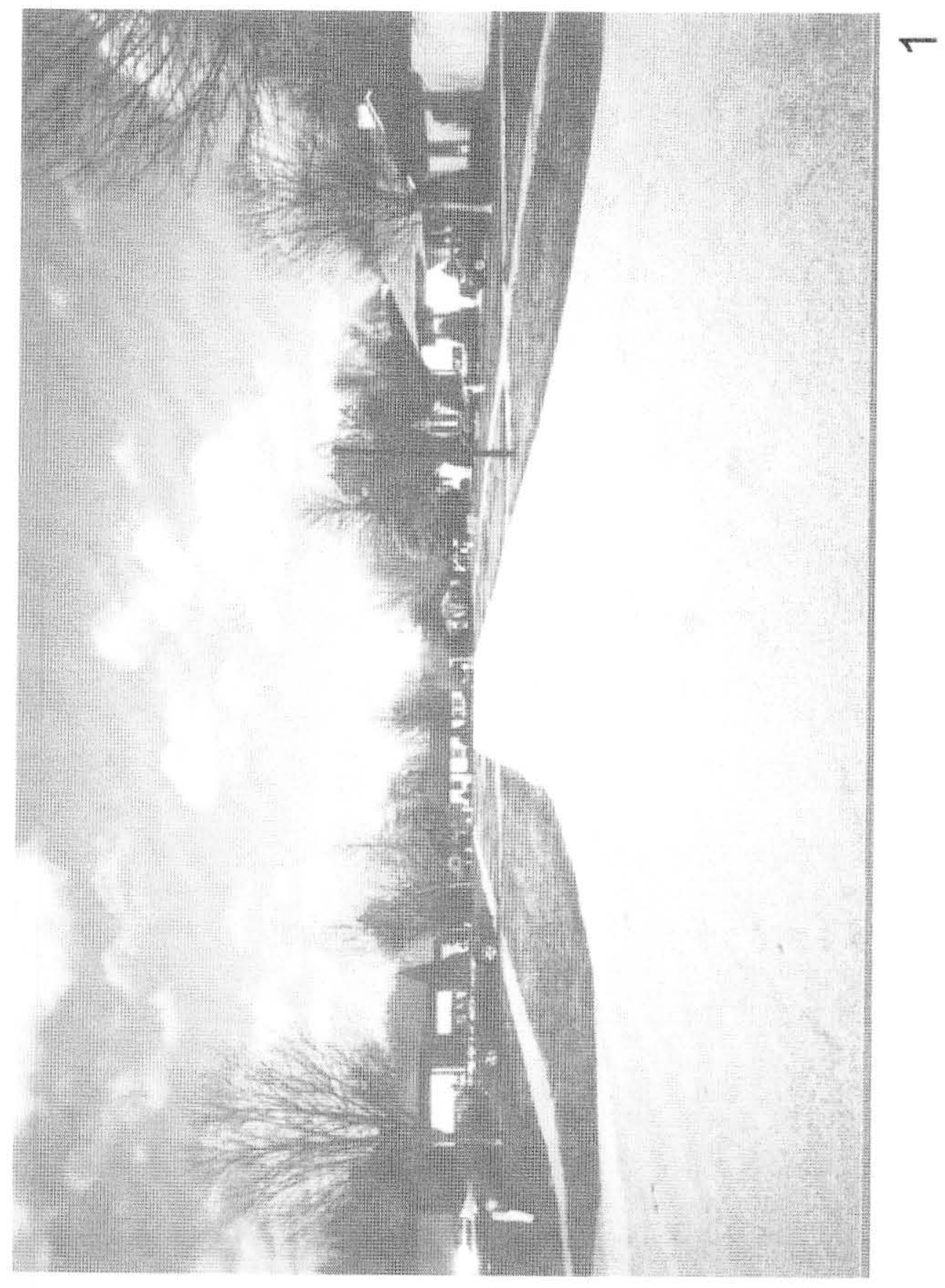




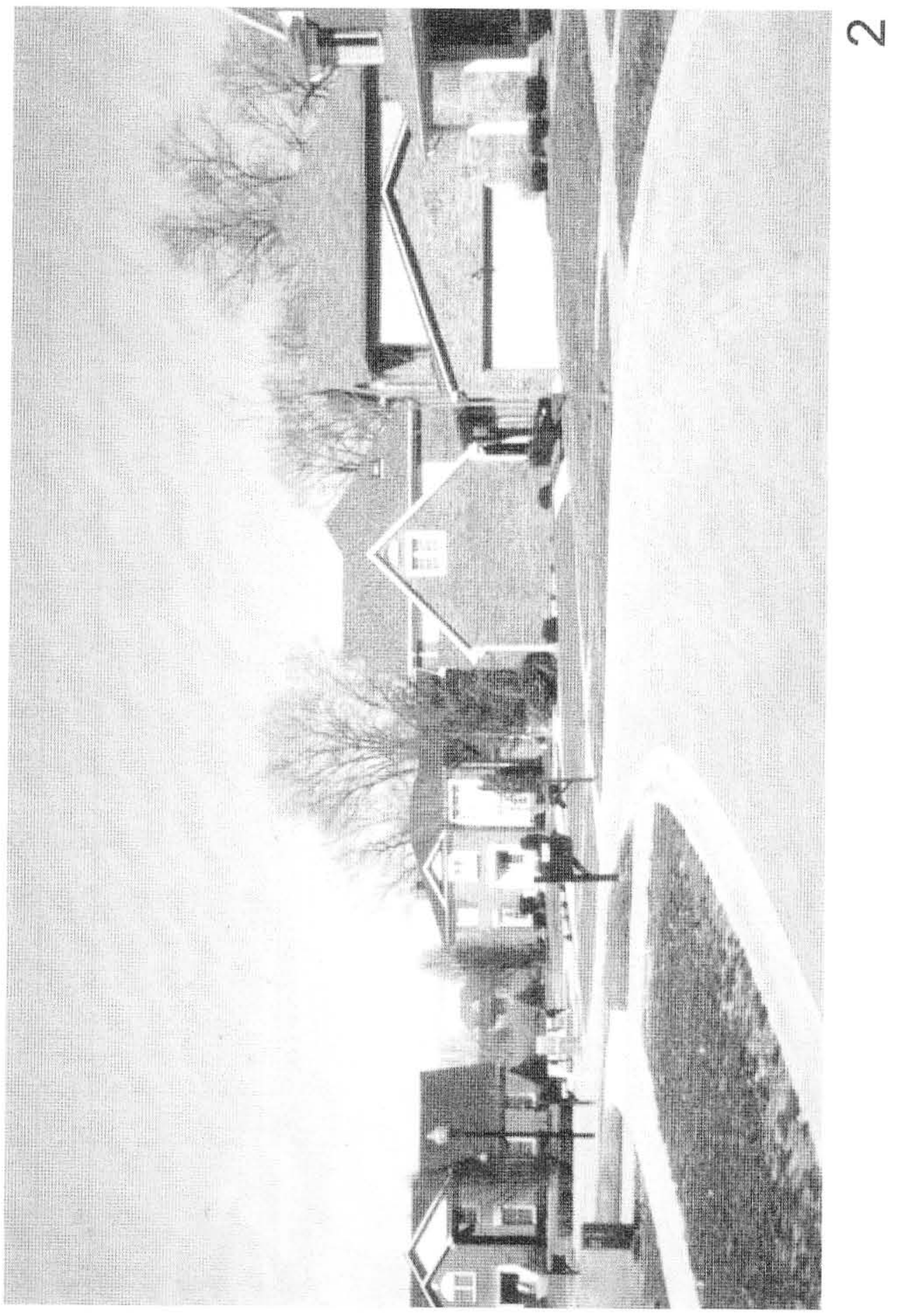




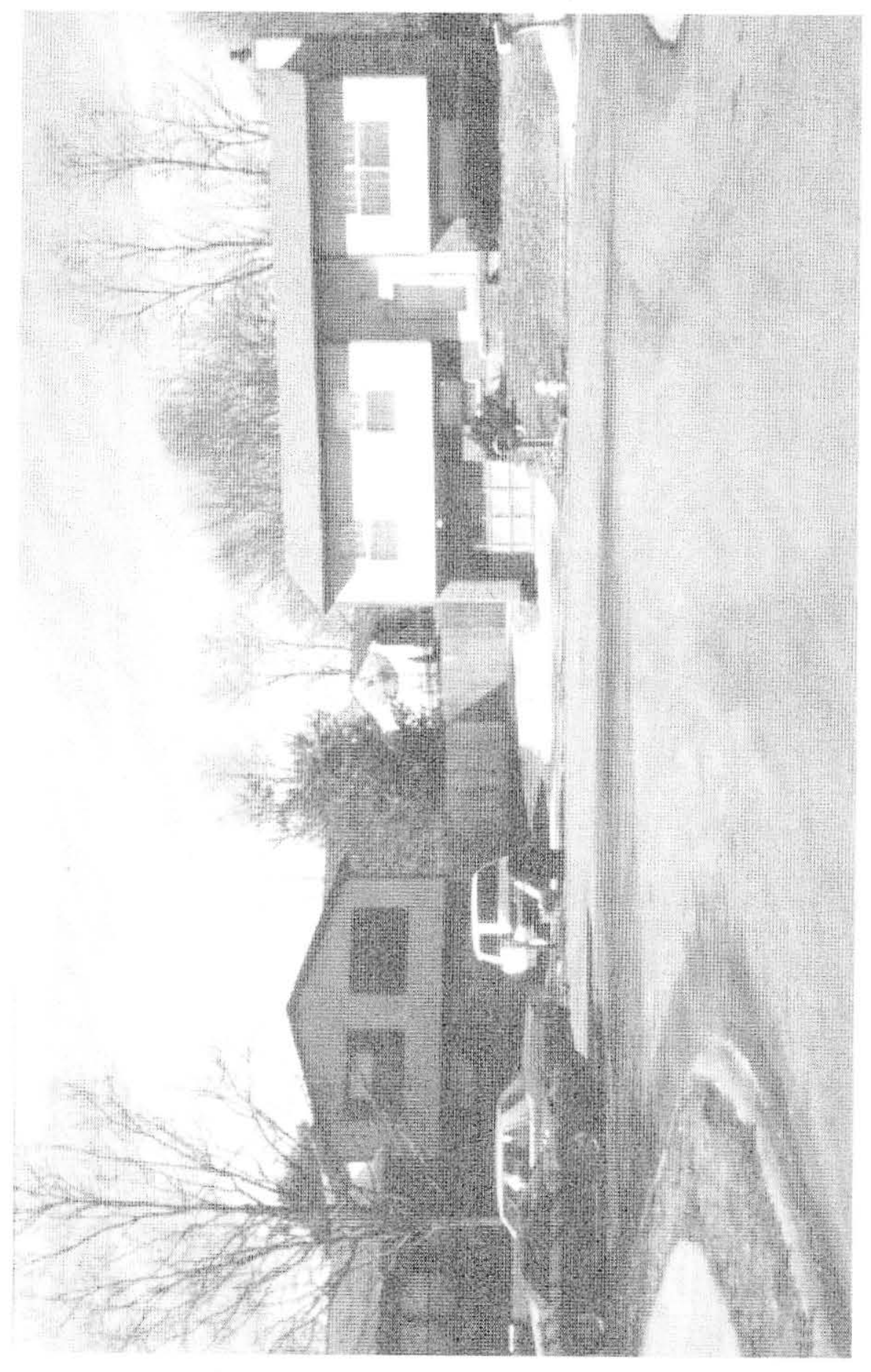

क) 


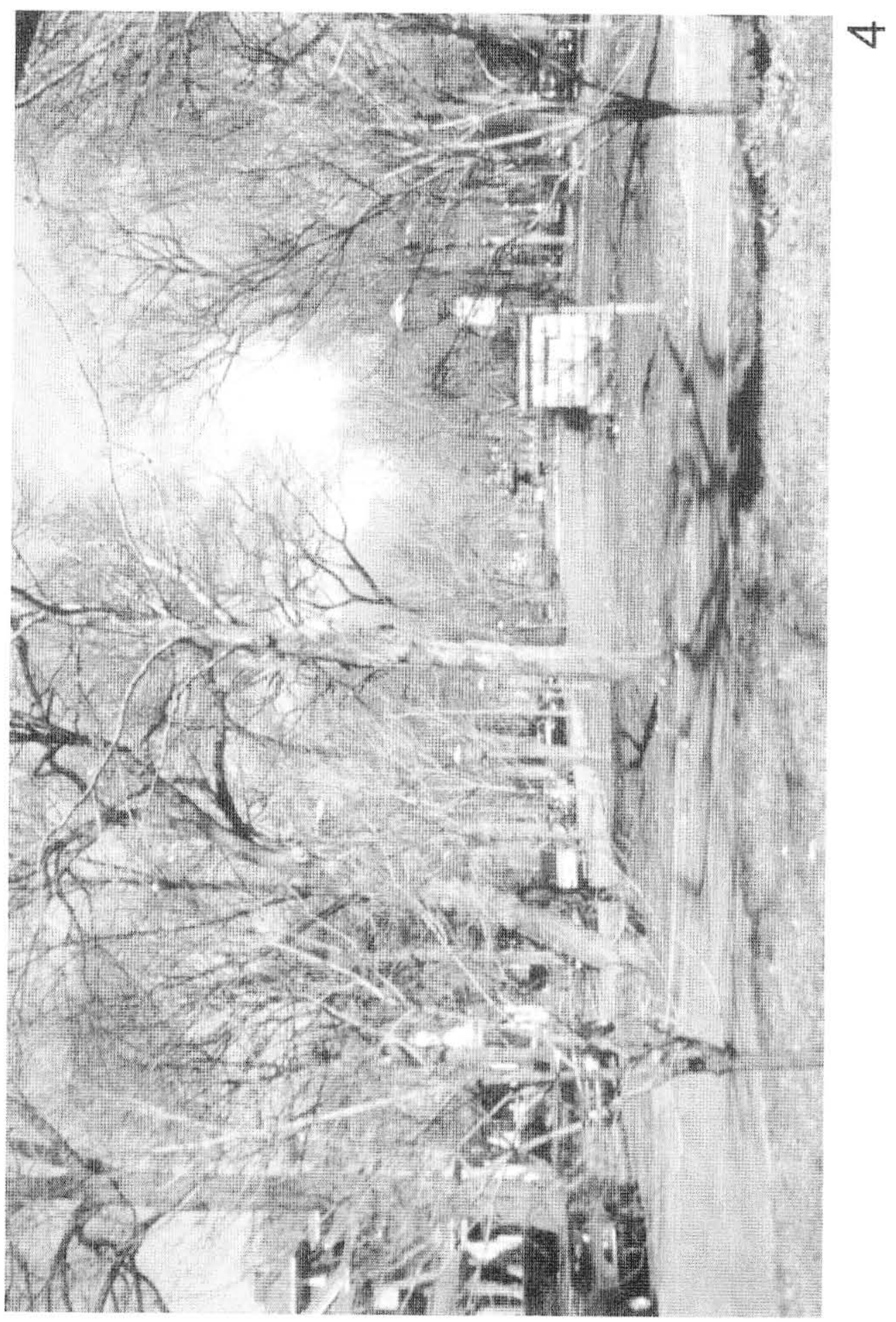




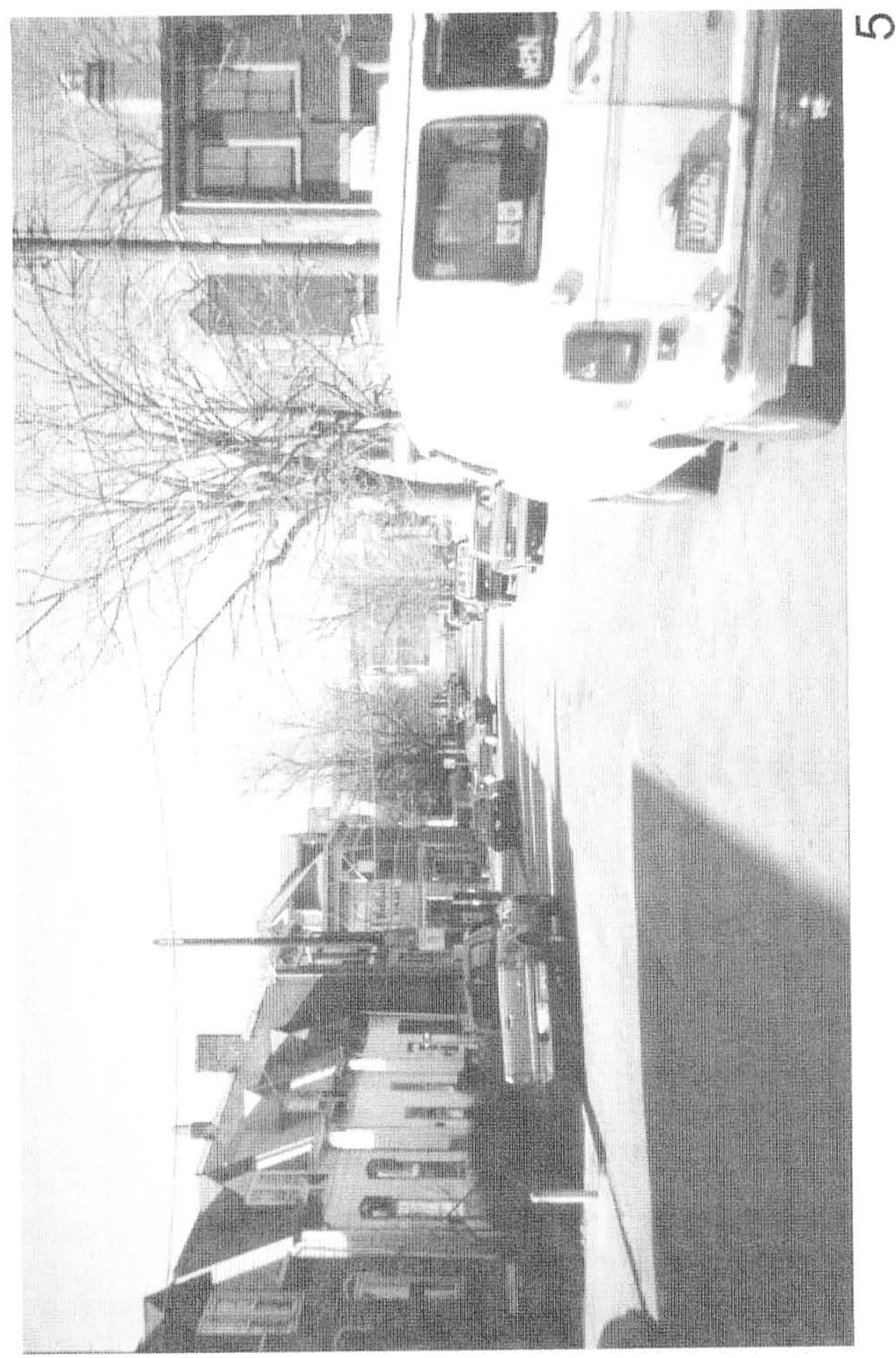




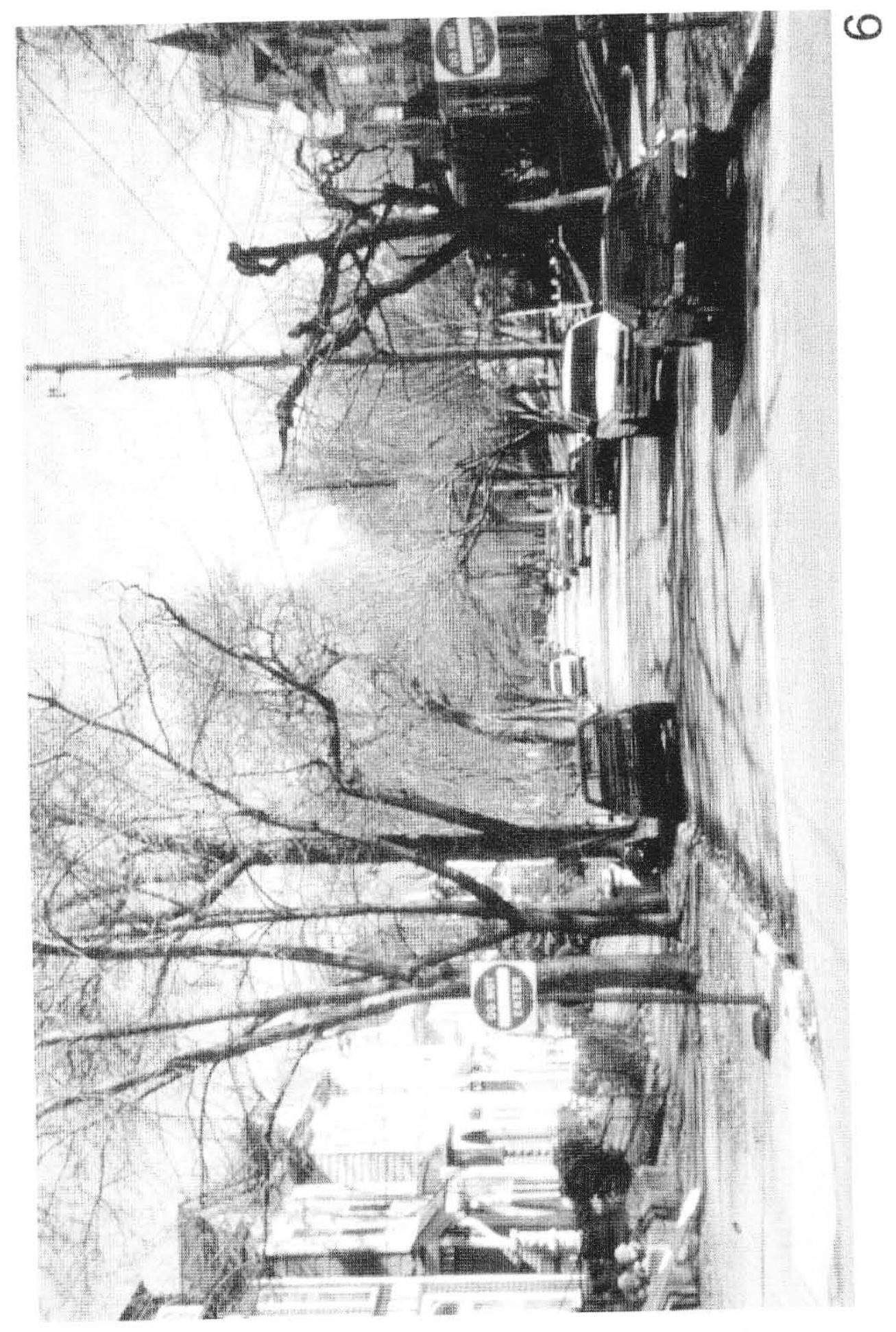




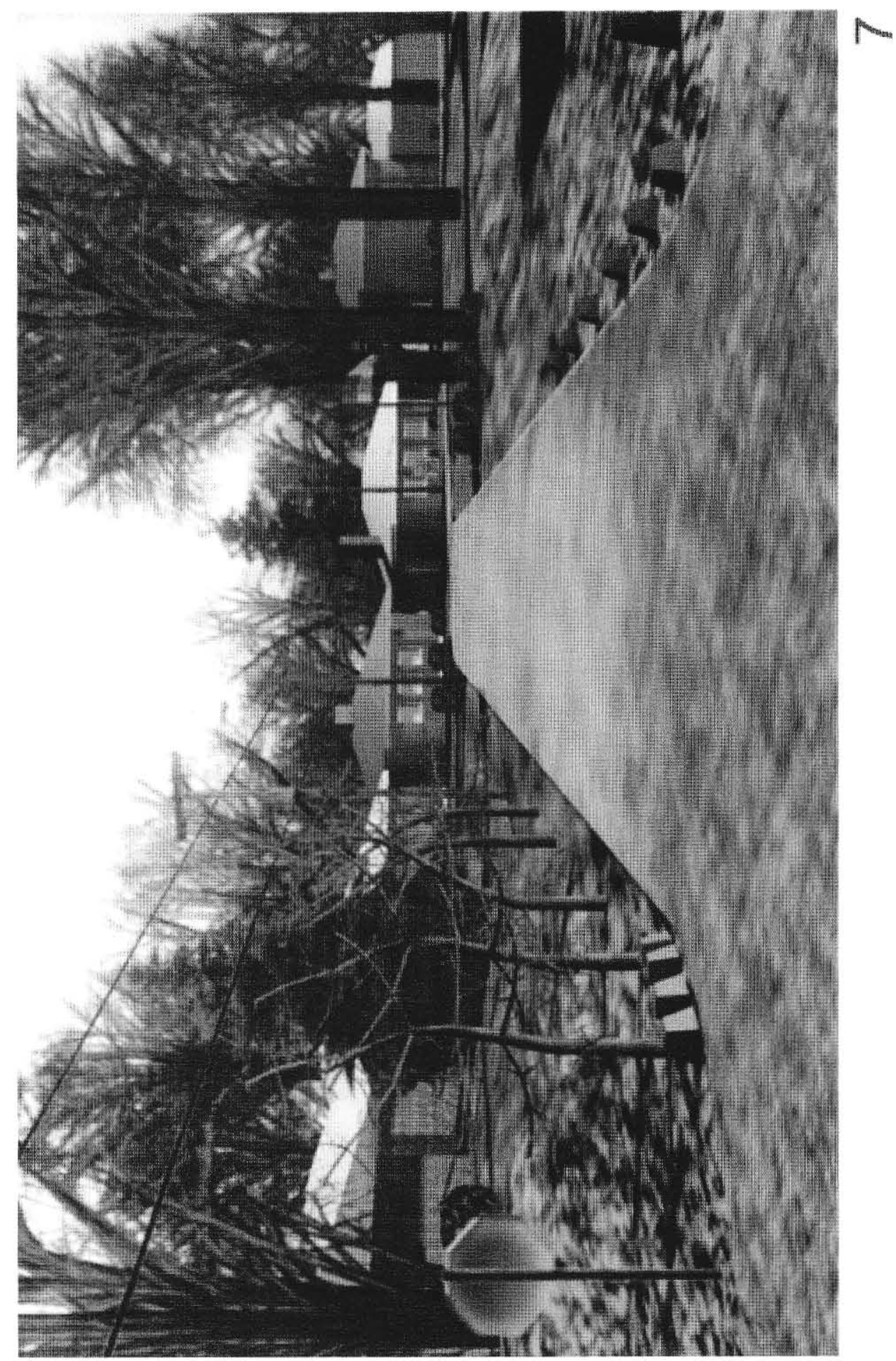




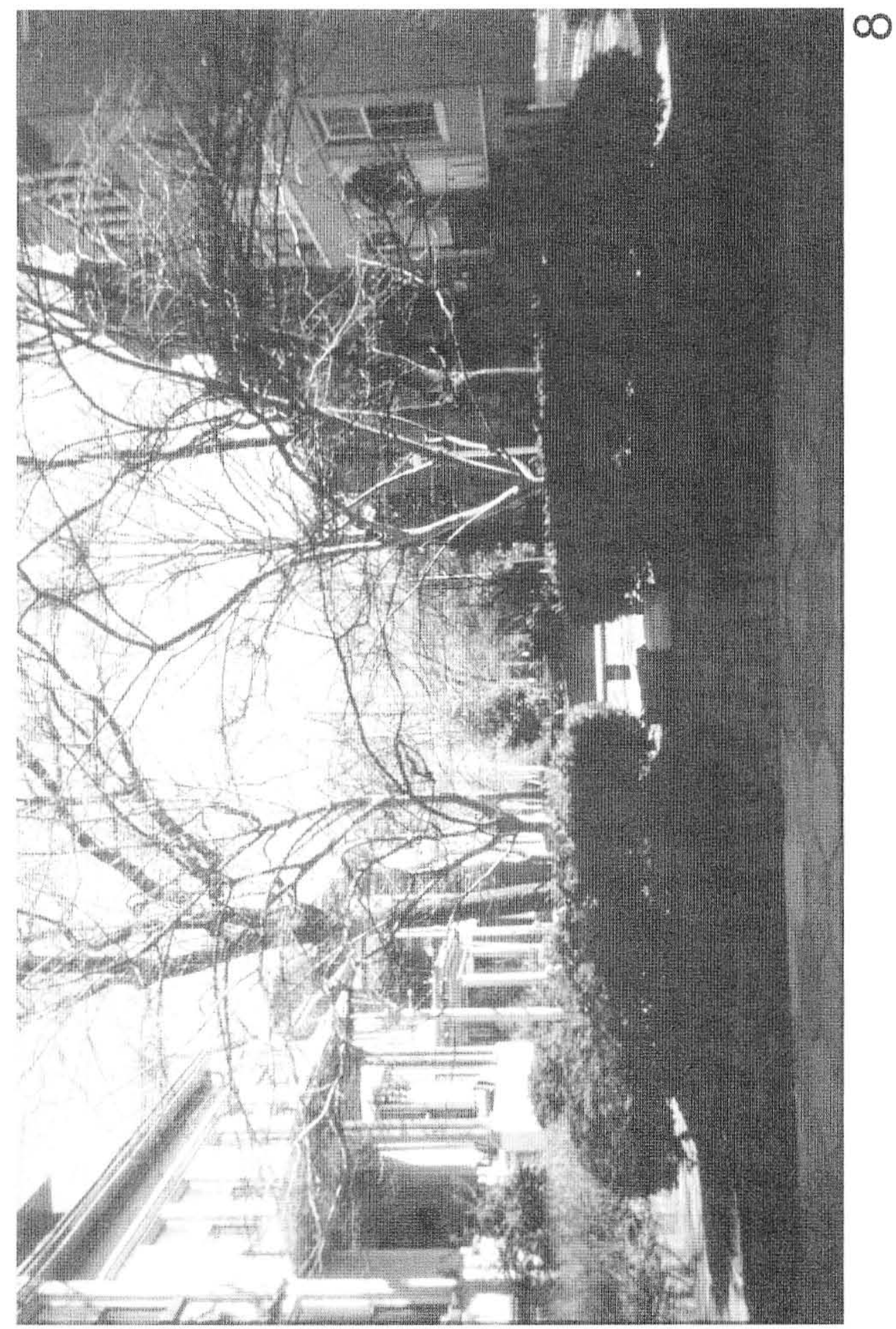




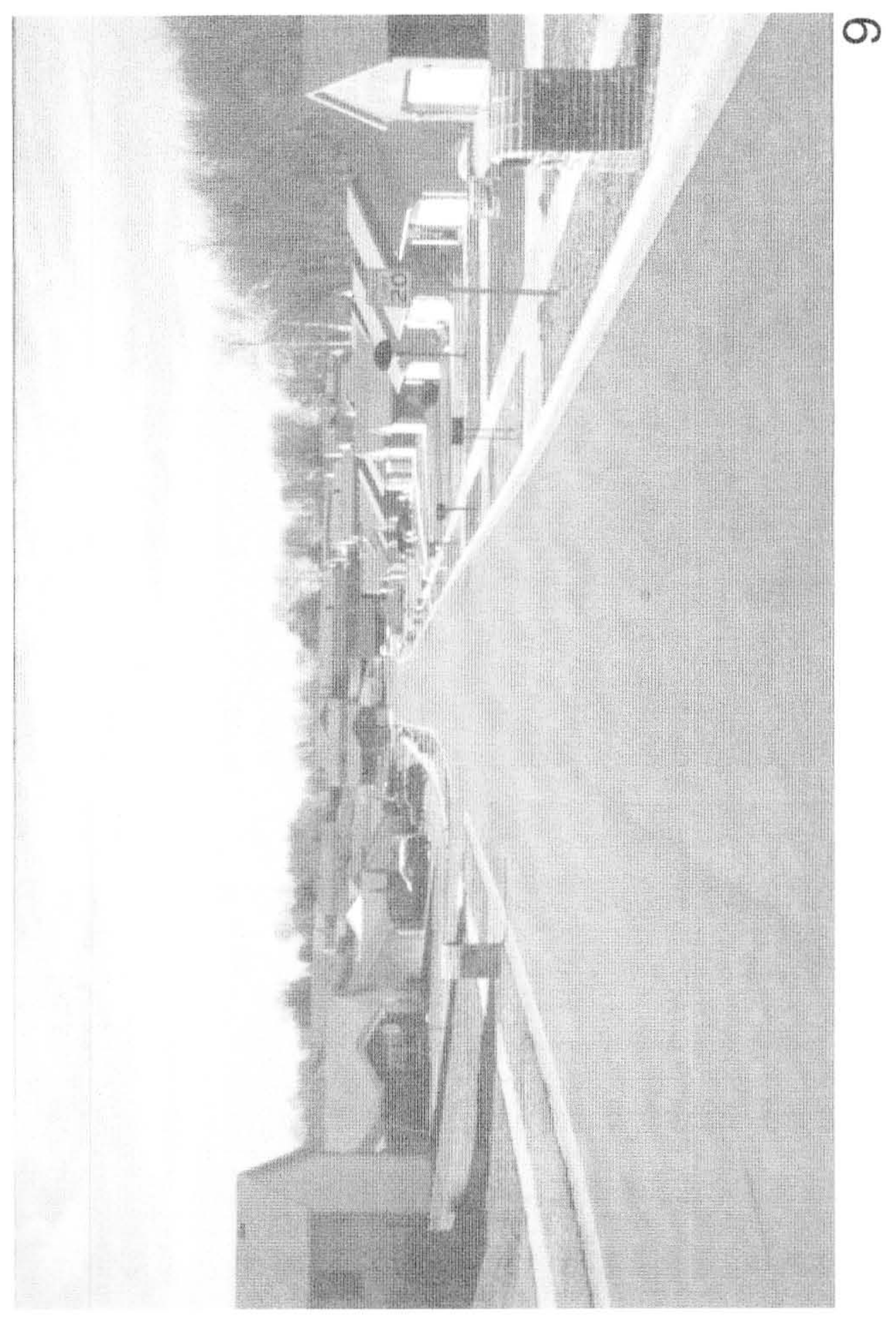




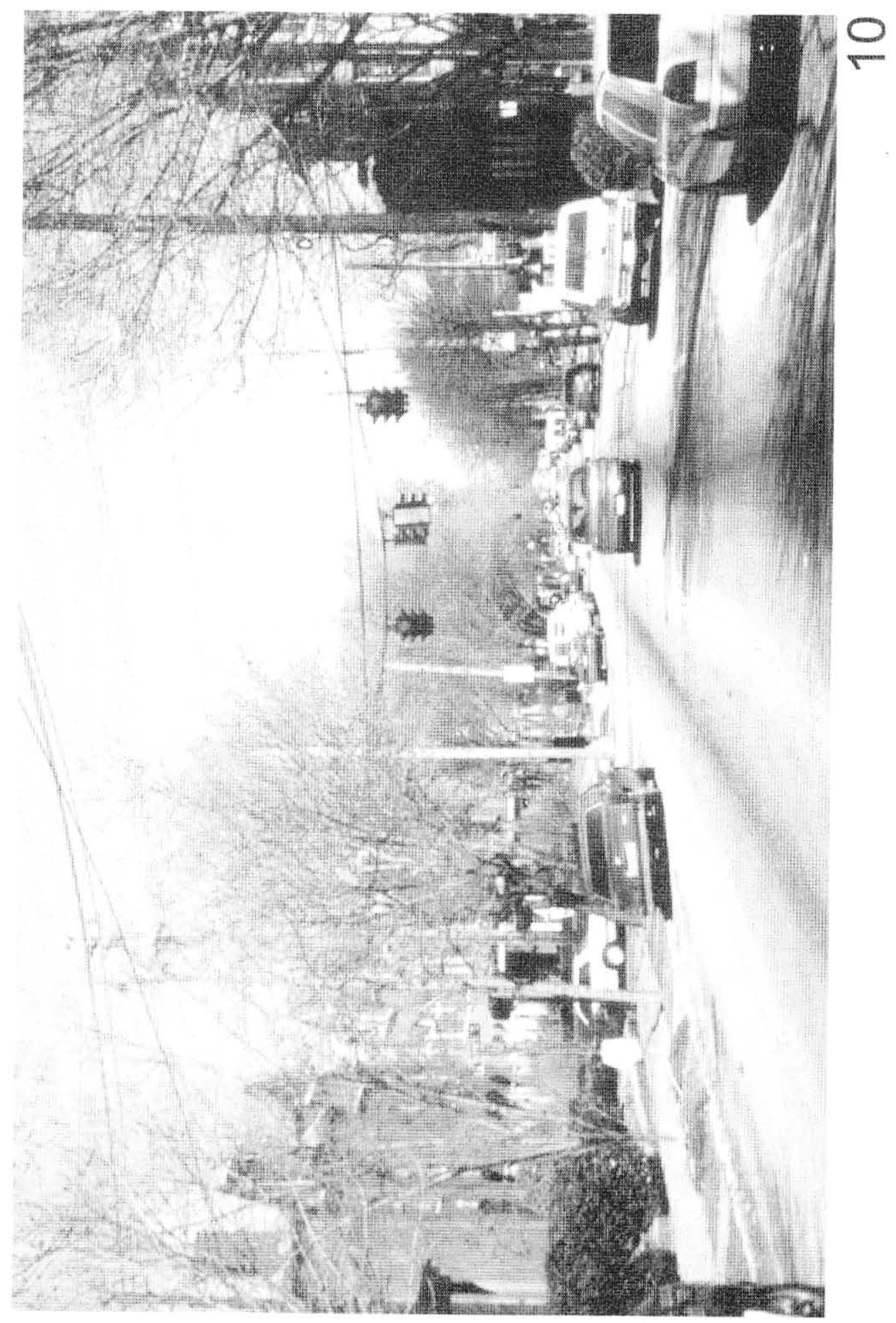




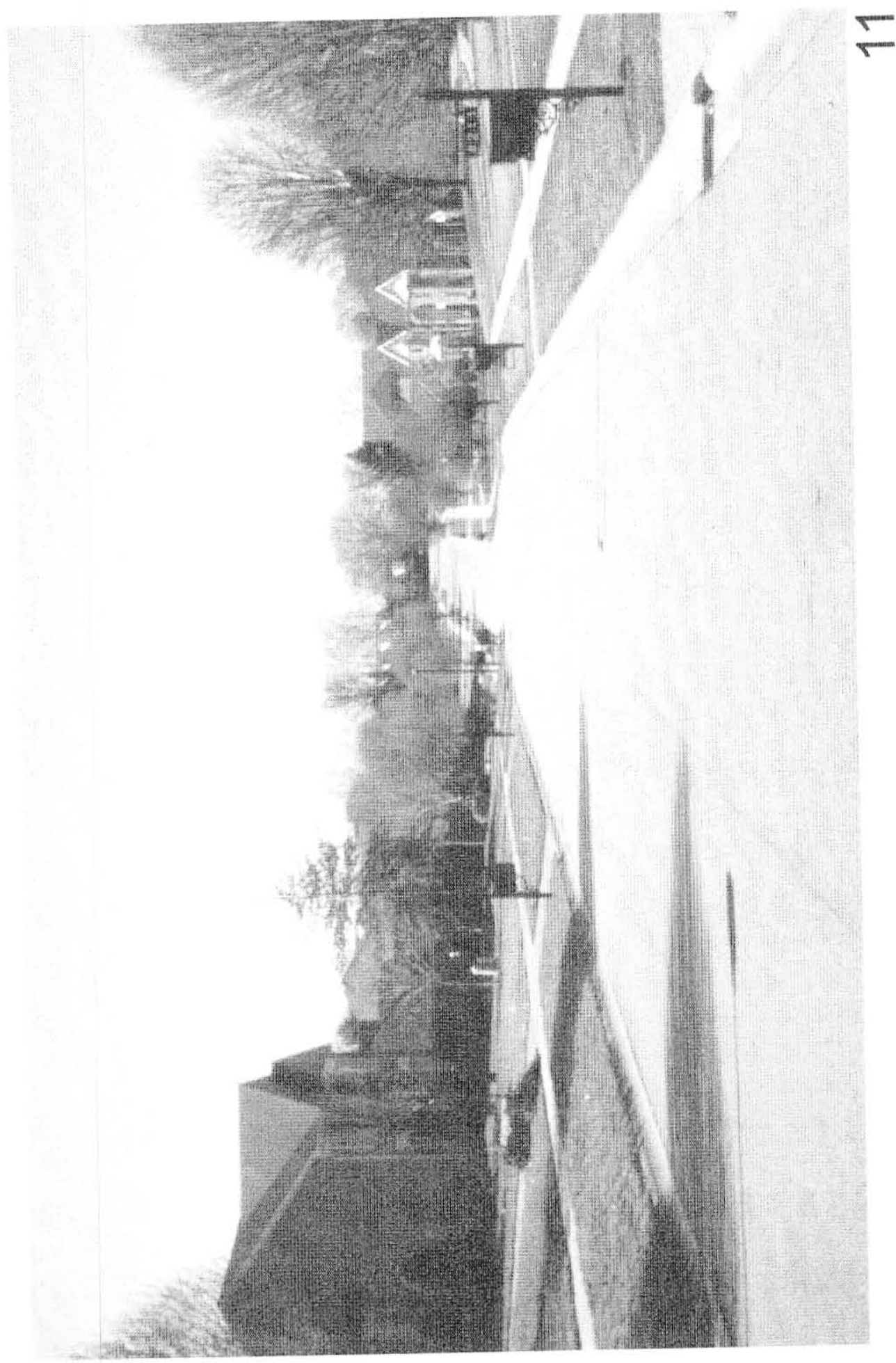




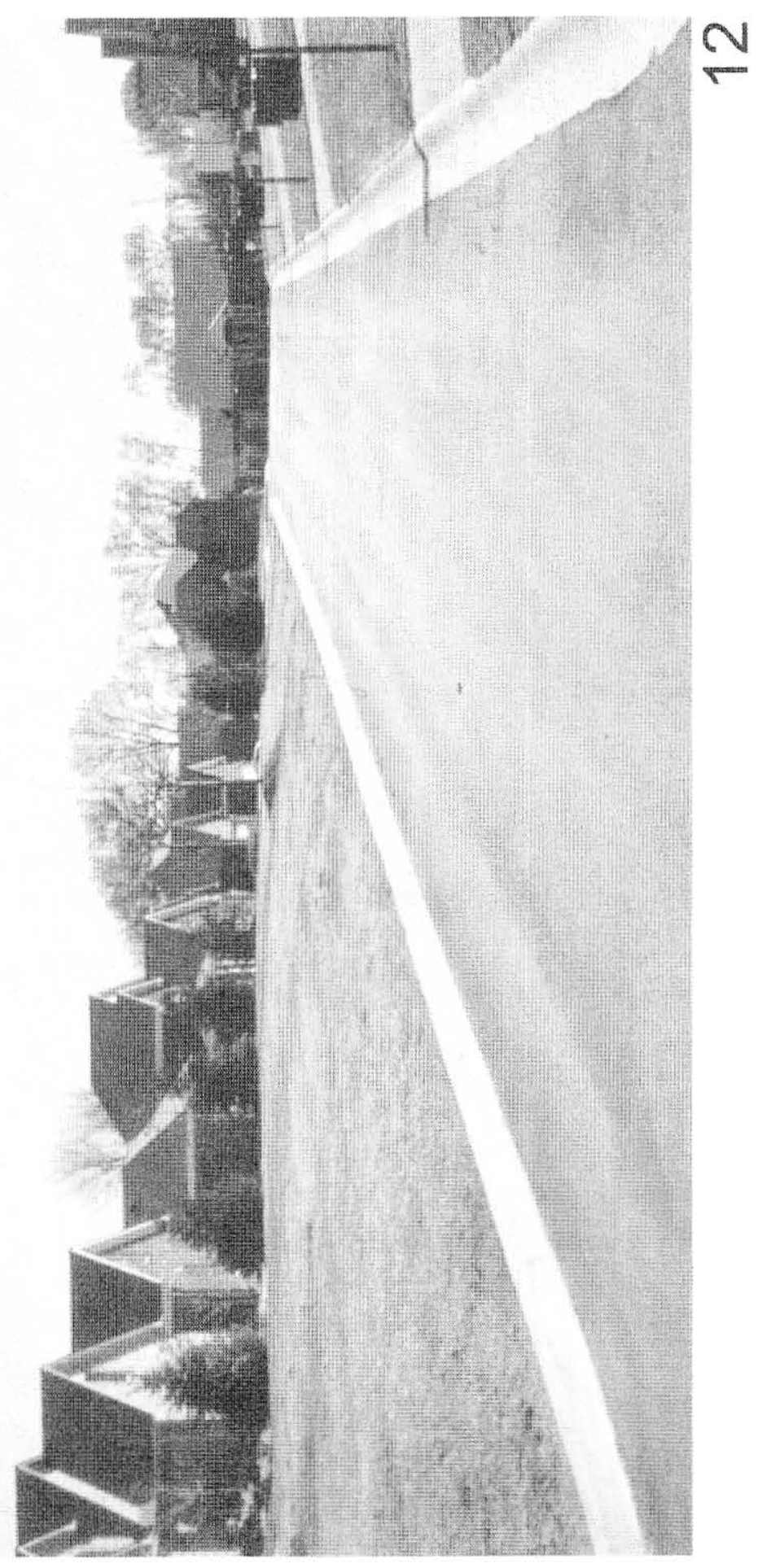




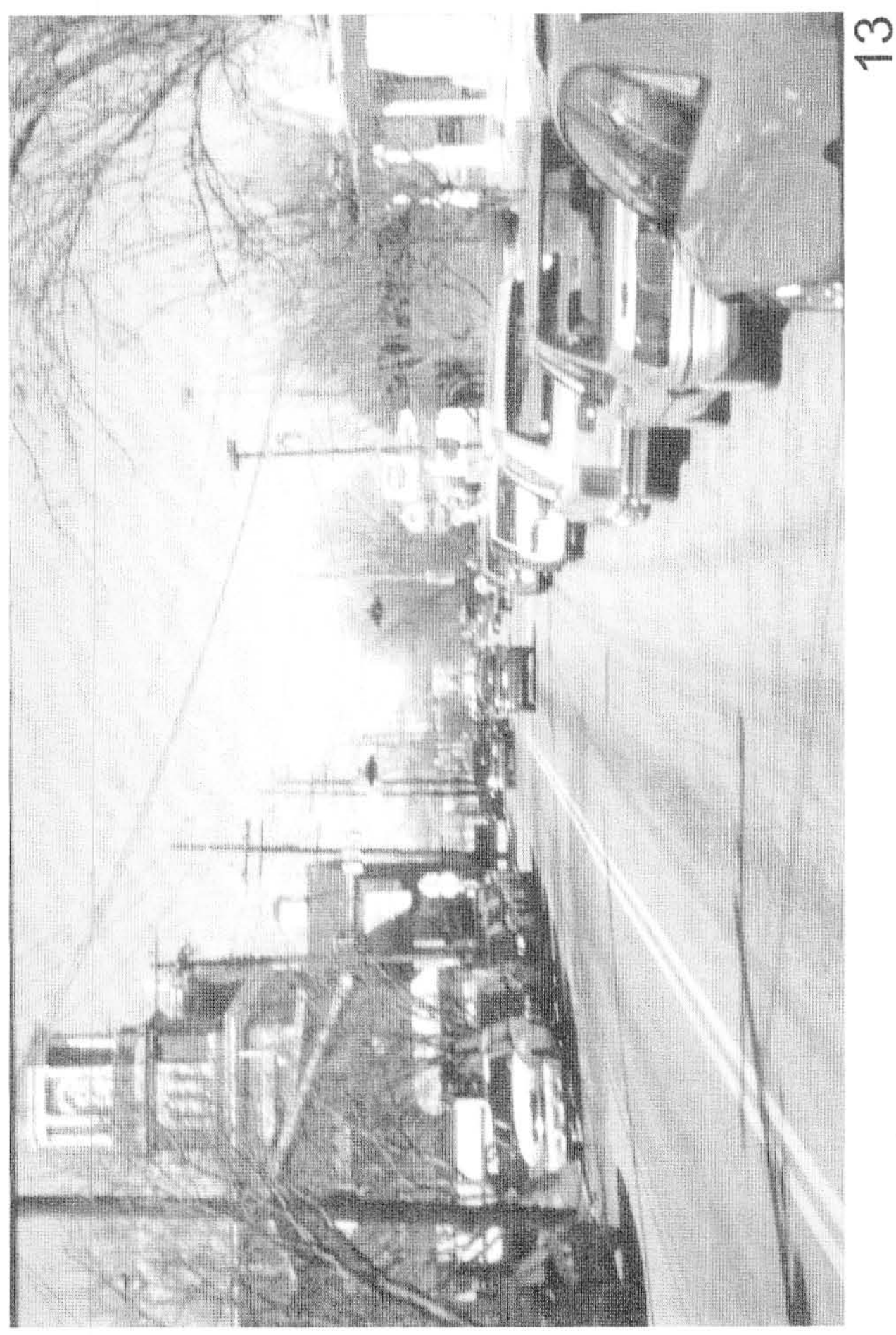




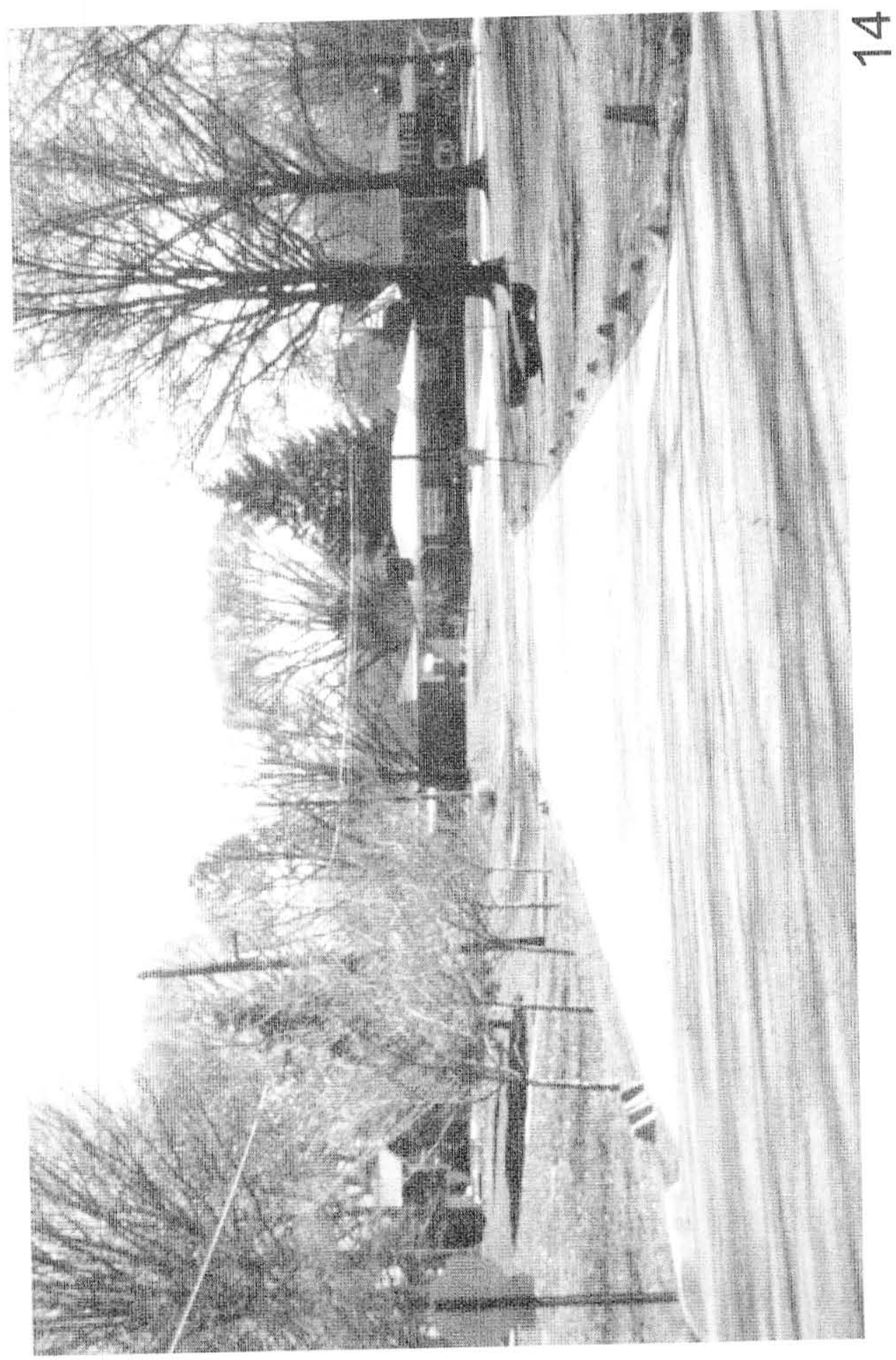




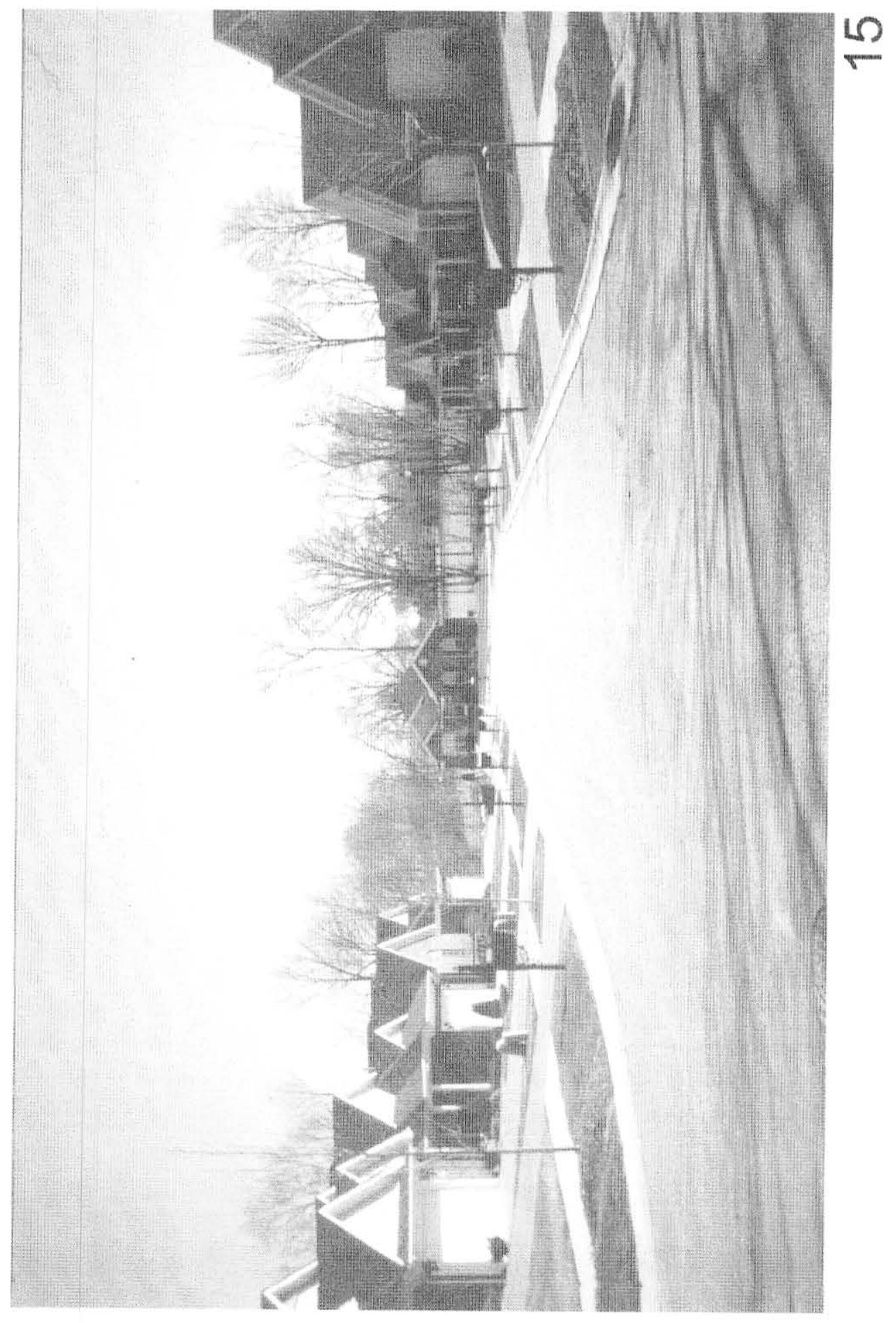




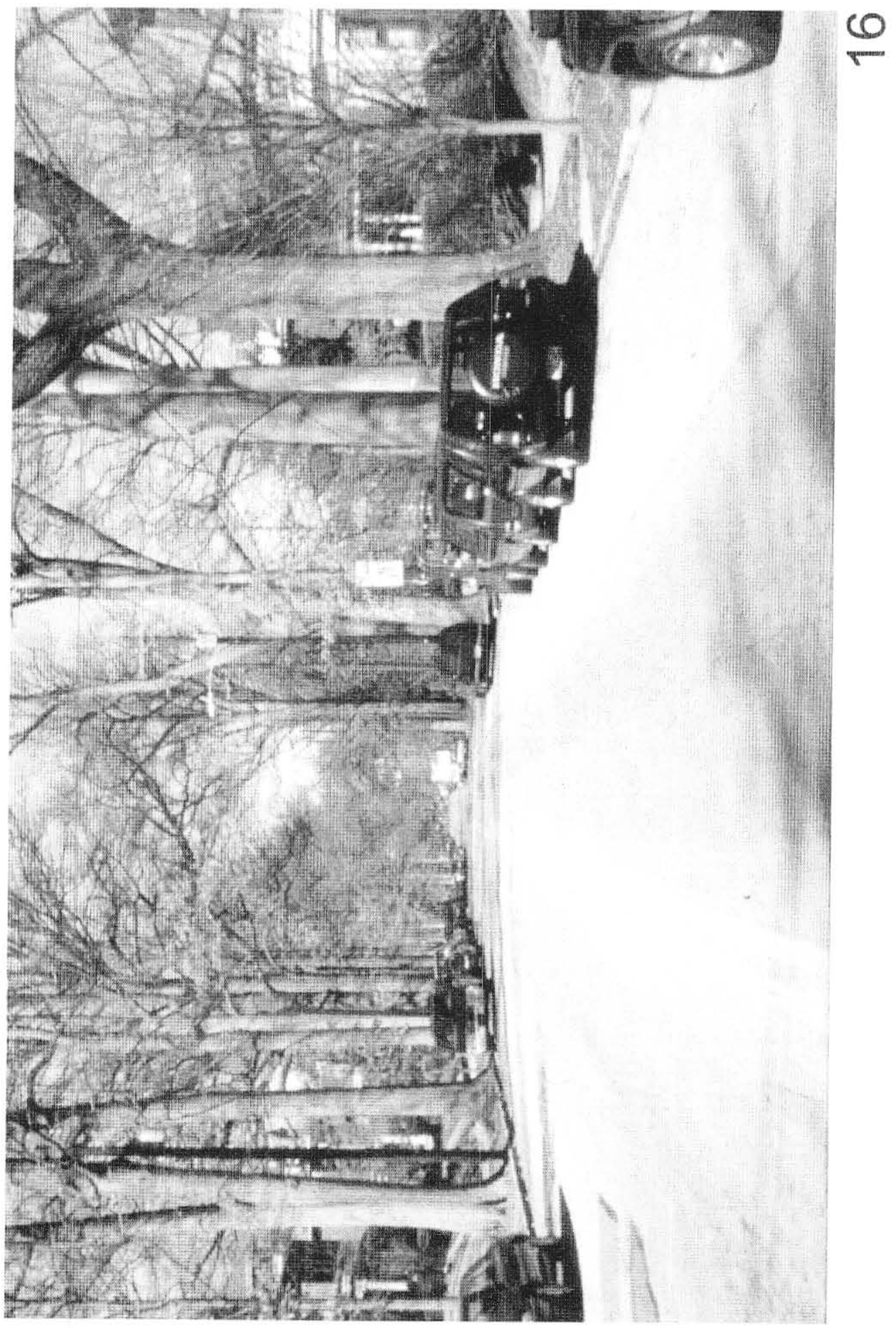




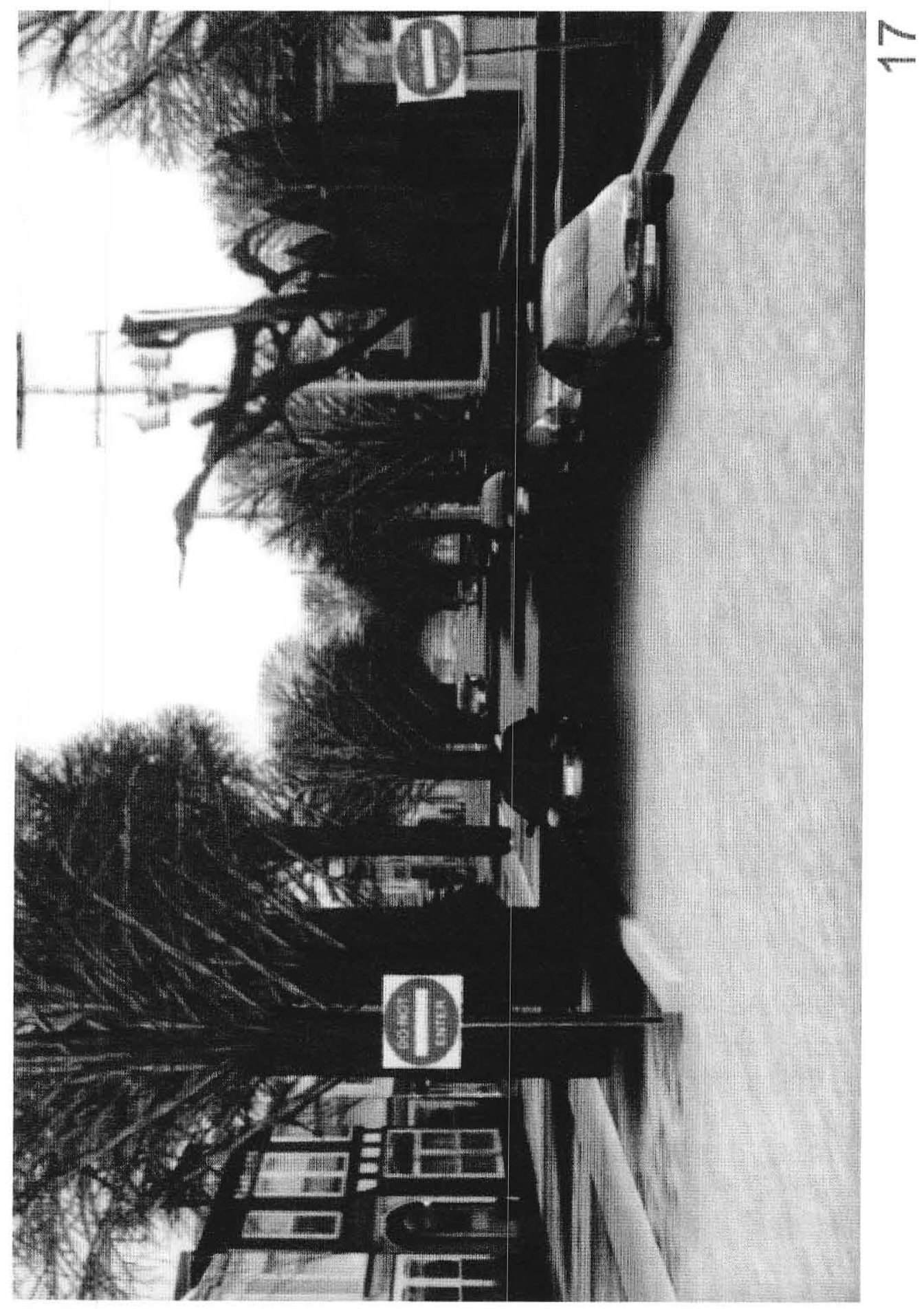




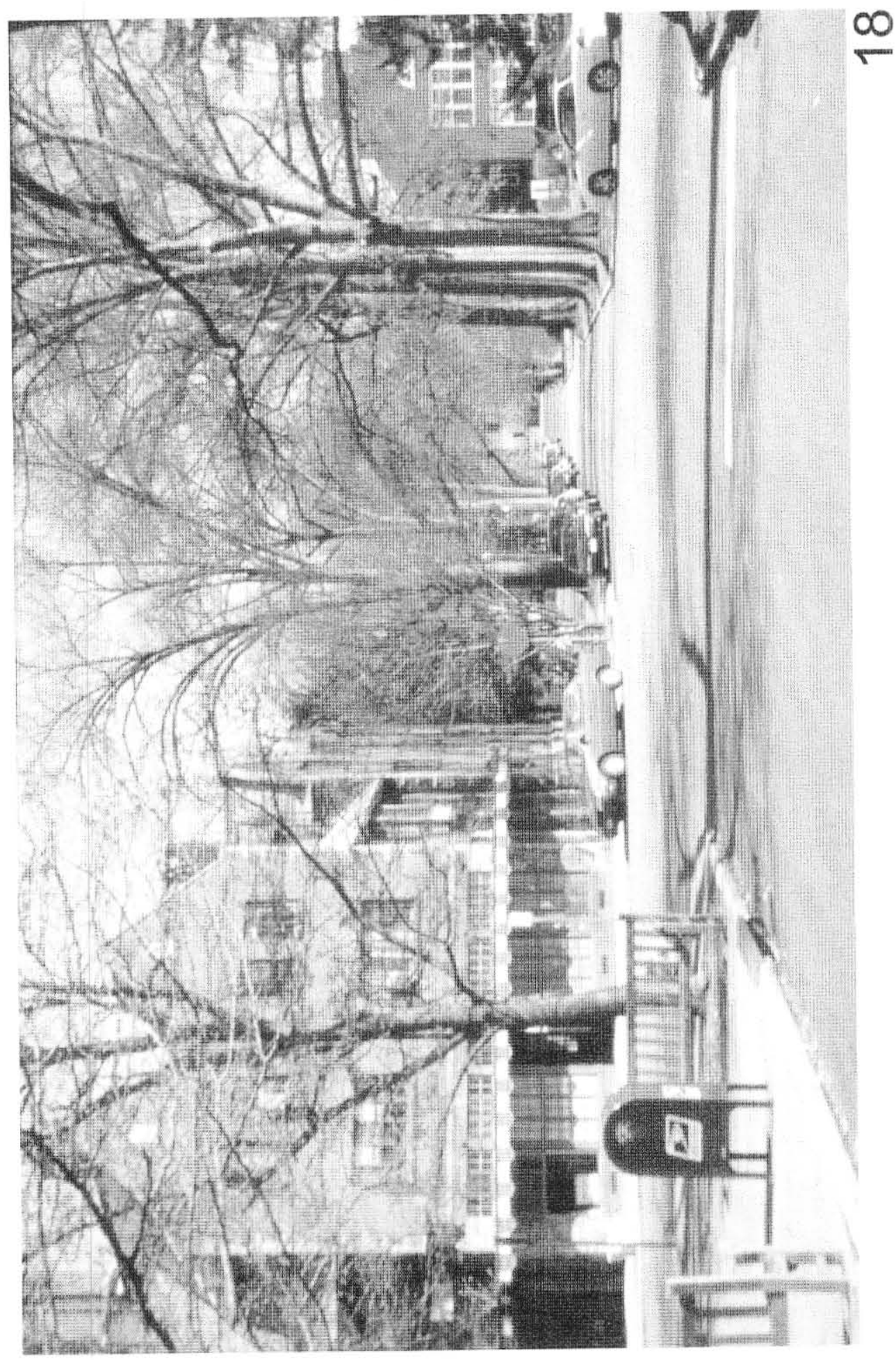




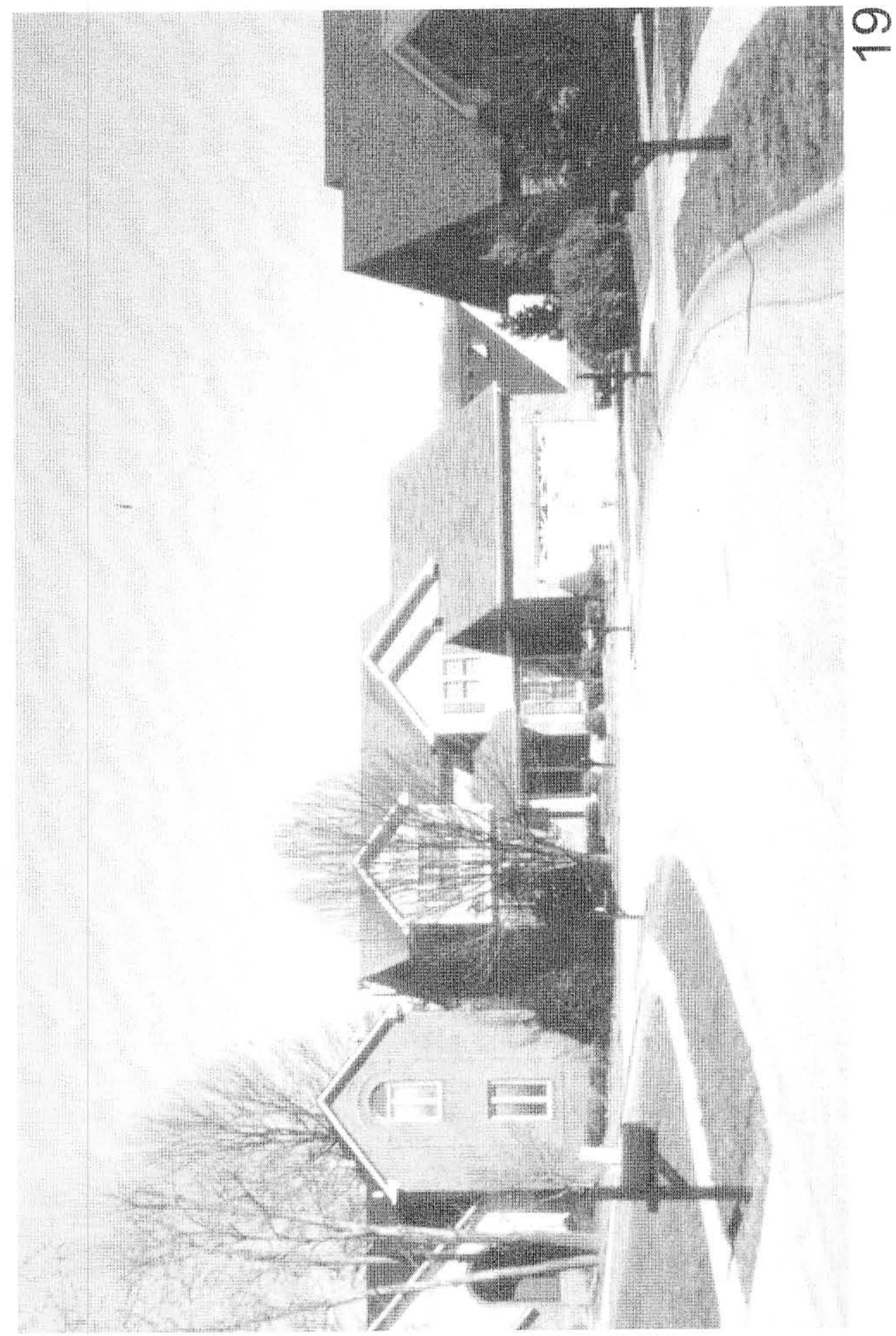




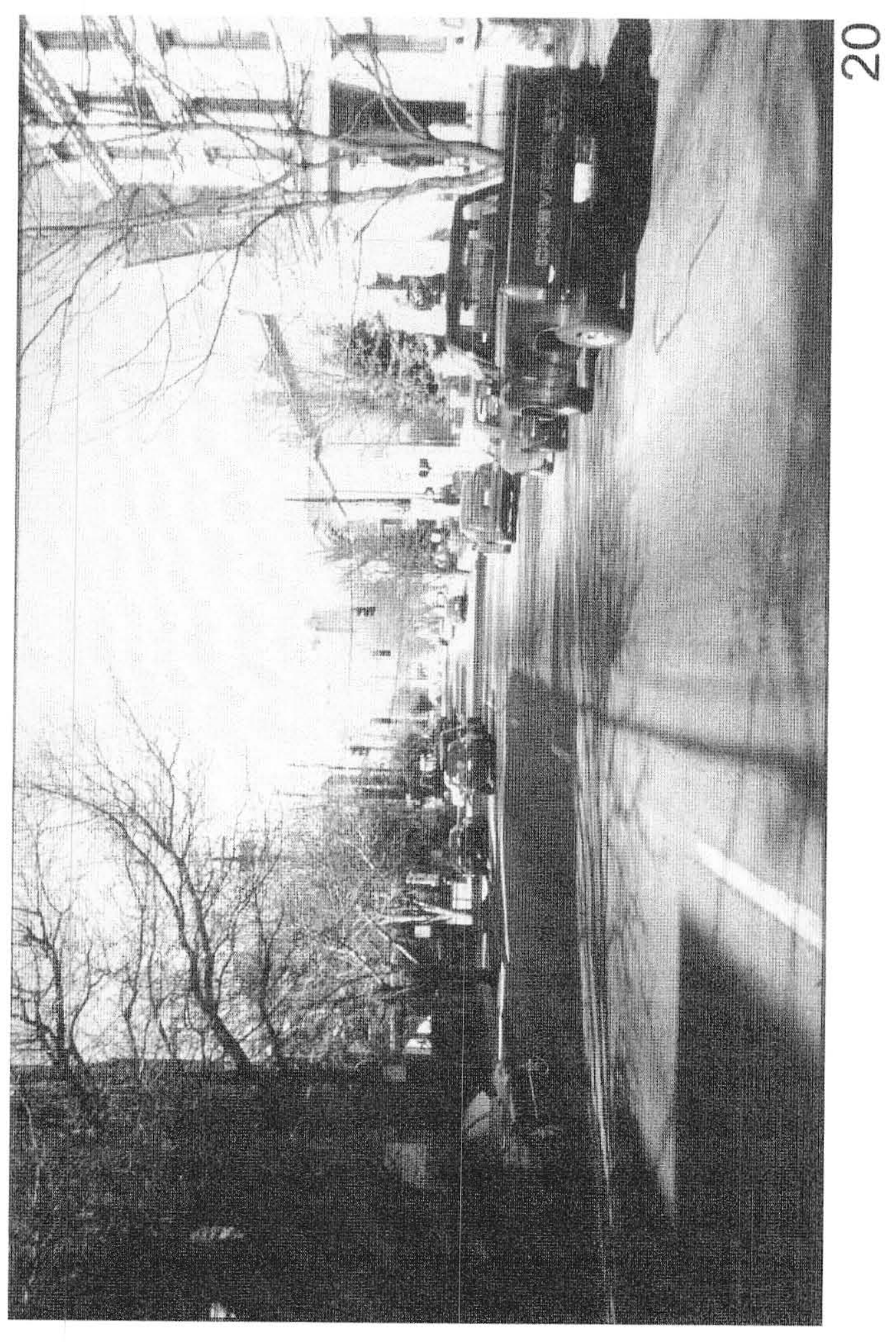


APPENDIX H

EXAMPLE QUESTIONAIRE

\section{VISUAL IMAGING STUDY \\ HORIZON RESEARCH INTERNATIONAL \\ LS5084 - DRAFT NO. 1}

\section{Intro}

Hello, and thank you for agreeing to participate in our survey. The survey should take about 20 minutes to complete. When you have finished taking the survey your name will be entered into one of five different drawings for $\$ 450$ each. To begin the survey, enter your password and click "Begin Interview." If you have any questions or experience any technical difficulties while completing the survey, please contact horizon@horizonresearchint.com.

1. Please turn to page [\#] of your booklet. Please take a moment to review the image that is on this page.

Overall, how appealing do you find the scene that is being displayed in this image?

Would you say ...?

Extremely appealing

Very appealing

Somewhat appealing

Not very appealing

Not at all appealing

2. Continue to look at the picture on page [\#]. How complex, or intricate, is the neighborhood scene in the picture? Would you say it is ...?

Extremely complex/Intricate

Very complex/Intricate

Somewhat complex/Intricate

Not very complex/Intricate

Not at all complex/Intricate

3. How familiar are you personally with the type of neighborhood that is displayed in the picture on page $[\#]$ of your booklet? Would you say you are ...? 


\section{APPENDIX H-CONT}

Extremely familiar with this type of neighborhood $\quad 1$

Very familiar with this type of neighborhood $\quad 2$

Somewhat familiar with this type of neighborhood $\quad \underline{3}$

Not very familiar with this type of neighborhood $\quad \underline{4}$

Not at all familiar with this type of neighborhood $\underline{5}$

RANDOMLY SELECT NEXT PICTURE TO REVIEW. REPEAT QUESTIONS 1-3 SERIES UNTIL ALL IMAGES HAVE BEEN EVALUATED.

\section{CLASSIFICATION}

A. In what year were you born?

B. What is your gender?

Male

Female

C. What is your marital status?

Married

Single/Never married

Divorced/Separated

Widowed

D. Are there any children under the age of 18 currently living in your home?

Yes

No 


\section{APPENDIX H--CONT}

E. Which of the following best describes your current living situation?

Homeowner

Rent

Other

F. What is the zip code where you live?

G. Which of the following categories best describe your total annual household income?

Less than $\$ 25,000$

$\$ 25,000$ to $\$ 34,999$ $\underline{2}$

$\$ 35,000$ to $\$ 44,999$

$\$ 45,000$ to $\$ 54,999$

$\$ 55,000$ to $\$ 74,999$

$\$ 75,000$ to $\$ 99,000$

$\underline{6}$

$\$ 100,000$ or more

\section{CLOSING}

Thank you for giving us your time. Those are all the questions we have. Please click the forward button to complete the survey and have your name entered into one of the $\$ 450$ prize drawings. 


\section{APPENDIX I}

\section{DEMOGRAPHIC PROFILE OF SUBJECTS}

$(n=304)$

Survey Sample

Gender

Male

Female

48

52

Age

$$
\text { 18-34 }
$$

$35-44$

45-54

55 and Older

30

22

19

29

52

48

Married

Single

Children At Home (percent yes) 32

Marital Status

Living Situation

Homeowner

68

Other

32

Income

Less Than $\$ 35,000$

42

$\$ 35,000$ to $\$ 74,999$

38

$\$ 75,000$ Plus

47

53

48

16

14

22

51

52

47

46

\section{U.S. Census}

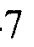

8

(6)

68

32

34

21 


\section{CURRICULUM VITAE}

NAME: James L. Mims

ADDRESS: 3504 Graham Road

Louisville, KY 40207

DOB: $\quad$ Coral Gables, Florida - November 28, 1953

\section{EDUCATION}

\& TRAINING

BLA., Landscape Architecture

University of Florida

1971-75

M.A., Urban and Regional Planning

University of Florida

1975-78 